Modelagem estocástica de sequências de disparos de um conjunto de neurônios

\author{
Azrielex Andrés Arias Rodríguez
}

DisSERTAÇÃo APRESENTADA

$\mathrm{AO}$

Instituto de Matemática e Estatística

$\mathrm{DA}$

Universidade De SÃo Paulo

PARA

OBTENÇÃO DO TÍTULO

$\mathrm{DE}$

Mestre em CiênCIAS

Programa: Estatística

Orientador: Prof. Dr. Antonio Galves

Durante o desenvolvimento deste trabalho o autor recebeu auxílio financeiro da CNPq

São Paulo, agosto de 2013 


\section{Modelagem estocástica de sequências de disparos de um conjunto de neurônios}

Esta versão da dissertação contém as correções e alterações sugeridas pela Comissão Julgadora durante a defesa da versão original do trabalho, realizada em 13/08/2013. Uma cópia da versão original está disponível no Instituto de Matemática e Estatística da Universidade de São Paulo.

Comissão Julgadora:

- Prof. Dr. Antonio Galves (orientador) - IME-USP

- Prof. Dr. Jesús Enrique García - UNICAMP

- Prof. Dr. André Frazão Helene - IB-USP 
En el borde del camino hay una silla la rapiña merodea aquel lugar la casaca del amigo está tendida el amigo no se sienta a descansar sus zapatos desgastados son espejos que le queman la garganta con el sol y a través de su cansancio pasa un viejo que le seca con la sombra el sudor.

En la punta del amor viaja el amigo en la punta más aguda que hay que ver esa punta que lo mismo caba en tierra que en las ruinas que en un rastro de mujer

es por eso que es soldado y es amante es por eso que es madera y es metal es por eso que lo mismo siembra rosas que razones de banderas y arsenal.

El que tenga una canción tendrá tormenta el que tenga compañia soledad el que siga buen camino tendrá sillas peligrosas que lo inviten a parar.

Pero vale la canción buena tormenta y la compañía vale soledad siempre vale la agonía de la prisa aunque se llene de sillas la verdad.

Historia de las sillas Silvio Rodríguez. 


\section{Agradecimentos}

São muitas as pessoas que me ajudaram tanto no pessoal como no acadêmico, durante os anos do mestrado no IME-USP.

Primeiramente, quero agradecer de forma especial ao Prof. Antonio Galves, obrigado por compartilhar seu conhecimento e pela oportunidade que me deu para ser seu orientando. Na primeira aula que assisti do Prof. Galves, percebi a paixão com a que faz seu trabalho, em boa parte foi essa paixão a que fez eu me sentir interessado na pesquisa sobre modelagem estocástica em neurociências. Eu tenho que lhe agradecer pela sua paciência nos momentos difíceis.

Ao Prof. Miguel Abadi, pela sua orientação na primeira parte do mestrado, da mesma forma que tenho que agradecer aos resto de professores do IME, em particular Prof. Luiz Renato Fontes, Prof. Luis Gustavo Esteves, Prof. Florencia Leonardi, Prof. Fabio Machado e Prof. Adilson Simonis, os quais ministraram as aulas que atendi durante esses dois anos e contribuíram enormemente na minha formação acadêmica.

A minha mãe, quem sempre se esforçou para me dar a melhor educação possível, e pelo apoio que tenho recebido constantemente, mesmo a pesar da minha ausência.

Ao Juan Carlos Ruge, porque sempre tem estado presente para discutir desde assuntos pessoais até a demonstração de algum teorema que não consegui entender.

A Karina Yaginuma, pelas discussões relacionadas aos resultados deste trabalho, muito obrigado por estar sempre preste a escutar e pelos aportes.

Meus amigos da Colômbia: Alba, Adriana, Angie, Julian, Juan Carlos, Cesar, Ángela Henker, Grettel, porque mesmo na distância senti o seu apoio em diferentes momentos.

A Diana Franco, porque desde que soube que eu estava no Brasil, sempre me ajudou para ter um pedaço da Colômbia comigo. 
Aos meus amigos e colegas do IME: Nathália, Mel, Daniel, Alejandra Rada e Felipe. Com vocês tive a possibilidade de discutir sobre temas acadêmicos, questões pessoais, eventualmente assistir um cinema na Av. Paulista (obrigado Av. Paulista!). Vou embora do Brasil, mas levo comigo um pouco de vocês. Obrigado também por me ajudar a melhorar meu português.

A Ángela Luna, porque juntos andamos por este caminho, juntos decidimos sair da Colômbia com a intenção de fazer o que sempre tínhamos querido, e ainda seguimos nesse caminho.

Ao Artur Zalewska, por todo o que compartilhamos durante os últimos dois anos e porque sei que mesmo na distância seguiremos unidos.

Ao Felipe Restrepo, pela convivência durante o primeiro ano, as conversas filosóficas e as não tão filosóficas.

Ao Carlos e o Ivan, porque foram minha família durante um ano de convivência, e agora são como uns irmãos para mim.

Aos grupos de teatro Amadododito e o Núcleo Pedagógico da Companhia Pau D’Arco: Núcleo Zámek. O primeiro dirigido pelo Alan Pires, onde conheci pessoas maravilhosas como à Marina Kallas, os sábados de ensaio não podiam ser melhores. Já ao Nucleo Zámek, tenho que agradecer de forma especial aos seus diretores Luis Fernanado Pasquareli e Bia Szvat por essa forma de fazer teatro, por essa paixão pelo teatro que vocês sabem transmitir muito bem e porque toda quarta feira me lembraram da forma em que se vive o teatro no meu país.

Ao Brasil por ter me acolhido, ao CNPq pelo apoio financeiro deste projeto. 


\section{Resumo}

RODRÍGUEZ, A. A. A. Modelagem estocástica de sequências de disparos de um conjunto de neurônios. 2013. 65 f. Dissertação (Mestrado) - Instituto de Matemática e Estatística, Universidade de São Paulo, São Paulo, 2013.

O presente trabalho constitui um primeiro esforço por modelar disparos de neurônios usando cadeias estocásticas de memória de alcance variável. Esses modelos foram introduzidos por Rissanen (1983). A ideia principal deste tipo de modelos consiste em que a definição probabilística de cada símbolo depende somente de uma porção finita do passado e o comprimento dela é função do passado mesmo, tal porção foi chamada de contexto e o conjunto de contextos pode ser representado através de uma árvore. No passado vários metodos de estimação foram propostos, nos quais é necessário especificar algumas constantes, de forma que Galves et al.(2012) apresentaram o critério do menor maximizador $(S M C)$, sendo este um algoritmo consistente que independe de qualquer constante.

De outro lado na área da neurociência vem tomando força a ideia de que o processamento de informação do cérebro é feito de forma probabilística, por esta razão foram usados os dados coletados por Sidarta Ribeiro e sua equipe, correspondentes à atividade neuronal em ratos, para estimar as árvores de contextos que caracterizam os disparos de quatro neurônios do hipocampo e identificar possíveis associações entre eles, também foram feitas comparações de acordo com o estado comportamental do rato (Vigília / Sono), em todos os casos foi usado o algoritmo SMC para a estimação das árvores de contexto. Por último, é aberta uma discussão sobre o tamanho de amostra necessário para a implementação deste tipo de análise.

Palavras-chave: modelagem estocástica, árvore de contextos, cadeias estocásticas de memória de alcance variável, algoritmo contexto, criterio do mínimo maximizador, neurociência, atividade neuronal. 


\section{Abstract}

RODRÍGUEZ, A. A. A. Stochastic modeling of spike trains of a set of neurons. 2013. 65 f. Dissertação (Mestrado) - Instituto de Matemática e Estatística, Universidade de São Paulo, São Paulo, 2013.

This work describes an initial effort to model spike trains of neurons using Variable Length Markov Chains (VLMC). These models were introduced by Rissanen(1983). The principal idea of this kind of models is thaht the probabilistic definition of each symbol only depends on a finite part of the past and the length of this relevant portion is a function of the past itself. This portion were called context and the set of contexts can be represented as a rooted labeled tree. In the past, several methods of estimation were proposed, where is necessary to fix any constants, for this reason Galves et al.(2012) introduced the smallest maximizer criterion (SMC), which is a consistent and constant free model selection procedure.

By the other side, in the neuroscience area has gained strength the idea that the information processing in the brain is done in a probabilistic way, for this reason were used the data collected by Sidarta Ribeiro and his team, related to the neuronal activity in rats, to estimate the context trees that describing the spike trains of four neurons of hipocampus region and to identify associations between them, comparisions were also made according to the behavioural state of the rat (Wake / Sleep), in all cases the algorithm were used the SMC algortithm to estimate the context trees. Finally, is opened a discussion on the sample size required for the implementation of this kind of analysis.

Keywords: stochastic modeling, context tree, Variable length Markov chains, context algorithm, smallest maximizer criterion, neuroscience, neuronal activity. 


\title{
Sumário
}

\author{
Lista de Figuras
}

Lista de Tabelas

xii

1 Introdução

2 Apresentação dos dados

3 Cadeias estocásticas com memória de alcance variável $\quad 8$

3.1 Definições básicas . . . . . . . . . . . . . . . . . . . . . . . . 9

3.2 Algoritmo contexto . . . . . . . . . . . . . . . . . . . 11

3.3 Critério do menor maximizador $(\mathrm{SMC}) \ldots \ldots \ldots \ldots$

3.3.1 Implementação do algoritmo SMC . . . . . . . . . . . . . . . . . . 15

3.4 Modelos para a interação de neurônios . . . . . . . . . . . . . . . . . . . 16

4 Análise dos dados e resultados $\quad 22$

4.1 Análise individual . . . . . . . . . . . . . . . . . . . . . . . . . . . . . . 22

4.2 Análise conjunta de neurônios . . . . . . . . . . . . . . . . . . . . 25

4.3 Contraste entre grupos de neurônios . . . . . . . . . . . . . . . . . . . . . . . 28

4.4 Avaliação da influência entre neurônios . . . . . . . . . . . . . . . . . . . . . . 29

4.5 Comparações entre sono e vigília . . . . . . . . . . . . . . . . . . . . 35 
4.6 Análise conjunta dos quatro neurônios . . . . . . . . . . . . . . . . . . 43

4.7 Discussão sobre o tamanho da amostra . . . . . . . . . . . . . . . . . 47

4.7.1 Exercício 1 . . . . . . . . . . . . . . . . . 47

4.7 .2 Exercício $2 \ldots \ldots \ldots \ldots \ldots$

5 Conclusões $\quad 51$

$\begin{array}{ll}\text { Referências Bibliográficas } & 53\end{array}$

A Codificação de sequências de disparos $\quad 55$

B Codificação de disparos com contato com os objetos(Comida/Não comida) 56

C Codificação de disparos com estado comportamental (Vigília/Sono) 58

$\begin{array}{ll}\text { D Função para o cálculo de probabilidades de transição } & 60\end{array}$

$\begin{array}{lll}\text { E Disposição de dados para a analise da seção } 4.6 & 61\end{array}$

F Disposição de dados para avaliação de influência por estado comportamental 63

G Funções para simulação de sequências, usando a árvore maximal 65

H Programa para o primeiro exercício de simulação da seção $4.7 \quad 67$ 


\section{Lista de Figuras}

4.1 Árvores de contexto para os neurônios do hipocampo . . . . . . . . . . . . . . . . 23

4.2 Árvores estimadas para a interação entre disparo e tubo de comida . . . . . . . . 24

4.3 Árvores de contexto estimadas para pares de neurônios . . . . . . . . . . . . . . . 26

4.4 Árvores de contexto estimadas para interação de três neurônios . . . . . . . . . . 27

4.5 Árvore estimada para o contraste do neurônio HP15a versus HP2a, HP12a e HP12b . 29

4.6 Árvore estimada para o contraste do neurônio HP15a versus HP12a e HP12b . . . . 29

4.7 Árvores de contexto estimadas para avaliação da influência do neurônio HP15a . 31

4.8 Árvores de contexto estimadas para avaliação da influência do neurônio HP2a . . 31

4.9 Árvores de contexto estimadas para avaliação da influência do neurônio HP12a . 32

4.10 Árvores de contexto estimadas para avaliação da influência do neurônio HP12b . 32

4.11 Árvores de contexto estimadas para avaliação da influência com a amostra de pré-exposição . . . . . . . . . . . . . . . . . . . . . . . . . . . . 33

4.12 Árvores de contexto estimadas para a avaliação da influência do neurônio HP15a sobre HP12a e HP12b conjuntamente: Comparacão entre as amostras de préexposição e exposição . . . . . . . . . . . . . . . . . . . . . . . . . . . . . . . 34

4.13 Árvores de contexto estimadas para amostras de vigília e sono de forma separada 37

4.14 Árvores de contexto estimadas para estado comportamental e disparo dos neurônios conjuntamente . . . . . . . . . . . . . . . . . . . . . . . . . . 38

4.15 Árvores de contexto para a avaliação da influência do neurônio HP2a, considerando o estado comportamental . . . . . . . . . . . . . . . . . . . . . . . . . 40 
4.16 Árvores de contexto para a avaliação da influência do neurônio HP12a, considerando o estado comportamental . . . . . . . . . . . . . . . . . . . . . . . . . . 41

4.17 Árvores de contexto para a avaliação da influência do neurônio HP12b, considerando o estado comportamental . . . . . . . . . . . . . . . . . . . . . . . . . . 42

4.18 Árvores de contexto para a avaliação da influência do neurônio HP15a, considerando o estado comportamental . . . . . . . . . . . . . . . . . . . . . . . 43

4.19 Árvore de contextos estimada para a sequência $1 \ldots$. . . . . . . . . . . . . . 46

4.20 Árvore de contextos estimada para a sequência $2 \ldots$. . . . . . . . . . . . . . 46

4.21 Árvore de contextos estimada para a sequência $3 \ldots$. . . . . . . . . . . . . . . . 46

4.22 Árvore geradora $\tau$ para o primeiro exercício de simulação . . . . . . . . . . . . . 47

4.23 Árvores estimadas no segundo exercício de simulação . . . . . . . . . . . . . . . 50 


\section{Lista de Tabelas}

4.1 Esquema de codificação de cada neurônio . . . . . . . . . . . . . . . . . . . . 22

4.2 Proporção de disparos durante o período de exposição . . . . . . . . . . . . . . . 23

4.3 Proporção de tempo de contato com os objetos . . . . . . . . . . . . . . . . . . . 24

4.4 Codificação para a análise de interaçao de disparos com objetos . . . . . . . . . . 24

4.5 Codificação para a análise de interaçao entre dois neurônios . . . . . . . . . . . 25

4.6 Codificação para a análise de interaçao entre três neurônios . . . . . . . . . . . 27

4.7 Codificação para a interação dos quatro neurônios . . . . . . . . . . . . . . . 28

4.8 Codificação para contrastar HP15a versus os outros três neurônios . . . . . . . . 28

4.9 Codificação para avaliar a influencia do neurônio HP15a sobre os outros neurônios do hipocampo . . . . . . . . . . . . . . . . . . . . . . 30

4.10 Codificação do estado comportamental . . . . . . . . . . . . . . . . . . . . . 35

4.11 Frequências absolutas e relativas da informação contida nos hipnogramas . . . . 35

4.12 Comparação entre informação dos hipnogramas de $1 \mathrm{seg}$. e $10 \mathrm{seg}$. . . . . . . . 36

4.13 Porções da amostra para a vigília e o sono . . . . . . . . . . . . . . . . . . 36

4.14 Tamanhos de amostra para a análise separada de vigília e o sono . . . . . . . . 36

4.15 Codificação para a análise conjunta do estado comportamental e o disparo de um neurônio . . . . . . . . . . . . . . . . . . . . . . . 37

4.16 Frequências relátivas das sequências relativas à interação entre estado comportamental e disparo dos neurônios . . . . . . . . . . . . . . . . . . . . . . . 38 
4.17 Codificação para avaliação da influência do neurônio A sobre o neurônio $B$, considerando o estado comportamental . . . . . . . . . . . . . . . . . . . . . . . . 39

4.18 Códigos assignados para cada neurônio . . . . . . . . . . . . . . . . . . . . . . 44

4.19 Frequências absolutas e relativas dos disparos de cada neurônio, durante o período de exposição . . . . . . . . . . . . . . . . . . . . . . . . . . . . . . . . . . . . 45

4.20 Frequência de disparos de cada neurônio, durante a etapa de pré-exposición . . . 45

4.21 Proporções de correta estimação dos contextos de $\tau$, segundo o tamanho de amostra 48 4.22 Proporções de correta estimação da altura de $\tau$, segundo o tamanho de amostra 48 


\section{Capítulo 1}

\section{Introdução}

O presente trabalho faz parte das atividades desenvolvidas no meio do Projeto MaCLinC e é uma das primeiras tentativas por modelar sequências de disparos de neurônios através de cadeias estocásticas com memória de alcance variável. Esses modelos foram introduzidos por Rissanen (1983) como um modelo flexível para compressão de dados. Inicialmente, o Rissanen os chamou de árvores probabilísticas e chegaram a ser populares na literatura estatística pelo nome de Cadeias de Markov de alcance variável (VLMC), no trabalho de Bühlman e Wyner (1999), onde foi provada a convergência do algoritmo.

A ideia por trás da noção dos modelos de memoria variável consiste em que a definição probabilística de cada símbolo, só depende de uma porção do passado, cujo tamanho depende do passado mesmo e foi chamada de contexto por Rissanen. O conjunto dos contextos satisfaz a propriedade do sufixo que indica que nenhum contexto é sufixo próprio de outro contexto. Essa propriedade permite representar todos os contextos através de uma árvore, de forma que o processo é descrito pela árvore de contextos e uma família associada de medidas de probabilidade, indexadas pela árvore de contextos. Rissanen também introduziu o algoritmo contexto para estimar a árvore probabilística de contextos.

Posteriormente, Csiszár e Talata (2006) mostraram que as árvores de contextos podem ser estimadas consistentemente fazendo uso do Critério de Informação Bayesiano (BIC). Tanto para o algoritmo contexto, quanto para o procedimento BIC, é necessário especificar algumas constantes, embora a consistência desses métodos não seja afetada pela escolha das constantes, é possível obter diferentes árvores. Sendo que para constantes próximas de zero, é obtida a árvore máxima e entre maior seja a constante menor vai ser a altura da árvore selecionada.

O anterior motivou o trabalho de Galves et al. (2012), onde é apresentado o critério do menor 
maximizador(SMC), que é um algoritmo que independe de qualquer constante, baseado na ideia de primeiro identificar um conjunto de árvores campeãs, sendo que a verossimilhança é maior para árvores maiores, desta forma os autores puderam definir como árvore geradora da amostra aquela que se encontra no ponto de inflexão para a função de verossimilhança. As VLMC já foram usadas na análise de diversos tipos de dados, por mencionar algumas das aplicações temos que no trabalho de Bühlman e Wyner (1999) analisaram sequências de DNA, posteriormente Leonardi (2007) usou VLMC para a classificação de proteínas e Galves et al. (2012) analisaram dados linguísticos.

Por outro lado, de acordo com Shepherd (1994), temos a neurobiologia definida como a disciplina responsável pelo estudo das células do sistema nervoso, a neurobiologia produz uma ampla quantidade de dados produto de experimentos que tentam explicar o comportamento dos neurônios. Existem diversos tipos de métodos para coletar dados da atividade cerebral, entre os mais reconhecidos encontram-se electroencefalogramas(EEG), ressonância magnética funcional(fMRI) e de acordo com Vasconcelos (2010) durante a década de 1990 foi desenvolvida uma técnica consistente na implantação de matrizes de micro-electrodos em regiões especificas do cérebro dos animais.

Buesing et al. (2011) citam vários autores que sugeriram que o processamento de informação no cérebro é feito de forma probabilística, adicionalmente Rolls e Deco (2010) mencionam o comportamento aleatório da atividade neuronal. Os dados a ser analisados foram coletados por Sidarta Ribeiro e sua equipe, com o objetivo de verificar a reverberação de experiências vividas durante o sono, se baseando na ativação de neurônios na região do hipocampo a partir da informação suministrada por eletrodos implantados no cérebro dos ratos.

Surgindo desta forma o primeiro objetivo desta dissertação que é caracterizar os disparos de um conjunto de neurônios através de cadeias estocásticas de memória de alcance variável. Além da informação relacionada com os disparos dos neurônios, foi registrado o estado comportamental dos ratos envolvidos no experimento, motivando o segundo objetivo do presente trabalho que consiste em deduzir o estado comportamental através das atividades de disparos, adicionalmente se pretende identificar associações e influências entre os neurônios.

Os dados aqui analisados correspondem a quatro neurônios do hipocampo (HP2a, HP12a, HP12b e HP15a) do rato codificado como ge4, para caracterizar os disparos dos neurônios foram construídas sequências binarias, que indicam os tempos em que os neurônios dispararam e foram estimadas árvores de contextos aplicando o critério SMC. Paso seguido foram testadas as associações entre os neurônios, definindo novas sequências com a intenção de encontrar árvores próprias de um processo de renovação, cujo estado de renovação esteja caracterizado pelo disparo de 
neurônios específicos que estariam influenciando os outros.

Foram contrastadas as árvores obtidas nas análises frente aos modelos sugeridos por Karina Yaginuma nos primeiros resultados da sua tese de doutorado, essas comparações junto com outras análises, levantaram a questão do tamanho de amostra e o impacto que ele pode ter na estimação de árvores de contexto, de forma que é aberta uma discussão sobre a validação das árvores obtidas nas análises dos dados.

Os neurônios HP2a, HP12b e HP15a, mostraram o comportamento de uma árvore de renovação, sendo que toda vez que eles dispararam se esquece o passado, esse comportamento foi corroborado durante o período de exposição quando o rato entrava em contato com a comida para os neurônios HP2a e HP15a, também foi encontrada evidência da influência do neurônio HP15a sobre os outros três neurônios durante o tempo de vigília, já para o tempo de sono, não foi possível verificar essa mesma influência.

A dissertação está organizada da seguinte forma. No capítulo 2 são apresentados alguns conceitos básicos de neurociências e uma descrição do experimento e os dos dados que foram analisados. No capítulo 3 são introduzidos os conceitos básicos de cadeias estocásticas com memória de alcance variável, também são mencionados os métodos de estimação, ressaltando o algoritmo contexto e o critério SMC, esse capítulo é finalizado com dois resultados da estudante de doutorado Karina Yaginuma. O capítulo 4 contem a análise dos dados e os resultados, e é fechado com uma discussão sobre os tamanhos de amostra. Finalmente, são reservadas para o capítulo 5 as conclusões da dissertação. 


\section{Capítulo 2}

\section{Apresentação dos dados}

Os dados aqui analisados foram gerados em um experimento projetado por Sidarta Ribeiro no Instituto Internacional de Neurociência de Natal Edmon e Lily Safra cujos detalhes podem ser encontrados em Ribeiro et al. (2007). O estudo tinha como objetivo verificar a reverberação durante o sono de experiências vivenciadas na vigília. As regiões cerebrais abarcadas neste estudo foram o hipocampo(HP), o córtex somástesico primario(S1), e o córtex visual primario(V1). O S1 é responsável pelo processamento das informções sensoriais tácteis, já o V1 é responsável pelo processamento das informações visuais, e a região do HP está envolvida com a memoria.

O experimento é iniciado com o procedimento de implantação de eletrodos, em ratos da linhagem Long Evans, pesando entre 300 e $350 \mathrm{~g}$, os quais foram criados em um ambiente controlado, uma vez os ratos passaram por um processo de recuperação da cirurgia, deram inicio à fase de coleta de dados, a qual está dividida em três etapas:

- Pré-exposição: Durante duas horas o rato é colocado em uma caixa sem luz, com a intenção de tornar o ambiente de experimentação conhecido, assim ele vai estar preparado para a seguinte etapa do experimento.

- Exposição: Essa etapa teve uma duração de 20 minutos, e nela foram colocados quatro novos objetos na caixa: uma bola, uma escova, uma haste pontiaguda e um tubo com comida. É importante mencionar que os animais nunca tiveram contato com os três primeiros objetos antes do momento do experimento. A comida foi colocada para garantir que o animal mostrasse interesse nos objetos.

- Pós-exposição: Os animais foram observados por um período entre 3 e 48 horas, sem a presença dos objetos complexos. 
Durante as três etapas e particularmente na terceira, foi cadastrado o estado comportamental dos ratos, classificado em quatro categorias: vigília, sono SWS, sono REM e um quarto estado denominado Whisker Twitching (WT), que é um estado especial da vigília em ratos.

A seguinte figura mostra as três etapas do experimento,

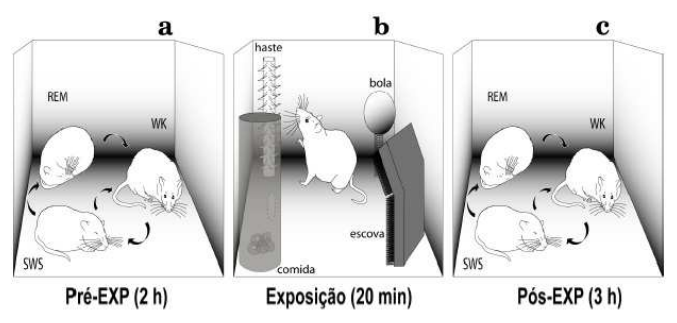

Durante o experimento inteiro foi registrada a atividade neuronal nas regiões cerebrais escolhidas (HP, S1 e V1 ), sendo que a partir dos micro-eletrodos o sinal é levado até um sistema para a visualização dos instantes dos spikes de cada neurônio. A seguinte figura mostra esse processo de seleção e registro da atividade neuronal,

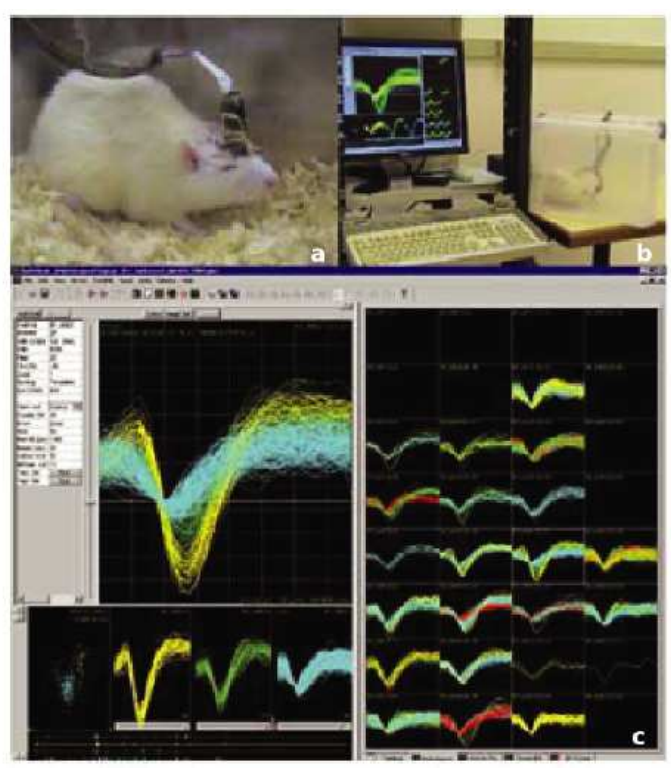

Existem alguns trabalhos onde esses dados foram analisados, o primeiro deles se encontra no artigo Ribeiro et al. (2007), onde se mostram indícios de correlação entre as atividades neuronais dos animais durante o tempo de exposição e o período de pós-exposição. Aqui usaram uma análise de correlação dos disparos, junto com algumas técnicas não paramétricas como os testes de Kruskal-Wallis e de Mann-Withney.

A tese doutoral de Vasconcelos (2010) está baseada na análise desses dados, cujo principal objetivo foi estudar a codificação de objetos complexos no córtex sensorial primário e no hipocampo durante o momento da vigília no escuro. Algumas das conclusões desse trabalho foram: 
- Usando alguns modelos mostrou-se que é possível classificar a resposta de objetos em função da ativação neuronal a qual parece depender de conjuntos de neurônios e não de neurônios específicos.

- A codificação de objetos pode ser realizada usando neurônios de áreas corticais primarias em ratos. De forma semelhante ao obtido em prévios experimentos com primatas adultos, onde os neurônios do córtex inferior temporal determinam o sucesso da classificação.

- Mesmo com o animal no escuro, é possível obter informação do córtex visual primário, para determinar com que objeto o animal teve contato.

Durante o experimento foi registrado o estado comportamental dos ratos durante o ciclo vigíliasono conforme é apresentado em Gervasoni et al. (2004). Para isto foram construídos hipnogramas de 1 e 10 segundos, baseados na atividade elétrica cortical do animal, classificando ele num dos seguintes quatro estados por intervalos de tempo de 1 ou 10 segundos, dependendo do tempo de referência do hipnograma:

- Vigília: Aqui tem agrupados dois estados: Exploração Ativa(AE) e de vigília tranquila(QW). No primeiro o rato está em conduta exploratória (em locomoção, se mexendo ou cheirando), com LFPs corticais de baixa amplitude e altas ondas theta $(5-9 \mathrm{~Hz})$ e gamma $(30-55$ $\mathrm{Hz}$ ). No segundo estado, o rato encontra-se imóvel ou em atividades automáticas como comendo ou bebendo, igual que no primeiro caso o animal apresenta LFPs corticais de baixa amplitude e oscilações tetha e gamma relativamente altas, ainda que menores que no estado de exploração ativa.

- Estado WT: Do inglês whisker twitching, caracterizado por movimentos rítmicos dos bigodes, o animal está imóvel e em pé, com oscilações cortico-talamicas de 7-12Hz.

- Sono SWS: O rato permanece deitado e imóvel, com leves movimentos respiratórios regulares, no inicio apresenta as oscilações do sono (sleep spindles) de 10-14 Hz, sendo superiores às ondas delta de 1-4 Hz. Na medida que se aprofunda no sono SWS, as oscilações delta tornam-se predominantes, mesmo que as oscilações do sono ainda continuam presentes.

- Sono REM: Nesse estado o animal está imóvel, com movimentos intermitentes dos bigodes e as orelhas, LFPs corticais de baixa amplitude e ondas tetha e gama de alta potência, semelhantes às observadas durante a vigília. 
A idéia do presente trabalho é usar modelagem estocástica, para encontrar associações entre os disparos dos neurônios e possíveis diferenças ou semelhanças entre os diferentes estados comportamentais do rato. 


\section{Capítulo 3}

\section{Cadeias estocásticas com memória de alcance variável}

Neste trabalho são considerados processos estacionários discretos sobre um alfabeto finito $A$, mais exatamente contamos com uma sequência de variáveis aleatórias, para nosso caso são funções dos tempos de disparo dos neurônios do hipocampo de ratos sometidos a um experimento. Suponha que estamos interessados em predizer o valor de $X_{n}$, isto é o estado no n-ésimo tempo de observação, podemos pensar que para isto o passado relevante tem um tamanho finito, por exemplo $k$, assim temos que para todo $n \geq 1$ as probabilidades de transição estão dadas por,

$$
P\left(X_{n}=x_{n} \mid X_{n-1}=x_{n-1}, \ldots, X_{1}=x_{1}\right)=P\left(X_{n}=x_{n} \mid X_{n-1}=x_{n-1}, \ldots, X_{n-k}=x_{n-k}\right)
$$

Assim temos que o processo que satisfaz a condição (3.1) é chamado de Cadeia de Markov de ordem $k$. Ferrari e Wyner (2003) ressaltam que dado um alfabeto de cardinalidade $|A|$, o número de parâmetros para ser estimados numa cadeia de Markov de ordem $k$, seria, $|A|^{k}(|A|-1)$, o qual cresce exponencialmente com a ordem da cadeia e pode ser grande incluso para valores pequenos de $k$.

Desta forma, surgem um tipo de modelos estocásticos de ordem finita, propostos por Rissanen (1983) e posteriormente chamados por Bühlman e Wyner (1999) como Cadeias de Markov de alcance variável, baseados na ideia de que a ordem da cadeia varia de acordo com o passado. No presente trabalho esses modelos são chamados de cadeias estocásticas com memória de alcance variável, as quais são apresentadas formalmente na próxima seção, para posteriormente abordar alguns métodos de estimação. 


\subsection{Definições básicas}

Boa parte das definições apresentadas nesta seção são tomadas de Bühlman e Wyner (1999). Seja $A$ um alfabeto, definido como um conjunto finito ou contável de símbolos. Em particular, $A$ pode ser um espaço de estado discreto e finito de um processo estocástico, cuja cardinalidade é notada por $|A|<\infty$.

Definição 3.1. Seja $\left(X_{t}\right)_{t \in \mathbb{Z}}$ um processo estocástico tomando valores em um alfabeto finito A. O processo $\left(X_{t}\right)_{t \in \mathbb{Z}}$ é uma cadeia de Markov de ordem $k$, se existir um elemento $k \in$ $\mathbb{N} \cup\{\infty\}$ tal que para todo $t \in \mathbb{Z}$ temos

$$
P\left(X_{t}=x_{t} \mid X_{t-1}=x_{t-1}, \ldots, X_{1}=x_{1}\right)=P\left(X_{t}=x_{t} \mid X_{t-1}=x_{t-1}, \ldots, X_{t-k}=x_{t-k}\right)
$$

Para toda sequência $x_{t}, x_{t-1}, \ldots \in A$. A cadeia será dita ainda estacionária se para todo $t \in \mathbb{Z}$ tivermos $P\left(X_{t}=a\right)=\Pi(a)$, onde $\Pi$ é a medida estacionária da cadeia.

Como é costume, as variáveis aleatórias são notadas por letras maiúsculas e os valores determinísticos por letras minúsculas, adicionalmente a sequência $\left(x_{i}, x_{i+1}, \ldots x_{j}\right)$ é denotada por $x_{i}^{j}$ tal que $i<j, \quad i, j \in \mathbb{Z} \cup\{-\infty, \infty\}$, cujo tamanho é $\left|x_{i}^{j}\right|=j-i+1$. Diz-se que uma sequência $s_{-j}^{1}$ é sufixo de uma sequência $x_{-k}^{-1}$, se $j \leq k$ e $s_{-i}=x_{-i}$, para todo $i=1, \ldots, j$. Isto será denotado como $s_{-j}^{1} \preceq x_{-k}^{-1}$. Se $j<k$, então $s$ é um sufixo proprio de $x$ e é denotado por $s \prec x$. Tendo que as probabilidades de transição de uma cadeia de Markov de ordem $k$, podem ser escritas assim,

$$
P\left(X_{t}=x_{t} \mid X_{t-1}=x_{t-1}, \ldots, X_{t-k}=x_{t-k}\right)=P\left(X_{t}=x_{t} \mid X_{t-k}^{t-1}=x_{t-k}^{t-1}\right)
$$

Fixando $t \in \mathbb{Z} X_{t}$ pode ser predito a partir de uma porção do passado $X_{-\infty}^{t-1}$, tais valores são chamados de contexto da variável $X_{t}$, ou seja, um contexto se refere a uma parte do passado que influencia o próximo estado da cadeia. Essa ideia é formalizada a continuação,

Definição 3.2. Seja $\left(X_{t}\right)_{t \in \mathbb{Z}}$ um processo estacionário com valores $X_{t} \in A, \quad|A|<\infty$. A função $c: A^{\infty} \rightarrow A^{\infty}$, dada por,

$$
c: x_{-\infty}^{0} \longmapsto x_{-\ell+1},
$$

é chamada de função contexto e para qualquer $t \in \mathbb{Z}, c\left(x_{-\infty}^{t-1}\right)$ é chamada de função contexto para $x_{t}$, sendo que $\ell$ é definida por,

$$
\ell=\min \left\{k, P\left(X_{1}=x_{1} \mid X_{-\infty}^{0}=x_{-\infty}^{0}\right)=P\left(X_{1}=x_{1} \mid X_{-k+1}^{0}=x_{-k+1}^{0}\right) \forall x_{1} \in A\right\}
$$


A partir da relação apresentada entre a função contexto e $\ell$, é possível definir a função comprimento do contexto, $\ell(\cdot)=|c(\cdot)|$. Tal definição de $\ell$, indica implicitamente que o comprimento do contexto de uma variável $X_{t}$ é $\ell=\left|c\left(x_{-\infty}^{t-1}\right)\right|=\ell\left(x_{-\infty}^{t-1}\right)$. Considerando os pontos até agora discutidos, seguem os conceitos formais de uma cadeia estocástica com memória de alcance variável.

Definição 3.3. Considere $\left(X_{t}\right)_{t \in \mathbb{Z}}$ um processo estacionário, tomando valores $X_{t} \in A$, $|A|<\infty$, sendo $c(\cdot)$ sua função contexto dada conforme definição 3.2. Seja $0 \leq k \leq \infty$ o menor inteiro, tal que,

$$
\left|c\left(x_{-\infty}^{0}\right)\right|=\ell\left(x_{-\infty}^{0}\right) \leq k, \quad \forall x_{-\infty}^{0} \in A^{\infty},
$$

então $\left(X_{t}\right)_{t \in \mathbb{Z}}$ será denominada uma cadeia estocástica com memória de alcance variável.

Devido à estacionariedade, a distribuição de probabilidade $P$ de uma cadeia estocástica com memória de alcance variável é completamente especificada pelas probabilidades de transição $P\left(X_{1}=x_{1} \mid c\left(x_{-\infty}^{0}\right)\right)$. O conjunto de contextos desta classe de modelos pode ser representada convenientemente por uma árvore, que é chamada de árvore de contextos.

É importante notar que a função contexto garante que nenhum contexto é um sufixo de outro contexto, isto é, se $x_{j}, x_{j-1}, \ldots, x_{1}$ é um contexto então nenhuma das subsequências $x_{k}, \ldots, x_{1}$, com $1 \leq k \leq j-1$ é um contexto. Graças a esta propriedade, a função contexto pode ser representada por uma árvore com uma raiz no topo, cujos ramos crescem para baixo, tal que cada nó interno tem no máximo $|A|$ descendentes e cada contexto é representado por um ramo, onde o sub-ramo do topo é determinado por $x_{0}$, o seguinte sub-ramo por $x_{-1}$ e assim sucessivamente.

Exemplo 3.1. Seja $A=\{0,1\}$, e a função contexto dada por,

$$
c\left(x_{-\infty}^{-1}\right)= \begin{cases}0, & \text { se } x_{-1}=0 \\ 1,1, & \text { se } x_{-1}=1, x_{-2}=1 \\ 0,0,1, & \text { se } x_{-1}=1, x_{-2}=0, x_{-3}=0 \\ 1,0,1, & \text { se } x_{-1}=1, x_{-2}=0, x_{-3}=1\end{cases}
$$

Então sua árvore contexto pode ser representada assim,

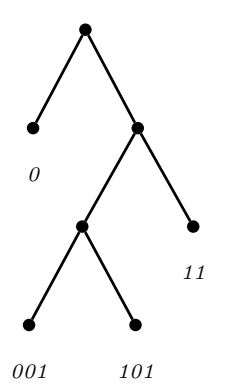




\subsection{Algoritmo contexto}

O objetivo do algoritmo contexto é estimar a função contexto, junto com as suas probabilidades de transição, dado um conjunto de dados $X_{1}, X_{2}, \ldots, X_{n}$. Foi proposto inicialmente por Rissanen (1983) e posteriormente Bühlman e Wyner provaram a sua consistência. O algoritmo pode ser resumido da seguinte forma: Primeiro, uma árvore maximal é escolhida como ponto de partida, a qual representa um modelo sobre-adjustado, como o espaço $A$ é finito não deve existir nenhuma dificuldade na construção desta árvore, sendo um problema simples e computacionalmente rápido. Em segundo lugar, é usado um procedimento backward para podar a árvore, usando um critério de decisão. Seguem algumas definições previas à explicação do algoritmo:

Definição 3.4. Um subconjunto $\tau$ de $S=\bigcup_{k=1}^{\infty} A^{\{-k, \ldots,-1\}}$ é uma árvore irredutível se satisfaz as seguintes condições:

1. Propriedade do sufixo: Para nenhum $w_{-k}^{-1} \in \tau$, temos $w_{-k+j}^{-1} \in \tau, \operatorname{para} j=1, \ldots, k-1$.

2. Irredutibilidade: Nenhuma sequência em $\tau$, pode ser substituída por um sufixo proprio sem violar a propriedade do sufixo.

Sobre o conjunto das árvores irredutíveis é definida a seguinte relação de ordem:

Definição 3.5. Dizemos que $\tau \preceq \tau^{\prime}$ se para todo $v \in \tau^{\prime}$, existe um $w \in \tau$ talque $w \preceq v$. Como é costumado o caso em que $\tau \preceq \tau^{\prime}$ com $\tau \neq \tau^{\prime}$ é denotado como $\tau \prec \tau^{\prime}$

Seja $p=\{p(\cdot \mid w): w \in \tau\}$ uma família de medidas de probabilidade em $A$ indexada pelos elementos de $\tau$. Os elementos de $\tau$ representam os contextos e o par $(\tau, p)$ será chamada de árvore probabilística de contextos.

O número de contextos de $\tau$ será denotado por $|\tau|$ e a sua altura é o tamanho máximo dos contextos de $\tau$,

$$
\ell(\tau)=\max \{\ell(w): w \in \tau\}
$$

Definição 3.6. O processo estacionário $\left(X_{t}\right)$ em A é una cadeia de Markov de alcance variável compatível com a árvore probabilística de contextos $(\tau, p)$ se:

1. Para qualquer $n \geq \ell(\tau)$ e qualquer sequência $x_{-n}^{-1}$ tal que $P\left(X-n^{-1}=x-n^{-1}\right)>0$ vale que

$$
P\left(X_{0}=a \mid X_{-n}^{-1}=x_{-n}^{-1}\right)=p\left(a \mid x_{-j}^{-1}\right) \quad \text { para todo } a \in A,
$$

em que $x_{-j}^{-1}$ é o único sufixo de $x_{-n}^{-1}$ que pertence a $\tau$. 
2. Nenhum sufixo próprio de $x_{-j}^{-1}$ satisfaz a condição 1.

Seja $w$ um vetor tal que $w \in \bigcup_{m=1}^{\infty} A^{m}$, então é definido o número de ocorrências da sequência $w$ na amostra $X_{1}^{n}$ como,

$$
N(w)=\sum_{t=1}^{n}=\mathbf{1}_{\left\{X_{t}^{t+|w|-1}=w\right\}}
$$

E seu estimador da probabilidade do vetor $w$ está dado por,

$$
\hat{P}(w)=\frac{N(w)}{n}
$$

Adicionalmente,

$$
\hat{P}(x \mid w)=\frac{N(w x)}{N(w)} \quad \text { para } x, w \in \bigcup_{m=1}^{\infty} A^{m}
$$

O algoritmo construi a árvore contexto estimada $\hat{\tau}$, como a maior árvore tal que,

$$
\Delta_{w u}=\sum_{x \in A} \hat{P}(x \mid w u) \log \left(\frac{\hat{P}(x \mid w u)}{\hat{P}(x \mid w)}\right) N(w u) \geq K
$$

Nos paragrafos seguintes é descrito o algoritmo em quatro passos.

Passo 1: É construída a árvore de contexto maximal $\tau_{\max }$, que consiste na maior árvore tal que todo elemento foi observado duas vezes nos dados. Portanto, $\tau_{\max }$ é tal que, se $w \in \tau_{\max }$ então $N(w) \geq 2$, e para toda árvore $\tau$, que seja gerada pela amostra onde seja garantido que $N(w) \geq 2$, se cumpre que $\tau \preceq \tau_{\max }$.

Por último é definida $\tau_{(0)}=\tau_{\max }$.

Passo 2: Todos os elementos de $\tau_{(0)}$ são examinados da seguinte forma. Seja $c_{0}(\cdot)$ a correspondente função contexto de $\tau_{(0)}, w$ e $u$ são definidos assim,

$$
w u=x_{-\ell+1}^{0}=c_{0}\left(x_{-\infty}^{0}\right) \quad u={ }_{-\ell+1} \quad w=x_{-\ell+2}^{0}
$$

Em que, $w u$ é um elemento de $\tau_{(0)}$ que é comparado com a sua versão podada $w$. Nota-se que se $\ell=1$, a versão podada é o ramo vazio $\emptyset$, isto é o nó raiz. $w u$ é podado para $w$ se,

$$
\Delta_{w u}=\sum_{x \in A} \hat{P}(x \mid w u) \log \left(\frac{\hat{P}(x \mid w u)}{\hat{P}(x \mid w)}\right) N(w u)<K
$$

com $K=K_{n} \sim C \log (n), C>2|A|+4$ e $\hat{P}(\cdot \mid \cdot)$ definida por (3.4).

A decisão sobre podar ou não cada elemento de $\tau_{(0)}$ gera (possivelmente) uma árvore menor $\tau_{(1)} \preceq \tau_{(0)}$. Obtendo assim a árvore $\tau_{(1)}$ com função contexto $c_{1}(\cdot)$. 
Passo 3: $\mathrm{O}$ passo 2 é repetido para $\tau_{(i)}$, gerando $\tau_{(i+1)}$, para $i=1,2, \ldots$, até que não seja mais possível podar. A última árvore de contextos é denotada por $\hat{\tau}$ e sua respectiva função contexto por $\hat{c}(\cdot)$.

Passo 4: As probabilidades de transição $p\left(x_{1} \mid c\left(x_{-\infty}^{0}\right)\right)$ são estimadas a partir de $\hat{P}\left(x_{1} \mid \hat{c}\left(x_{-\infty}^{0}\right)\right)$ onde $\hat{P}(\cdot \mid \cdot)$ é definida por (3.4).

\subsection{Critério do menor maximizador (SMC)}

Várias versões do algoritmo contexto tem sido propostas, a apresentada na seção anterior é da autoria de Bühlman e Wyner, posteriormente Csiszár e Talata (2006) usaram o critério BIC com o intuito de escolher o modelo que melhor se ajusta aos dados, porem esses algoritmos dependem de uma constante, motivando a construção de um procedimento livre de constantes introduzido em Galves et al. (2012). Nos seguintes parágrafos são apresentadas as bases do novo algoritmo.

Definição 3.7. Uma árvore irredutível $\tau$ é admissível para uma amostra $X_{1}, X_{2}, \ldots, X_{n}$ se $\ell(\tau) \leq d, \sum_{b \in A} N_{n}(w b)>0$ para qualquer $w \in \tau$ e para qualquer $j=d, \ldots, n-1$ existe uma sequência $w \in \tau$ tal que $w \preceq X_{1}^{j}$.

Se $\tau$ é admissível para a amostra $X_{1}^{n}$ a função de verossimilhança está dada por,

$$
L_{\tau}\left(X_{1}^{n}\right)=\prod_{w \in \tau} \prod_{a \in A} p(a \mid w)^{N_{n}(w a)}
$$

Seja $\tau_{n}=\tau\left(X_{1}, X_{2}, \ldots, X_{n}\right)$ o conjunto de todas as árvores de contexto admissíveis. Seja df $: \tau_{n} \rightarrow \mathbb{N}$ uma função que atribui a cada árvore $\tau \in \tau_{n}$ o número de graus de liberdade do modelo correspondente à árvore de contexto $\tau$. A definição de $\operatorname{df}(\tau)$ depende do tipo de modelo considerado, se não tiver alguma restrição então $\operatorname{df}(\tau)=(|A|-1)|\tau|$.

Segue a definição do estimador BIC para árvores contexto, proposto em Csiszár e Talata (2006), o qual é utilizado na construção do critério SMC.

Definição 3.8. O estimador BIC para árvores contexto com constante de penalização c $>0$ é definido como,

$$
\hat{\tau}_{B I C}\left(X_{1}^{n} ; c\right)=\arg \max _{\tau \in \tau_{n}}\left\{\log L_{\tau}\left(X_{1}^{n}\right)-c \cdot d f(\tau) \cdot \log n\right\}
$$


Para construir um procedimento de estimação da árvore de contextos livre de constantes, em Galves et al. (2012) consideraram o mapeamento,

$$
c \in[0, \infty) \longmapsto \hat{\tau}_{\mathrm{BIC}}\left(X_{1}^{n} ; c\right) \in \tau_{n}
$$

e a sua imagem é denotada por $C_{n}$,

$$
C_{n}=\left\{\tau_{n}^{c}=\hat{\tau}_{\mathrm{BIC}}\left(X_{1}^{n} ; c\right): c \in[0, \infty)\right\}
$$

As árvores pertencentes a $C_{n}$ são chamadas de árvores campeãs.

Note que as árvores campeãs são aquelas que maximizam a verossimilhança da amostra para cada número disponível de graus de liberdade. O conjunto $\tau_{n}$ não é totalmente ordenado com respeito à ordenação apresentada na definição 3.5. No entanto, o conjunto $C_{n}$ que contem as árvores campeãs é totalmente ordenado. Além disso, se o tamanho de amostra $n$ for suficientemente grande, então a árvore $\tau^{*}$ que gera a amostra $X_{1}^{n}$, pertence ao conjunto $C_{n}$, com a particular propriedade de que $\tau^{*}$ coincide com o ponto de inflexão da função de verossimilhança. $O$ anterior facilita a identificação de $\tau^{*}$ dentro do conjunto $C_{n}$. Essa é a base do algoritmo SMC e o conteúdo dos seguintes teoremas.

Teorema 3.1. Assuma que $X_{1}, \ldots, X_{n}$ é uma amostra de uma VLMC compatível com a árvore probabilística de contextos $\left(\tau^{*}, p^{*}\right)$, com $\tau^{*}$ finita e $d \geq \ell\left(\tau^{*}\right)$. Então, $C_{n}$ é totalmente ordenada com respeito a ordem $\prec e \tau^{*} \in C_{n}$ quando $n \rightarrow \infty$, quase certamente.

O próximo teorema mostra que existe uma mudança de regime no ganho da verossimilhança em $\tau^{*}$.

Teorema 3.2. Assuma que $X_{1}, \ldots, X_{n}$ é uma amostra de uma VLMC compatível com a árvore probabilística de contextos $\left(\tau^{*}, p^{*}\right)$, com $\tau^{*}$ finita e $d \geq \ell\left(\tau^{*}\right)$. Então, os seguintes resultados se cumprem quase certamente quando $n \rightarrow \infty$ :

1. Para qualquer $\tau \in C_{n}$, com $\tau \preceq \tau^{*}$, existe uma constante $c\left(\tau^{*}, \tau\right)>0$ tal que,

$$
\log L_{\tau^{*}}\left(X_{1}^{n}\right)-\log L_{\tau}\left(X_{1}^{n}\right) \geq c\left(\tau^{*}, \tau\right) n
$$

2. Para qualquer $\tau \prec \tau^{\prime}$, com $\tau^{*} \preceq \tau^{\prime}$ existe uma constante $c\left(\tau, \tau^{\prime}\right)>0$ tal que,

$$
\log L_{\tau^{\prime}}\left(X_{1}^{n}\right)-\log L_{\tau}\left(X_{1}^{n}\right) \leq c\left(\tau, \tau^{\prime}\right) \log n
$$


Defina a classe $C$ de todas as árvores campeãs para uma amostra infinita por,

$$
C=\bigcup_{n \geq 1} C_{n}
$$

O critério do menor maximizador seleciona a menor árvore $\hat{\tau}$ no conjunto $C$ tal que,

$$
\lim _{n \rightarrow \infty} \frac{\log L_{\tau}\left(X_{1}^{n}\right)-\log L_{\hat{\tau}}\left(X_{1}^{n}\right)}{n}=0
$$

para qualquer $\tau \preceq \hat{\tau}$.

As provas dos anteriores teoremas junto com a consistência do critério, podem ser encontradas em Galves et al. (2012).

\subsubsection{Implementação do algoritmo SMC}

Para a implementação do SMC, o primeiro passo consiste em identificar o conjunto de árvores campeãs, para isso é usado o algoritmo CTW introduzido por Willems et al. (1995) e adaptado ao critério BIC por Csiszár e Talata (2006), de onde é possível obter dada uma constante $c>0$ a árvore contexto $\hat{\tau}_{\mathrm{BIC}}\left(X_{1}^{n} ; c\right)$. Desta forma a estratégia consiste em variar os valores de $c$, iniciando desde um valor próximo de zero, até um valor suficientemente grande para que a árvore $\hat{\tau}_{\mathrm{BIC}}\left(X_{1}^{n} ; c\right)$ seja a árvore raiz.

Uma vez o conjunto de árvores campeãs $C_{n}$ é obtido, o seguinte passo é identificar a árvore $\hat{\tau}$. O teorema 3.1 garante que $\tau^{*} \in C_{n}$. Para identificar $\tau^{*}$, é selecionada a árvore cujo ganho em termos da verossimilhança é insignificante quando é comparada com as árvores maiores. Para conseguir isto em Galves et al. (2012) é usado um procedimento bootstrap da seguinte forma:

1. Para dois tamanhos de amostra diferentes $n_{1}<n_{2}<n$ são obtidas $B$ reamostras bootstrap independentes de $X_{1}, X_{2}, \ldots, X_{n}$. Essas reamostras são denotadas por $X^{*,(b, j)}=$ $\left\{X_{i}^{*,(b, j)}, i=1, \ldots, n_{j}\right\}$ em que $b=1, \ldots, B$ y $j=1,2$.

2. Para $j=1,2$ e para todo $\tau_{n} \in C_{n}$ e seu sucessor $\tau_{n}^{\prime} \in C_{n}$, de acordo com o ordenamento $\prec$, é calculada média,

$$
\Delta^{\left(\tau_{n}, \tau_{n}^{\prime}\right)}\left(n_{j}\right)=\frac{1}{B} \sum_{i=1}^{B} \frac{\log L_{\tau_{n}}\left(X^{*,(b, j)}\right)-\log L_{\tau_{n}^{\prime}}\left(X^{*,(b, j)}\right)}{n_{j}^{0.9}}
$$

3. É aplicado um $t$-teste para comparar as duas médias $E\left(\Delta^{\left(\tau_{n}, \tau_{n}^{\prime}\right)}\left(n_{1}\right)\right)$ e $E\left(\Delta^{\left(\tau_{n}, \tau_{n}^{\prime}\right)}\left(n_{2}\right)\right)$. 
4. É selecionada a árvore $\hat{\tau}$, a menor árvore campeã onde o teste rejeita a igualdade das médias em favor da alternativa que indica que $E\left(\Delta^{\left(\tau_{n}, \tau_{n}^{\prime}\right)}\left(n_{1}\right)\right)<E\left(\Delta^{\left(\tau_{n}, \tau_{n}^{\prime}\right)}\left(n_{2}\right)\right)$.

Para a seleção de reamostras bootstrap qualquer método para cadeias estocásticas de alcance variável pode ser usado. Neste trabalho foi usado o mesmo método que aparece em Galves et al. (2012), que consiste em identificar a sequência $v$ de tamanho $d$ de maior frequência, sendo $d=\log _{|A|} n$, a profundidade da árvore maximal. De forma que a amostra $X_{1}, X_{2}, \ldots, X_{n}$ pode ser escrita como $a_{n_{1}}, v, a_{n_{2}}, v, \ldots, v, a_{n_{m}}$, então a reamostra é feita por meio de uma seleção aleatória com reposição das sequências $a_{n_{1}}, a_{n_{2}}, \ldots, a_{n_{m}}$.

\subsection{Modelos para a interação de neurônios}

Nesta seção serão apresentados os primeiros resultados da tese de doutorado de Karina Yaginuma, quem está trabalhando na obtenção de modelos estocásticos que expliquem a interação entre neurônios. Seja $N$ o conjunto de neurônios que compõem um sistema biológico neural, agora suponhamos que observamos um subconjunto de $N$, denotado por $F$. Agora o interesse é encontrar relações de dependência entre os neurônios do conjunto $F$. Nesta seção, é estudado o caso em que $F=\{i, j\}$, isto é $|F|=2$.

Para começar sejam $\left(X_{t}(i)\right)_{t \in \mathbb{Z}} \mathrm{e}\left(X_{t}(j)\right)_{t \in \mathbb{Z}}$ dois processos independentes associados às árvores probabilísticas de contextos $\left(\tau_{i}, p_{i}\right)$ e $\left(\tau_{j}, p_{j}\right)$, em que $p_{i}=\left\{p_{i}(\cdot \mid w): w \in \tau_{i}\right\}$ e $p_{j}=\left\{p_{j}(\cdot \mid w)\right.$ : $\left.w \in \tau_{j}\right\}$. Pela independência se sabe que, para o processo conjunto $Z_{t}=\left(X_{t}(i), X_{t}(j)\right)$, e para qualquer $(a, b) \in\{0,1\}^{2}$,

$$
\begin{aligned}
P\left\{Z_{t}=(a, b) \mid Z_{-\infty}^{t-1}\right. & \left.=\left(x_{-\infty}^{t-1}(i), x_{-\infty}^{t-1}(j)\right)\right\} \\
& =P\left\{X_{t}(i)=a, X_{t}(j)=b \mid X_{-\infty}^{t-1}(i)=x_{-\infty}^{t-1}(i), X_{-\infty}^{t-1}(j)=x_{-\infty}^{t-1}(j)\right\} \\
& =P\left\{X_{t}(i)=a \mid X_{-\infty}^{t-1}(i)=x_{-\infty}^{t-1}(i)\right\} P\left\{X_{t}(j)=a \mid X_{-\infty}^{t-1}(j)=x_{-\infty}^{t-1}(j)\right\} \\
& =p_{i}\left(a \mid w_{i}\right) p_{j}\left(b \mid w_{j}\right),
\end{aligned}
$$

em que, $w_{i}$ e $w_{j}$ são os contextos das sequências $x_{-\infty}(i)$ e $x_{-\infty}(j)$ associadas às árvores $\tau_{i}$ e $\tau_{j}$, respectivamente. $\mathrm{O}$ próximo resultado mostra a árvore de contextos para o processo $\left(Z_{t}\right)_{t \in \mathbb{Z}}$.

Proposição 3.1. Considere dois processos estacionários $\left(X_{t}(i)\right)_{t \in \mathbb{Z}} e\left(X_{t}(j)\right)_{t \in \mathbb{Z}}$ independentes com árvores de contextos $\tau_{i}$ e $\tau_{j}$. Nessas condições, a árvore de contextos $\tau_{\{i, j\}}$ do processo conjunto $Z_{t}=\left(X_{t}(i), X_{t}(j)\right)$ é dada pelos pares de sequências $(u, v), \ell(u)=\ell(v)$, tais que, 
1. ou $u \in \tau_{i}$ e $v \in \tau_{j}$,

2. ou se $u \in \tau_{i}$, então existe $s \prec v$ tal que $s \in \tau_{j}$,

3. ou se $v \in \tau_{j}$, então existe $s \prec u$ tal que $s \in \tau_{i}$.

Demonstração. Suponha que $(u, v) \in \tau_{\{i, j\}}$, vai ser mostrado que $\tau_{\{i, j\}}$ é uma árvore de contexto, provando que satisfaz as condições da definição 3.4.

1. Propriedade do sufixo: Sejam $u^{\prime}, v^{\prime} \in F$ tal que $u^{\prime} \prec u$ e $v^{\prime} \prec v \operatorname{com} \ell\left(u^{\prime}\right)=\ell\left(v^{\prime}\right)$, a ideia da prova consiste em mostrar que se $(u, v) \in \tau_{\{i, j\}}$ então $\left(u^{\prime}, v^{\prime}\right) \notin \tau_{\{i, j\}}$ Desde que $(u, v) \in \tau_{\{i, j\}}$, então $(u, v)$ satisfaz alguma das condições a, b ou c dadas na propsição. Analisando cada uma dessas condições pode ser observado o seguinte:

- Se $(u, v)$ satisfaz a condição 1 , então $u^{\prime} \notin \tau_{i}$ e $v^{\prime} \notin \tau_{j}$, então $\left(u^{\prime}, v^{\prime}\right) \notin \tau_{\{i, j\}}$.

- Se $(u, v)$ satisfaz a condição 2 , então $u \in \tau_{i}$ e existe $s \in \tau_{j}$ tal que $s \prec v$. Então $u \notin \tau_{i}$, mas o que pode ser dito de $v^{\prime}$ ?

- Se $v^{\prime} \prec s$ ou $s \prec v^{\prime}$ então $v^{\prime} \notin \tau_{j}$ então $\left(u^{\prime}, v^{\prime}\right) \notin \tau_{\{i, j\}}$.

- Se $s=v^{\prime}$ então $v^{\prime} \in \tau_{j}$. Pela condição $2,\left(u^{\prime}, v^{\prime}\right) \in \tau_{\{i, j\}}$ se existe um $s^{\prime} \in \tau_{i}$ tal que $s^{\prime} \prec u^{\prime}$. No entanto, se sabe que $u^{\prime} \prec u$ e se $s^{\prime} \prec u^{\prime}$, então $s^{\prime} \notin \tau_{i}$. Concluindo que $\left(u^{\prime}, v^{\prime}\right) \notin \tau_{\{i, j\}}$.

- Analogamente, se $(u, v)$ satisfaz a condição 3 , então $\left(u^{\prime}, v^{\prime}\right) \notin \tau_{\{i, j\}}$.

2. Irredutibilidade: Suponha que $\ell(u)=\ell(v)=k$ e denote o sufixo proprio de $u$, por $u^{l-}$ definido pela sequência $u_{-l}, \ldots, u_{-k}$, para $l \in 1, \ldots, k-1$. Não pode ser substituido o par $(u, v)$ pelo seu sufixo proprio $\left(u^{l-}, v^{l-}\right)$, pois se $u \in \tau_{i}$ ou $v \in \tau_{j}$, então nenhum sufixo de $u$ ou $v$ pertence ao conjunto $\tau_{i}$ e $\tau_{j}$, respectivamente.

Exemplo 3.2. Sejam $\left(X_{t}(i)\right)_{t \in \mathbb{Z}} e\left(X_{t}(j)\right)_{t \in \mathbb{Z}}$ dois processos independentes, gerados pelas árvores de contexto $\tau_{i}$ e $\tau_{j}$, definidas assim,

$$
\begin{aligned}
\tau_{i} & =\{1,10,100,000\} \\
\tau_{j} & =\{0,1\}
\end{aligned}
$$

A árvore de contexto $\tau_{\{i, j\}}$ do processo conjunto $Z_{t}=\left(X_{t}(i), X_{t}(j)\right)$, está definida por,

$\tau_{\{i, j\}}=\{1,3,10,30,12,32,000,100,200,300,020,120,220,320,002,102,202,302,022,122,222,322\}$

A seguinte tabela indica que condição da proposição 3.1 é satisfeita para cada um dos contextos encontrados em $\tau_{\{i, j\}}$ e as respectivas sequências $u, v$ e s, em cada caso, 


\begin{tabular}{|c|c|c|c|c||c|c|c|c|c|}
\hline Contexto & Condição & $u$ & $v$ & $s$ & Contexto & Condição & $u$ & $v$ & $s$ \\
\hline 1 & 1 & 1 & 0 & - & 120 & 2 & 100 & 010 & 0 \\
3 & 1 & 1 & 1 & - & 220 & 2 & 000 & 110 & 0 \\
10 & 2 & 10 & 00 & 0 & 320 & 2 & 100 & 110 & 0 \\
30 & 2 & 10 & 10 & 0 & 002 & 2 & 000 & 001 & 1 \\
32 & 2 & 10 & 11 & 1 & 102 & 2 & 100 & 001 & 1 \\
12 & 2 & 10 & 01 & 1 & 202 & 2 & 000 & 101 & 1 \\
000 & 2 & 000 & 000 & 0 & 302 & 2 & 100 & 101 & 1 \\
100 & 2 & 100 & 000 & 0 & 022 & 2 & 000 & 011 & 1 \\
200 & 2 & 000 & 100 & 0 & 122 & 2 & 100 & 011 & 1 \\
300 & 2 & 100 & 100 & 0 & 222 & 2 & 000 & 111 & 1 \\
020 & 2 & 000 & 010 & 0 & 322 & 2 & 100 & 111 & 1 \\
\hline
\end{tabular}

Desta forma a árvore do processo conjunto $\left(Z_{t}\right)_{t \in \mathbb{Z}}$ é representada pelo seguinte grafo,

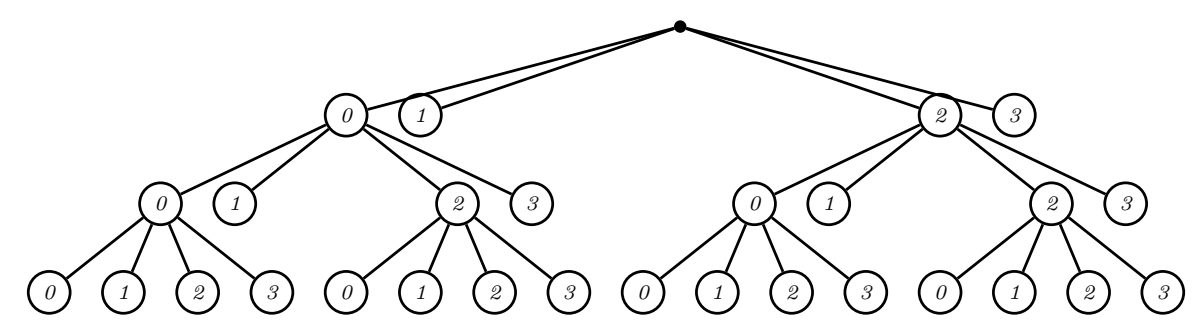

Seja $p_{\{i, j\}}=\left\{p_{\{i, j\}}(\cdot \mid u, v):(u, v) \in \tau_{\{i, j\}}\right\}$ a família de probabilidades em $A^{2}$ indexada pelos elementos de $\tau_{\{i, j\}}$. No primeiro caso da proposição 3.1 temos que,

$$
p_{\{i, j\}}(a, b \mid u, v)=p_{i}(a \mid u) p_{j}(b \mid v)
$$

Nos outros dois casos, há duas possíveis situações ou $u \notin \tau_{i}$ ou $v \notin \tau_{j}$, porém para cada caso existe $s$ tal que $s \prec u$ e $s \in \tau_{i}$ ou $s \prec v$ e $s \in \tau_{j}$. Portanto,

$$
p_{\{i, j\}}(a, b \mid u, v)=p_{i}(a \mid u) p_{j}(b \mid s) \quad \text { ou } \quad p_{\{i, j\}}(a, b \mid u, v)=p_{i}(a \mid s) p_{j}(b \mid v)
$$

Agora é considerado o caso em que os processos não são independentes. Sejam $\left(X_{t}(i)\right)_{t \in \mathbb{Z}}$ e $\left(X_{t}(j)\right)_{t \in \mathbb{Z}}$ dois processos estacionários em $A=\{0,1\}$, com distribuição condicional dada por,

$P\left\{X_{t}(i)=1, X_{t}(j)=1 \mid X_{-\infty}^{t-1}(i), X_{-\infty}^{t-1}(j)\right\}=P\left\{X_{t}(i)=1 \mid X_{-\infty}^{t-1}(i), X_{-\infty}^{t-1}(j)\right\} P\left\{X_{t}(j)=1 \mid X_{-\infty}^{t-1}(j)\right\}$

Isto é, o processo $\left(X_{t}(j)\right)_{t \in \mathbb{Z}}$ é independente do processo $\left(X_{t}(i)\right)_{t \in \mathbb{Z}}$. Agora suponha que,

$$
P\left\{X_{t}(i)=1 \mid X_{-\infty}^{t-1}(i), X_{-\infty}^{t-1}(j)\right\}=f\left(N^{j}\left[U_{t}^{i}, t-1\right]\right)
$$

em que $f: \mathbb{N} \rightarrow(0,1]$,

$$
U_{t}^{i}=\sup \left\{m<t: X_{m}(i)=1\right\}
$$


é o último instante em que o neurônio $i$ dispara antes do instante $t$ e

$$
N^{j}[s, t]=\sum_{m=s}^{t} X_{m}(j) \quad \text { para } s, t \in \mathbb{Z}, s<t
$$

Suponha também que $\left(X_{t}(j)\right)_{t \in \mathbb{Z}}$ é compatível com a árvore de contexto $\left(\tau_{j}, p_{j}\right)$ tal que,

$$
P\left\{X_{t}(j)=a \mid X_{-\infty}^{t-1}(j)\right\}=p_{j}(a \mid w), a \in A \text { e } w \preceq X_{-\infty}^{t-1}(j) \text { tal que } w \in \tau_{j}
$$

Proposição 3.2. Considere o processo conjunto $\left(Z_{t}\right)_{t \in \mathbb{Z}}=\left(X_{t}(i), X_{t}(j)\right)_{t \in \mathbb{Z}}$ descrito acima. A árvore de contexto $\tau_{\{i, j\}}$ definida pelo processo é dada pelos pares $\left(x_{-k}^{-1}(i), x_{-k}^{-1}(j)\right)$ tais que,

1. ou $k=\min \left\{t \geq 1: x_{-t}(i)=1\right\}$ e $x_{-k}^{-1}(j) \in \tau_{j}$

2. ou $k=\min \left\{t \geq 1: x_{-t}(i)=1\right\}$ e $x_{-l}^{-1}(j) \in \tau_{j}$, para algum $1 \leq l<k$,

3. ou $x_{-k}^{-1}(j) \in \tau_{j}$ e $\min \left\{t \geq 1: x_{-t}(i)=1\right\}<k$.

Demonstração. Do mesmo jeito que na prova da proposição 3.1, basta com verificar que $\tau_{\{i, j\}}$ é uma árvore de contexto, cujos elementos $\left(x_{-k}^{-1}(i), x_{-k}^{-1}(j)\right)$ satisfazem as condições apresentadas na proposição 3.2 .

1. Propriedade do sufixo: Suponha que o par $\left(x_{-k}^{-1}(i), x_{-k}^{-1}(j)\right)$ satisfaz a condição $(2)$, pode se mostrar por absurdo que $\left(x_{-k}^{-1}(i), x_{-k}^{-1}(j)\right)$ não é sufixo de nenhum outro elemento de $\tau_{\{i, j\}}$. Para isto suponha que existe um elemento $\left(w_{i}, w_{j}\right) \in \tau_{\{i, j\}}$ tal que $w_{i}=$ $x_{-m}^{-(k+1)}(i) x_{-k}^{-1}(i)$ e $w_{j}=x_{-m}^{-(k+1)}(j) x_{-k}^{-1}(j)$, em que $x_{-m}^{-(k+1)}(i), x_{-m}^{-(k+1)}(j) \in A^{(m-k)}$, para $m>k$.

Desde que $\left(x_{-k}^{-1}(i), x_{-k}^{-1}(j)\right)$ satisfaz $(2)$, então $\forall x_{-m}^{-(k+1)}(i) \in A^{m-k}, m \neq \min \{t>1$ : $\left.x_{-t}(i)=1\right\}$.

E como $x_{-l}^{-1}(j) \in \tau_{j}$, então $\forall x_{-m}^{-(k+1)}(j) \in A^{m-k}, w_{j} \notin \tau_{j}$.

Logo , o par $\left(w_{i}, w_{j}\right)$ não satisfaz nenhuma das condições. Portanto, se $\left(x_{-k}^{-1}(i), x_{-k}^{-1}(j)\right) \in$ $\tau_{i, j}$ e satisfaz a condição (2), então o par não é sufixo de nenhum outro elemento de $\tau_{\{i, j\}}$.

Agora suponha que $\left(x_{-k}^{-1}(i), x_{-k}^{-1}(j)\right)$ satisfaz a condição $(3)$, então $\left(w_{i}, w_{j}\right)$ não satisfaz a condição (2), pois

$$
\min \left\{1<t \leq m: x_{-t}(i)=1\right\}<k<m, \forall x_{-m}^{-(k+1)} \in A^{m-k}
$$

E pela condição $(3), x_{-k}^{-1}(j) \in \tau_{j}$, então $w_{j} \notin \tau_{j}$. Portanto, se $\left(x_{-k}^{-1}(i), x_{-k}^{-1}(j)\right) \in \tau_{i, j}$ e satisfaz a condição (3), então o par não é sufixo de nenhum outro elemento de $\tau_{\{i, j\}}$. 
2. Irredutibilidade: Se $\left(x_{-k}^{-1}(i), x_{-k}^{-1}(j)\right)$ satisfaz a condição $(2)$, tal que $x_{-m}^{-1} \in \tau_{j}$, para $m<k$. Para qualquer par no conjunto

$$
\tau^{\prime}=\left\{(u, v): u=10^{k} \text { e } v=x_{-k}^{-(m+1)}(j) x_{-m}^{-1}(j), \forall x_{-k}^{-(m+1)}(j) \in A^{k-m}\right\}
$$

que pertence à $\tau_{\{i, j\}}$, então o par $\left(x_{-(k-1)}^{-1}(i), x_{-(k-1)}^{-1}(j)\right)$ é sufixo de algum par em $\tau^{\prime}$. Portanto, não é possível substituir $\left(x_{-k}^{-1}(i), x_{-k}^{-1}(j)\right)$ por $\left(x_{-(k-1)}^{-1}(i), x_{-(k-1)}^{-1}(j)\right)$ sem violar a propriedade do sufixo.

Se $\left(x_{-k}^{-1}(i), x_{-k}^{-1}(j)\right)$ satisfaz a condição (3) tal que,

$$
k^{\prime}=\min \left\{1<t \leq k: x_{-t}(i)=1\right\}, \quad \text { para } k^{\prime}<k
$$

Como qualquer par no conjunto $\tau=\left\{(u, v): u=x_{-k}^{-\left(k^{\prime}+1\right)}(i) x_{-k^{\prime}}^{-1}(i), \forall x_{-k}^{-\left(k^{\prime}+1\right)}(i) \in\right.$ $A^{k-k^{\prime}}$ e $\left.v=x_{-k}^{-1}(j)\right\}$ pertence à $\tau_{\{i, j\}}$, então o par $\left(x_{-(k-1)}^{-1}(i), x_{-(k-1)}^{-1}(j)\right)$ é sufixo de algum par em $\tau$. Portanto, não podemos substituir $\left(x_{-k}^{-1}(i), x_{-k}^{-1}(j)\right)$ por $\left(x_{-(k-1)}^{-1}(i), x_{-(k-1)}^{-1}(j)\right)$ sem violar a propriedade do sufixo.

A árvore associada ao processo $\left(X_{t}(i)\right)_{t \in \mathbb{Z}}$ está dada por $\tau_{i}=\left\{10^{k}, k \geq 0\right\}$. Seja $p_{i}=\left\{p_{i}(\cdot \mid w)\right.$ : $\left.w \in \tau_{i}\right\}$ então,

$$
\begin{aligned}
P\left\{X_{0}(i)=1 \mid X_{-\infty}^{-1}(i)\right\} & =\sum_{k \geq 0} P\left\{X_{0}(i)=1 \mid X_{-\infty}^{-1}, N^{j}\left[U_{0}^{i},-1\right]=k\right\} P\left\{N^{j}\left[U_{0}^{i},-1\right]=k\right\} \\
& =\sum_{k \geq 0} P\left\{X_{0}(i)=1 \mid N^{j}\left[U_{0}^{i},-1\right]=k\right\} P\left\{N^{j}\left[U_{0}^{i},-1\right]=k\right\} \\
& =\sum_{k \geq 0} f(k) P\left\{N^{j}\left[U_{0}^{i},-1\right]=k\right\} \\
& =p_{i}\left(1 \mid X_{U_{0}^{i}}^{-1}(i)\right)
\end{aligned}
$$

Usando a notação $p\left(a \mid N^{j}\left[U_{n}^{i}, n-1\right]\right)=P\left(X_{n}=a \mid X_{0}^{n-1}(i), X_{0}^{n-1}(j)\right)$, a verossimilhança da amostra do processo descrito $X_{1}^{n}(i)$ dado $X_{0}(i)=1$ e $X_{0}^{n-1}(j)$ é dada por,

$$
\begin{aligned}
P\left\{X_{1}^{n}(i)=a_{1}^{n} \mid X_{0}(i)=1, X_{0}^{n-1}(j)\right\} & =p_{i}\left(a_{1} \mid 1\right) \prod_{m=2}^{n} p_{i}\left(a_{m} \mid N^{j}\left[U_{m}^{i}, m-1\right]\right) \\
& =\prod_{b \in A} \prod_{k=0}^{n} p(b \mid k)^{M}(b, k)
\end{aligned}
$$

Em que,

$$
M(b, k)=\sum_{m=1}^{n}=\mathbf{1}_{X_{m}(i)=b, N^{j}}\left[U_{m}^{i}, m-1\right]=k
$$


E o logaritmo natural da verossimilhança está dado por,

$$
\begin{aligned}
L(p) & =\log P\left\{X_{1}^{n}(i)=a_{1}^{n} \mid X_{0}(i)=1, X_{0}^{n-1}(j)\right\} \\
& =\sum_{b \in A} \sum_{k=0}^{n} M(b, k) \log p(b \mid k)
\end{aligned}
$$

Dadas as amostras $X_{0}^{n}(i)$ e $X_{0}^{n}(j)$, é possível calcular os valores de $M(b, k)$ para todo $b \in A$ e $k \in\{0,1, \ldots, n\}$. Se $b=1$ e para um $\bar{k}$ fixo, a derivada parcial de 3.7 está dada por,

$$
\frac{\partial L(p)}{\partial p(1 \mid \bar{k})}=M(1, \bar{k}) \frac{1}{p(1 \mid \bar{k})}-M(0, \bar{k}) \frac{1}{1-p(1 \mid \bar{k})},
$$

então o estimador de máxima verossimilhança para $\{p(b \mid k): b \in A, k \in\{0,1, \ldots, n\}\}$ está dado por,

$$
\hat{p}_{n}(b \mid k)=\frac{M(b, k)}{M(0, k)+M(1, k)}
$$

Exemplo 3.3. Sejam $\left(X_{t}(i)\right)_{t \in \mathbb{Z}} e\left(X_{t}(j)\right)_{t \in \mathbb{Z}}$ dois processos tais que o processo $i$ satisfaz a condição dada em (3.6), isto é o estado no tempo t do neurônio $i$, depende da quantidade de disparos do neurônio $j$, desde a última vez que disparou o neurônio $i$. Enquanto, o neurônio $j$ independe do neurônio $i$ e é compativel com a árvore de contexto $\tau_{j}=\{0,1\}$.

A ideia aqui é determinar a árvore de contexto $\tau_{\{i, j\}}$ do processo conjunto $Z_{t}=\left(X_{t}(i), X_{t}(j)\right)$. Sendo que a árvore associada ao processo $\left(X_{t}(j)\right)_{t \in \mathbb{Z}}$ é dada por $\tau_{i}=\left\{10^{k}: k>0\right\}$, e considerando que os elementos de $\tau_{\{i, j\}}$ estão definidos pelos pares $\left(x_{-k}^{-1}(i), x_{-k}^{-1}(j)\right)$, é possivel concluir que:

1. Se $k=\min \left\{t \geq 1: x_{-t}(i)=1\right\}$, então isto garante que $x_{-k}^{-1}(i) \in \tau_{i}$.

2. Se $x_{-l}^{-1}(j) \in \tau_{j}$ para algum $1 \leq l<k$, então um sufixo próprio de $x_{-k}^{-1}(j)$ pertence a $\tau_{j}$.

3. Se $\min \left\{t \geq 1: x_{-t}(i)=1\right\}<k$, então um sufixo próprio de $x_{-k}^{-1}(i)$ pertence a $\tau_{i}$.

Assim as três implicações anteriores verificam uma equivalencia entre as condições das proposições 3.1 e 3.2, motivo pelo qual a árvore de contextos do processo conjunto resulta ser uma extensão da árvore obtida no exemplo 3.2, e é represenada pelo seguinte grafo,

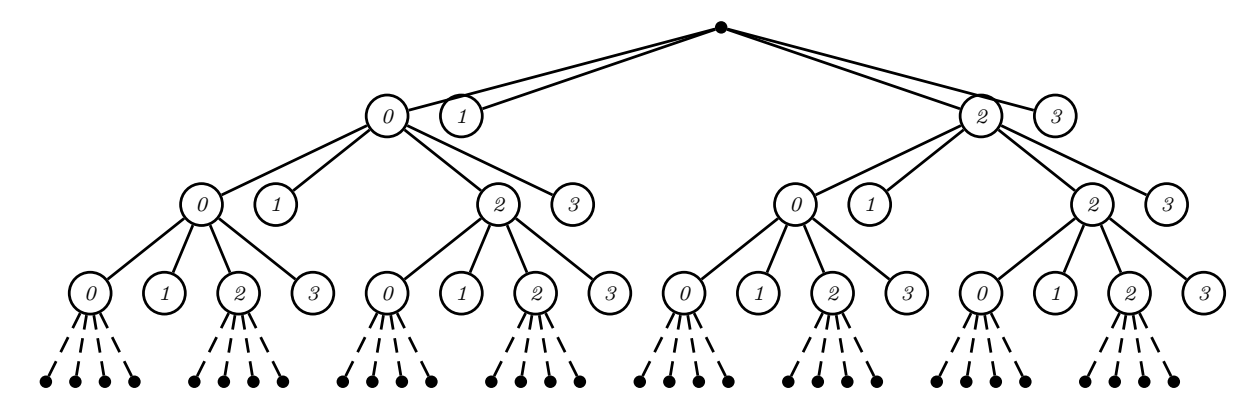




\section{Capítulo 4}

\section{Análise dos dados e resultados}

\subsection{Análise individual}

Numa etapa inicial foram modelados cada um dos neurônios de forma separada, construindo janelas sucessivas de $10 \mathrm{~ms}$, e para cada janela se determinou se o neurônio teve pelo menos um disparo, atribuindo o valor 1 nessa situação, já se na janela não teve disparo nenhum do neurônio, foi atribuído o código 0 . Desta forma para cada neurônio temos uma sequência de símbolos no alfabeto $A=\{0,1\}$. A seguinte tabela ilustra a situação aqui descrita,

\begin{tabular}{|c|c|c|}
\hline $\begin{array}{c}\text { Limite } \\
\text { Inferior }\end{array}$ & $\begin{array}{c}\text { Limite } \\
\text { Superior }\end{array}$ & $\begin{array}{c}\text { Disparo } \\
\text { do neurônio }\end{array}$ \\
\hline 0 & 10 & 0 \\
10 & 20 & 1 \\
20 & 30 & 1 \\
30 & 40 & 0 \\
40 & 50 & 0 \\
50 & 60 & 1 \\
$\vdots$ & $\vdots$ & $\vdots$ \\
\hline
\end{tabular}

Tabela 4.1: Esquema de codificação de cada neurônio

Neste trabalho foram considerados os quatro neurônios do hipocampo que foram registados para o rato ge4, os quais foram codificados como HP2a, HP12a, HP12b e HP15a. Inicialmente foram geradas as sequências de disparos de cada neurônio, durante o período de exposição, sendo cada uma delas de tamanho 130.000 e das quais foram obtidas as proporções de disparo que são apresentadas na seguinte tabela, 


\begin{tabular}{|c|c|}
\hline Neurônio & Proporção \\
\hline HP2a & 0,0165 \\
HP12a & 0,1167 \\
HP12b & 0,1031 \\
HP15a & 0,0390 \\
\hline
\end{tabular}

Tabela 4.2: Proporção de disparos durante o período de exposição

Supondo que os disparos futuros de um neurônio dependem de uma porção do passado dos disparos do mesmo neurônio, e que essa porção do passado pode depender do padrão dos disparos observado, além de que as sequências estão definidas por um tempo discreto, se considerou que uma forma apropriada de modelar essas sequências obtidas poderia ser a partir de cadeias estocásticas de memória de alcance variável, determinando que porção do passado é relevante em cada caso para posteriormente determinar a probabilidade do neurônio disparar na próxima janela.

Em Galves et al. (2012) foi proposto um procedimento de seleção de uma árvore contexto $\left(\tau^{*}, p^{*}\right)$, compatível com uma amostra $X_{1}, X_{2}, \ldots, X_{n}$, que foi apresentado no capítulo 3 . As seguintes foram as árvores de contexto obtidas para os quatro neurônios do hipocampo, durante a etapa de exposição, para o rato ge4,

\begin{tabular}{|l|l|l|l|}
\hline Neurônio HP2a & Neurônio HP12a & Neurônio HP12b \\
\hline$\ell(\tau)=16$ & & &
\end{tabular}

Figura 4.1: Árvores de contexto para os neurônios do hipocampo

Para os quatro neurônios, foram obtidas árvores que podem ser associadas com processos de renovação, cujo estado de renovação é o estado 1 , porém a altura das quatro árvores é diferente. Isto é, para predizer o estado na seguinte janela, precisa tomar a porção do passado que vá até o último disparo.

Durante a etapa de exposição foram registrados os tempos em que o rato teve contato com cada um dos quatro objetos, obtendo as seguintes proporções de tempo em que o animal interagiu com os objetos, 


\begin{tabular}{|c|ccccc|}
\hline Objeto & Bola & Escova & Haste & Comida & Nenhum \\
\hline Proporção & 0,0664 & 0,0398 & 0,0461 & 0,6226 & 0,2250 \\
\hline
\end{tabular}

Tabela 4.3: Proporção de tempo de contato com os objetos

Então surge uma primeira questão: Será que o comportamento dos neurônios é diferenciado pelo contato com os objetos? Numa tentativa por analisar de maneira conjunta o estado comportamental do rato junto com o disparo dos neurônios do hipocampo, durante a etapa de exposição, foi feita seguinte codificação, onde é considerado como 1 se o rato estava em contato com a comida e 0 em caso contrário, criando assim uma nova sequência cujos estados estão dados pela terceira coluna,

\begin{tabular}{|c|c|c|}
\hline Disparo & Comida & Estado \\
\hline 0 & 0 & 0 \\
1 & 0 & 1 \\
0 & 1 & 2 \\
1 & 1 & 3 \\
\hline
\end{tabular}

Tabela 4.4: Codificação para a análise de interaçao de disparos com objetos As seguintes são as árvores obtidas na análise dessas sequências para os quatro neurônios do hipocampo,

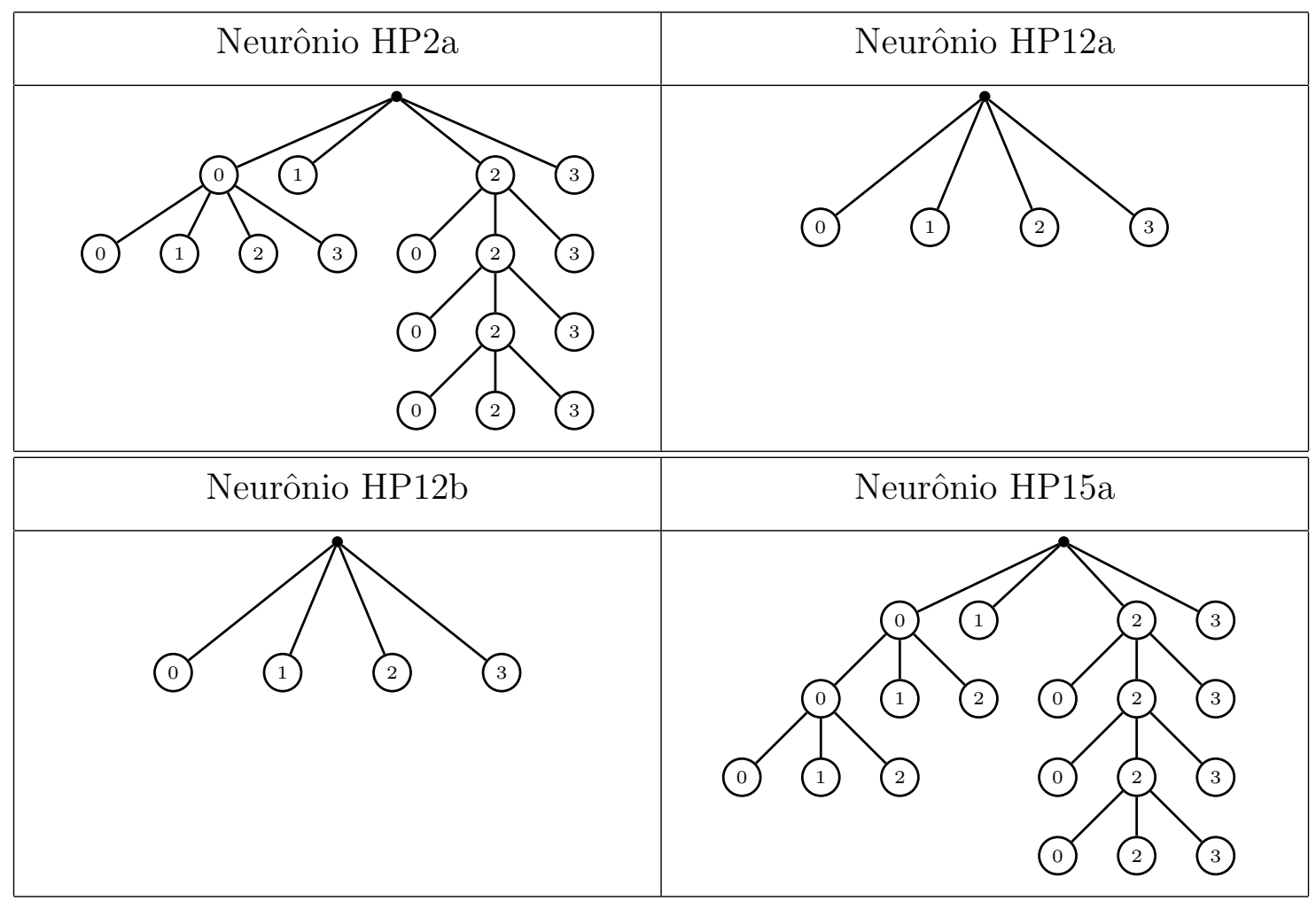

Figura 4.2: Árvores estimadas para a interação entre disparo e tubo de comida 
As árvores obtidas com a inclusão do estado comportamental do rato confirmam que o comportamento dos disparos obedecem a um processo de renovação, no casos dos neurônios HP2a e HP15a sempre que os estados 1 e 3 são contextos. Também se observam ramos de maior comprimento para o estado 2, correspondente ao caso em que o rato está em contato com a comida, isto pode obedecer justamente ao fato de que o rato permanece mais tempo em contato com a comida, garantindo assim que a árvore estimada seja mais precisa.

Para os neurônios HP12a e HP12b temos o comportamento de uma cadeia de Markov de ordem 1 , bem vale a pena considerar a possibilidade de que os disparos destes neurônios não somente dependam do comportamento deles mesmos e sim também do comportamento de outros neurônios, sendo esse o foco das análises apresentadas nas seguintes seções.

Também é importante ressaltar que a profundidade das árvores na análise que incorpora o estado comportamental do rato durante a etapa de exposição é menor em comparação com aquelas obtidas na análise dos disparos, a pesar de ter o mesmo tamanho de amostra, mostrando-se um impacto na qualidade das árvores estimadas produto do incremento da cardinalidade do alfabeto.

\subsection{Análise conjunta de neurônios}

Aqui é considerado um conjunto $F$ de neurônios e o objetivo é identificar árvores que descrevam a interação entre os neurônios, com a intenção de identificar possíveis associações entre os neurônios. Primeiramente, é fixado $|F|=2$, então $F=\{i, j\}$, tendo que a codificação das sequências está dada por,

\begin{tabular}{|c|c|c|}
\hline Neurônio j & Neurônio i & Estado \\
\hline 0 & 0 & 0 \\
0 & 1 & 1 \\
1 & 0 & 2 \\
1 & 1 & 3 \\
\hline
\end{tabular}

Tabela 4.5: Codificação para a análise de interaçao entre dois neurônios

Nas proposições 3.1 e 3.2, foram apresentados modelos para a interação de dois neurônios, assumindo no primeiro caso independência entre os neurônios e no segundo caso um modelo específico de dependência em que os contextos do neurônio $i$ consideram a porção do passado que vá até o último disparo dele mesmo, mas suas probabilidades de transição associadas dependem da quantidade de disparos do neurônio $j$ durante esse período de tempo. Foram estimadas as árvores de contexto todos os pares de neurônios, seguem os resultados, 


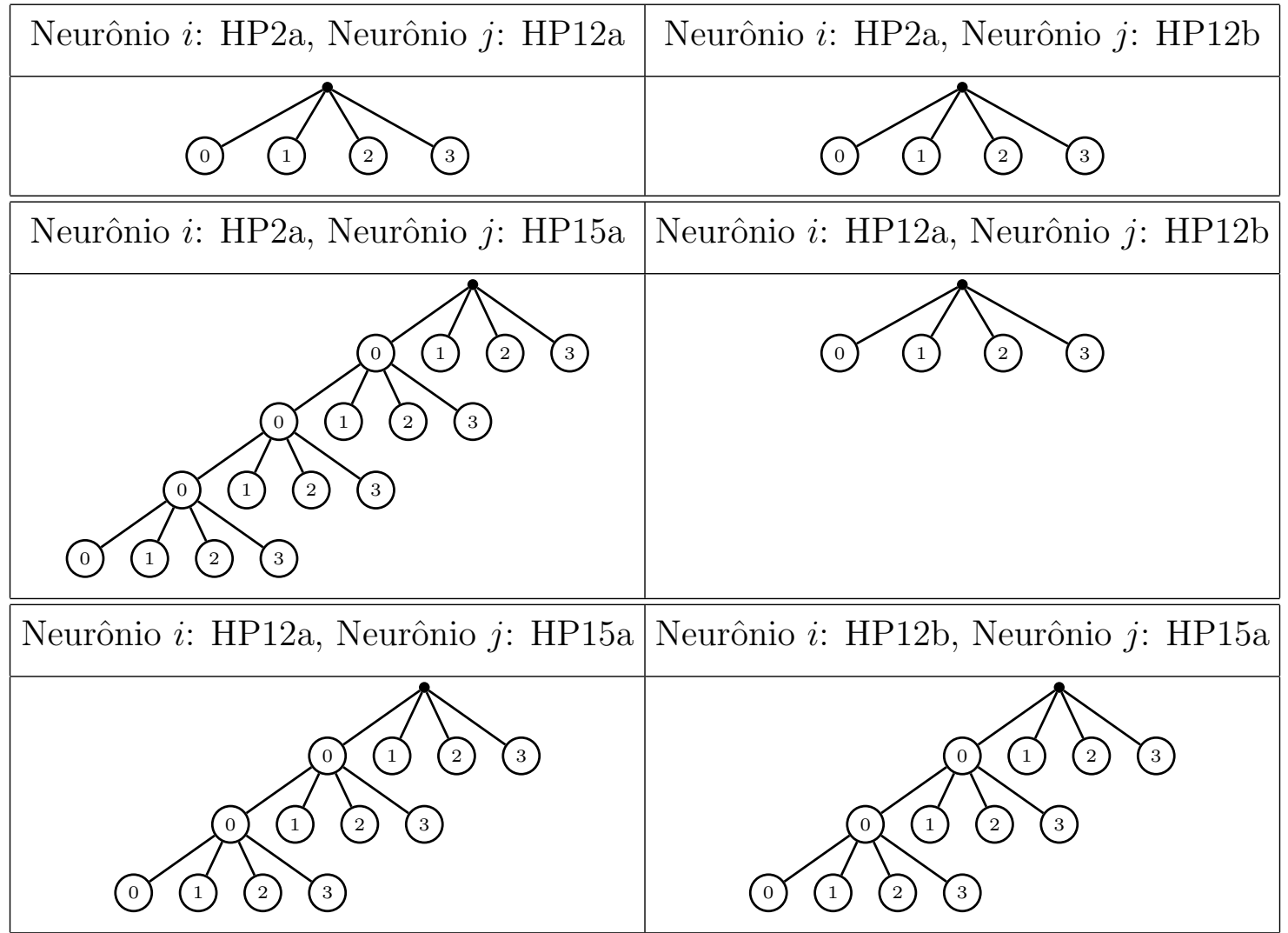

Figura 4.3: Árvores de contexto estimadas para pares de neurônios

Além do modelo de dependência apresentado na proposição 3.2, outros modelos de dependência podem ser considerados e em alguns casos sem muito esforço podem ser construídas as árvores de contexto do processo conjunto.

Por exemplo, suponha que árvore associada ao processo $\left(X_{t}(i)\right)_{t \in \mathbb{Z}}$ é $\tau_{i}=\left\{10^{k}, k \geq 0\right\}$ e de outro lado tem o processo $\left(X_{t}(j)\right)_{t \in \mathbb{Z}}$, cujos contextos estão dados pelo seu passado até a última vez em que o neurônio $i$ foi disparado. Nesse caso a árvore do processo conjunto $\left(Z_{t}\right)_{t \in \mathbb{Z}}=\left(X_{t}(i), X_{t}(j)\right)_{t \in \mathbb{Z}}$ coincidiria com a árvore apresentada no exemplo 3.3 , devido a que basta com que o neurônio $i$ seja disparado para predizer o futuro tanto de $i$ como de $j$.

A árvore do exemplo 3.3 também seria a obtida para o caso de independência dos dois processos, onde as árvores associadas aos processos $\left(X_{t}(i)\right)_{t \in \mathbb{Z}}$ e $\left(X_{t}(j)\right)_{t \in \mathbb{Z}}$ sejam respetivamente, $\tau_{i}=$ $\left\{10^{k}, k \geq 0\right\}$ e $\tau_{j}=\{0,1\}$.

Desta forma, aqui são apresentados dois modelos além do modelo de independência, que conduziriam à mesma árvore de contextos para o processo conjunto $\left(Z_{t}\right)_{t \in \mathbb{Z}}$, impedindo desta forma deduzir alguma coisa sobre a associação entre neurônios a partir da árvore do processo conjunto.

Com relação às árvores apresentadas na figura 4.3, observa-se o comportamento do processo de 
renovação quando o neurônio HP15a faz parte da modelagem, nos outros casos tem cadeias de Markov, surgindo assim a hipóteses de que o neurônio HP15a influencia os outros neurônios.

O que se observa nas árvores que envolvem o neurônio HP15a é que sempre que disparar pelo menos um dos dois neurônios envolvidos, podemos esquecer o passado, o qual não está dizendo especificamente que o neurônio HP15a esteja exercendo uma influência sobre os outros neurônios. Numa tentativa para comprovar a hipóteses de que o neurônio HP15a influencia os outros neurônios, fizeram-se árvores envolvendo três neurônios na codificação assim,

\begin{tabular}{|c|c|c|c|}
\hline Neurônio k & Neurônio j & Neurônio i & Estado \\
\hline 0 & 0 & 0 & 0 \\
0 & 0 & 1 & 1 \\
0 & 1 & 0 & 2 \\
0 & 1 & 1 & 3 \\
1 & 0 & 0 & 4 \\
1 & 0 & 1 & 5 \\
1 & 1 & 0 & 6 \\
1 & 1 & 1 & 7 \\
\hline
\end{tabular}

Tabela 4.6: Codificação para a análise de interaçao entre três neurônios

Obtendo as seguintes árvores,

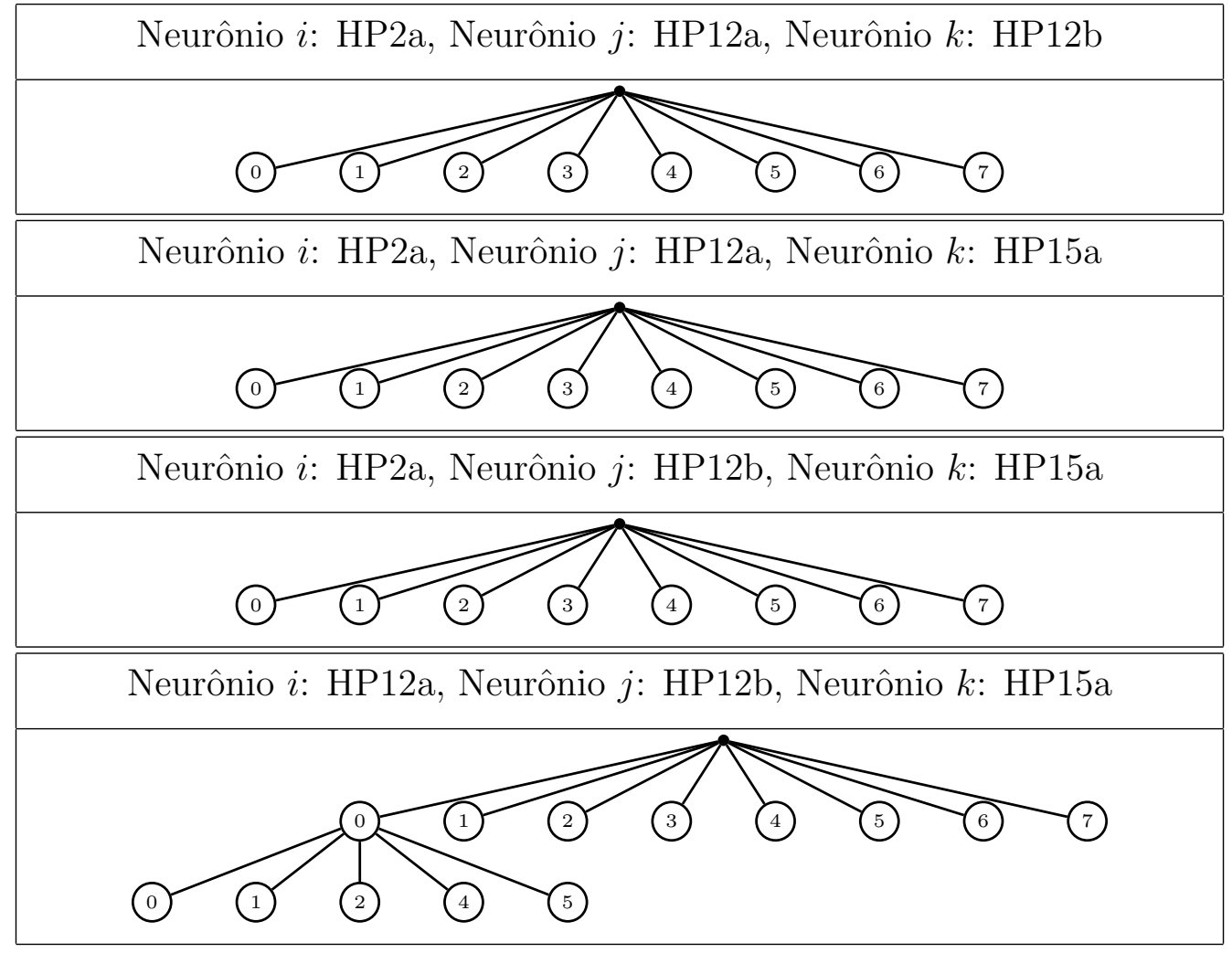

Figura 4.4: Árvores de contexto estimadas para interação de três neurônios 
As árvores estimadas para a interação de três neurônios, também não entregam alguma informação adicional sobre influencia de neurônios, só foi encontrado um caso em que a árvore não corresponde a uma cadeia de Markov de ordem 1, o qual envolve os neurônios HP15a, HP12a e HP12b, ainda assim não há evidência clara de que o neurônio HP15a esteja influenciando os outros. Para terminar essa fase da análise foi considerado o caso em que os quatro neurônios são codificados de maneira que se considera a interação entre eles, assim,

\begin{tabular}{|c|c|c|c|c||c|c|c|c|c|}
\hline HP15a & HP12b & HP12a & HP2a & Estado & HP15a & HP12b & HP12a & HP2a & Estado \\
\hline 0 & 0 & 0 & 0 & 0 & 1 & 0 & 0 & 0 & 8 \\
0 & 0 & 0 & 1 & 1 & 1 & 0 & 0 & 1 & 9 \\
0 & 0 & 1 & 0 & 2 & 1 & 0 & 1 & 0 & 10 \\
0 & 0 & 1 & 1 & 3 & 1 & 0 & 1 & 1 & 11 \\
0 & 1 & 0 & 0 & 4 & 1 & 1 & 0 & 0 & 12 \\
0 & 1 & 0 & 1 & 5 & 1 & 1 & 0 & 1 & 13 \\
0 & 1 & 1 & 0 & 6 & 1 & 1 & 1 & 0 & 14 \\
0 & 1 & 1 & 1 & 7 & 1 & 1 & 1 & 1 & 15 \\
\hline
\end{tabular}

Tabela 4.7: Codificação para a interação dos quatro neurônios

Encontrando neste ultimo caso uma cadeia de Markov de ordem 1, desta forma se conclui que a análise dos processos conjuntos não subministrou informação que permitisse determinar associações entre os neurônios.

\subsection{Contraste entre grupos de neurônios}

Numa tentativa adicional por observar uma influência do neurônio HP15a, foi feita uma codificação onde fosse contrastado o neurônio HP15a contra os outros neurônios interagindo simultaneamente, isto é primeiro foi construída uma sequencia indicando se algum dos neurônios HP2a, HP12a ou HP12b dispararam e posteriormente foi combinada esta nova sequência com a sequência do neurônio HP15a, para finalmente ter uma codificação da seguinte forma,

\begin{tabular}{|c|c|c|}
\hline HP15a & HP2a - HP12a - HP12b & Estado \\
\hline Não dispara & Não disparam & 0 \\
\hline Não dispara & Dispara pelo menos um & 1 \\
\hline Dispara & Não disparam & 2 \\
\hline Dispara & Dispara pelo menos um & 3 \\
\hline
\end{tabular}

Tabela 4.8: Codificação para contrastar HP15a versus os outros três neurônios 
A árvore encontrada com essa codificação foi,

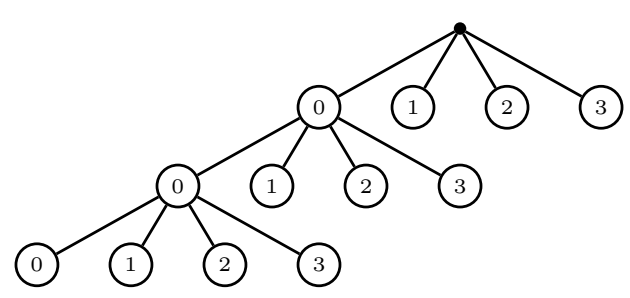

Figura 4.5: Árvore estimada para o contraste do neurônio HP15a versus HP2a, HP12a e HP12b

Considerando que na análise conjunta de três neurônios a maior árvore obtida envolvia a interação entre os neurônios HP12a, HP12b e HP15a, foi feita uma codificação análoga à apresentada na tabela 4.8, só que nesta ocasião são contrastados o neurônio HP15a contra os neurônios HP12a e HP12b, estimando a seguinte árvore de contextos,

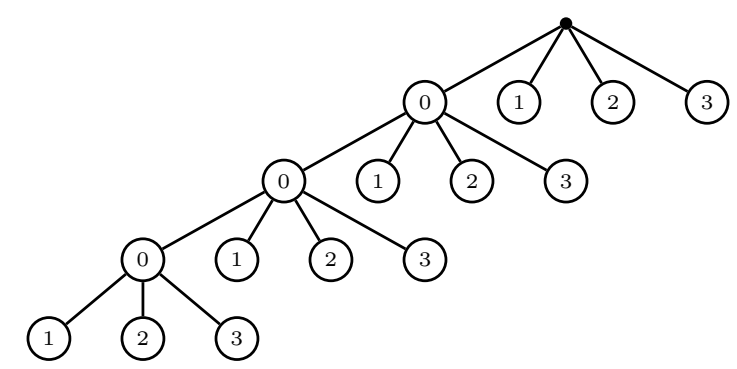

Figura 4.6: Árvore estimada para o contraste do neurônio HP15a versus HP12a e HP12b

Nenhuma das árvores até aqui apresentadas, mostrou evidência de influência de algum dos neurônios. No entanto é possível verificar que o tamanho do alfabeto envolvido no processo, modifica a qualidade das árvores estimadas. Por exemplo, quando $|A|=2$ as árvores estimadas facilmente chegaram a ser de altura $\ell(\tau)=16$, de outro lado para casos onde o alfabeto cresce as árvores estimadas são pouco profundas, em particular quando $|A|=16$, foi obtido $\ell(\tau)=1$.

\subsection{Avaliação da influência entre neurônios}

Sejam $\left(X_{t}(i)\right)_{t \in \mathbb{Z}}$ e $\left(X_{t}(j)\right)_{t \in \mathbb{Z}}$ dois processos estacionários em $A=\{0,1\}$, é definido um novo processo $\left(Z_{t}\right)_{t \in \mathbb{Z}}$ em $A_{Z}=\{0,1,2\}$ da seguinte forma,

$$
Z_{t}= \begin{cases}0 & \text { se } X_{t}(i)=X_{t}(j)=0 \\ 1 & \text { se } X_{t}(j)=1 \\ 2 & \text { se } X_{t}(i)=1, X_{t}(j)=0\end{cases}
$$


É possível afirmar que o processo $\left(X_{t}(i)\right)$ influencia o processo $\left(X_{t}(j)\right)$ se são simultaneamente satisfeitas as seguintes condições:

1. Para todo $k \in \mathbb{N}$ e $b \in A_{Z}$

$$
P\left(Z_{t}=b \mid Z_{t-k-1}^{t-1}=a_{t-k}^{t-1} 2, Z_{-\infty}^{t-k-2}=a_{-\infty}^{t-k-2}\right)=P\left(Z_{t}=b \mid Z_{t-k-1}^{t-1}=a_{t-k}^{t-1} 2\right)
$$

Em que,

$$
\begin{aligned}
& a_{t}^{t-1}=\emptyset \\
& a_{t-k}^{t-1}=\left(a_{t-1}, a_{t-2}, \ldots, a_{t-k}\right) \quad \text { com } a_{j} \in\{0,1\}
\end{aligned}
$$

2. Para algum $k, \exists w \neq \emptyset$ tal que,

$$
\begin{aligned}
& P\left(Z_{t}=b \mid Z_{t-k-1}^{t-1}=0^{k} 1, Z_{t-k-2-|w|}^{t-k-2}=w, Z_{-\infty}^{t-k-2-|w|-1}=a_{-\infty}^{t-k-2-|w|-1}\right) \\
& =P\left(Z_{t}=b \mid Z_{t-k-1}^{t-1}=0^{k} 1, Z_{t-k-2-|w|}^{t-k-2}=a_{t-k-2-|w|}^{t-k-2}\right)
\end{aligned}
$$

A condição 4.1 quer dizer que sempre que o processo $\left(Z_{t}\right)$ atinja o estado 2 se esquece o passado, o estado 2 é atingido toda vez que seja disparado unicamente o neurônio associado ao processo $\left(X_{t}(i)\right)$. De outro lado, a condição 4.2 indica que deve existir pelo menos um caso em que não seja suficiente encontrar o estado 1 no processo $\left(Z_{t}\right)$ para esquecer o passado.

Existe evidência de que sempre que o neurônio HP15a é incorporado nas análises, as árvores tendem a mostrar o comportamento de um processo de renovação, mesmo sem indicar especificamente que o estado de renovação esteja associado ao neurônio HP15a. O anterior motivou a verificação das condições 4.1 e 4.2, usando a seguinte codificação que mistura a informação do neurônio HP15a e cada um dos outros neurônios por separado, assim,

\begin{tabular}{|c|c|c|}
\hline Neurônio a testar & Neurônio HP15a & Estado \\
\hline 0 & 0 & 0 \\
0 & 1 & 2 \\
1 & 0 & 1 \\
1 & 1 & 1 \\
\hline
\end{tabular}

Tabela 4.9: Codificação para avaliar a influencia do neurônio HP15a sobre os outros neurônios do hipocampo

Para verificar a influência do neurônio HP15a, basta com estimar a árvore contexto do processo $\left(Z_{t}\right)_{t \in \mathbb{Z}}$ e encontrar que sempre que o processo chega no estado 2 o passado é esquecido contrário ao que deve acontecer com o estado 1 . Seguem as árvores que foram obtidas, 


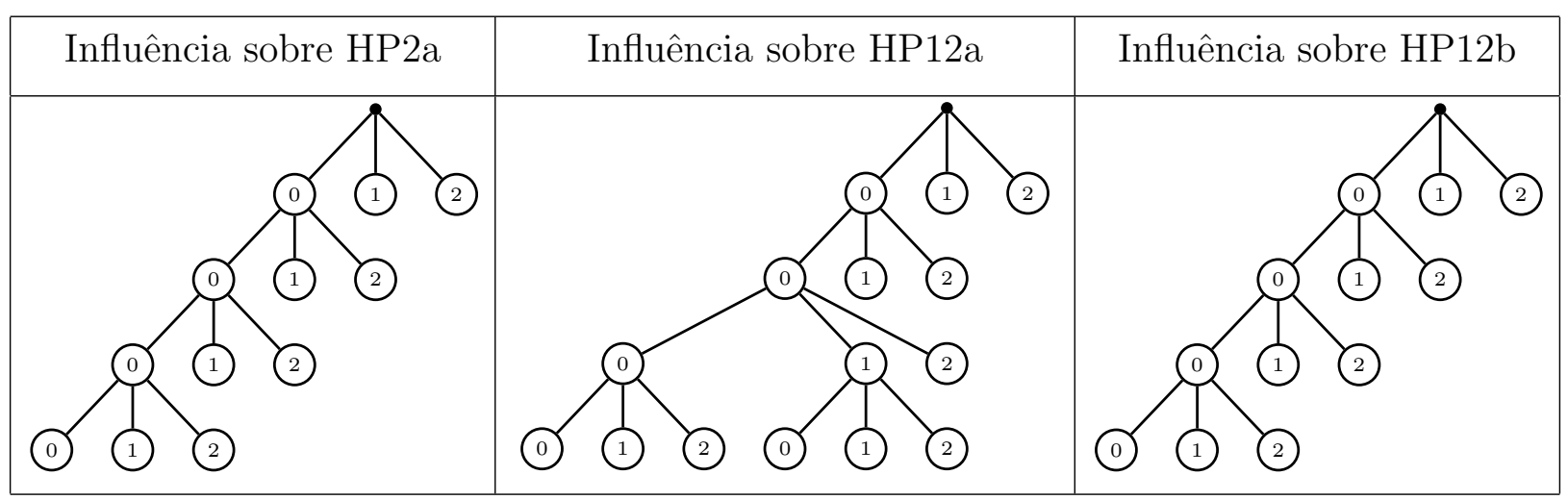

Figura 4.7: Árvores de contexto estimadas para avaliação da influência do neurônio HP15a

No caso das sequências que testaram a influência do neurônio HP15a sobre os neurônios HP2a e HP12b, se encontrou que o passado é esquecido sempre que é disparado algum dos neurônios, sem especificar que seja o neurônio HP15a quem prevalece. Desta forma não foi encontrada suficiente evidência de que o neurônio HP15a esteja influenciando algum desses neurônios (HP2a e HP12b). Já para o neurônio HP12a, encontrou-se uma árvore levemente diferente, observa-se que aparecem os contextos 0010, 1100 e 2100, indicando que o estado 1 se afasta do comportamento típico de um estado de renovação, enquanto o estado 2 é um contexto e sempre que ele aparecer o passado será esquecido.

O mesmo procedimento foi feito para avaliar uma possível influência do neurônio HP2a sobre os outros três neurônios, neste caso não foi encontrada evidência de que o modelo proposto no inicio desta seção seja satisfeito, as seguintes foram as árvores obtidas,

\begin{tabular}{|c|c|c|}
\hline Influência sobre HP12a & Influência sobre HP12b & Influência sobre HP15a \\
\hline (1) (1) & (1) (1) & (1) (1) \\
\hline
\end{tabular}

Figura 4.8: Árvores de contexto estimadas para avaliação da influência do neurônio HP2a Para o neurônio HP12a também não foi encontrada evidência de influenciar algum dos outros neurônios, seguem as árvores estimadas, 


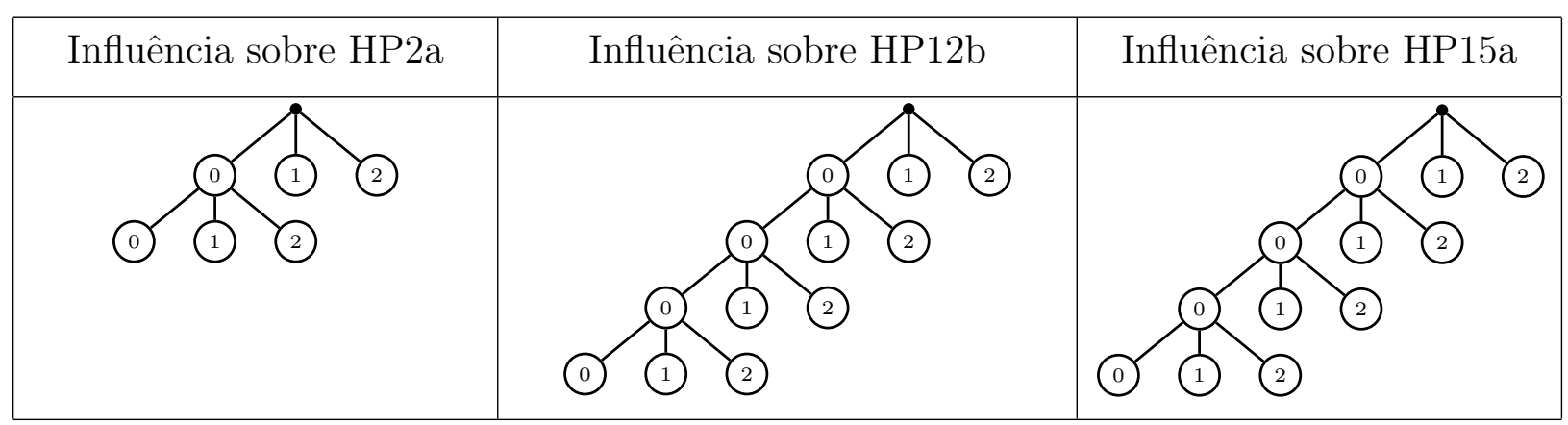

Figura 4.9: Árvores de contexto estimadas para avaliação da influência do neurônio HP12a

Seguem as árvores que avaliam a influência do neurônio HP12b,

\begin{tabular}{|l|c|c|c|}
\hline Influência sobre HP2a & Influência sobre HP12a & Influência sobre HP15a \\
\hline & &
\end{tabular}

Figura 4.10: Árvores de contexto estimadas para avaliação da influência do neurônio HP12b

Assim, foi observado até este ponto das análises que os neurônios HP2a, HP12a e HP12b não mostram evidências de estar influenciando o comportamento de algum outro neurônio, já para o neurônio HP15a foi detectada uma influência dele sobre o neurônio HP2a. Mesmo assim a árvore que corrobora a influência de HP15a sobre HP12a, não é muito diferente com relação às árvores que avaliam a influência sobre HP2a e HP12b, surgiu assim a hipóteses de que pode estar influenciando algum desses neurônios, mas o tamanho da amostra não é suficiente para detectá-la.

Por esse motivo, foram feitas todas as árvores usando a amostra do período de pre-exposição que tem 580.000 observações. Seguem as árvores que avaliam a influência de cada neurônio sobre os outros, para o período de pre-exposição, 


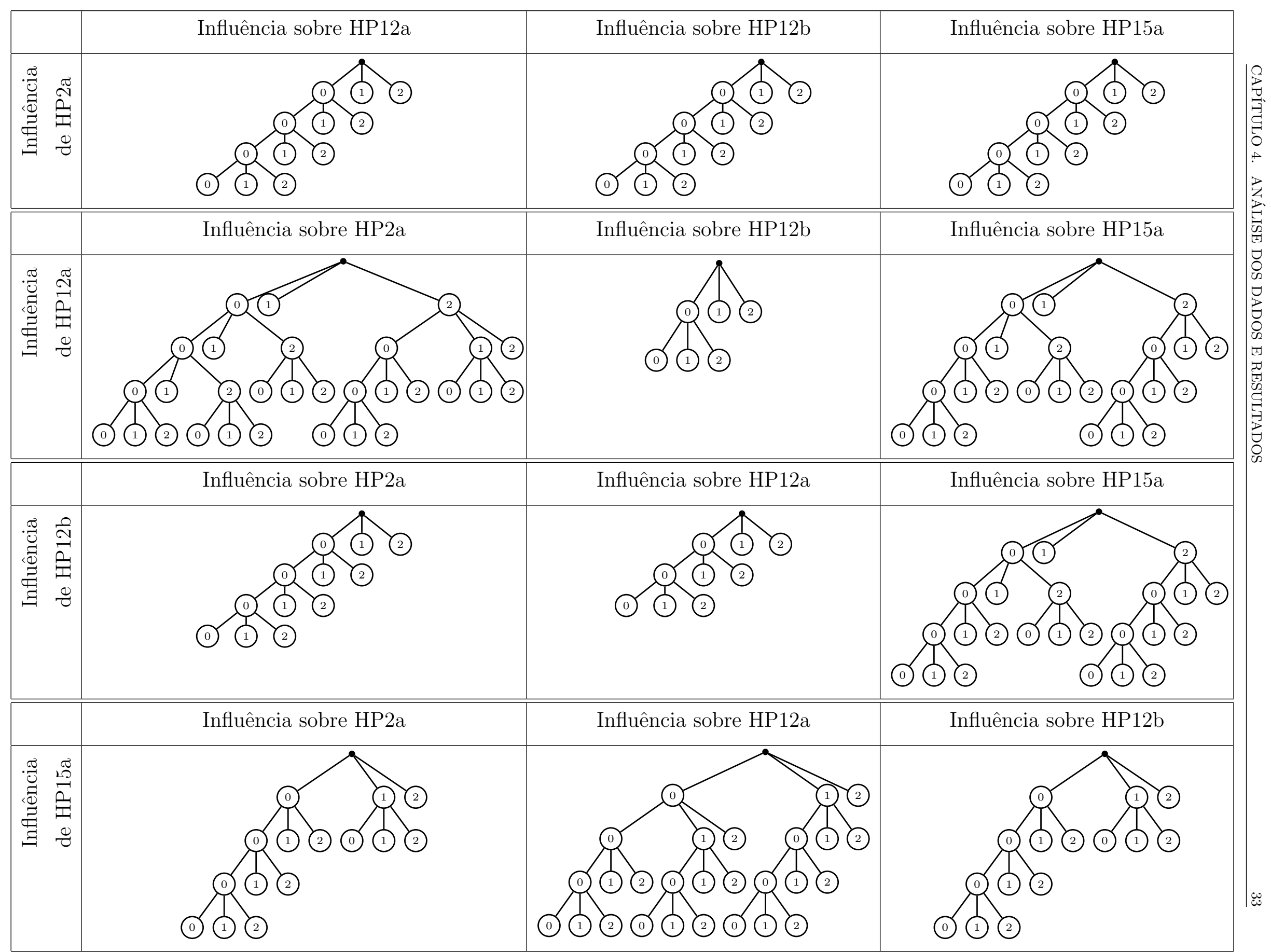

Figura 4.11: Árvores de contexto estimadas para avaliação da influência com a amostra de pré-exposição 
Encontrou-se que as árvores obtidas para o período de pré-exposição são maiores ou iguales às árvores da amostra de exposição, isto pode estar explicado pelo tamanho da amostra que é superior na pré-exposição. De outro lado, a análise da amostra durante a pré-exposição revela uma influência do neurônio HP15a sobre os outros três neurônios. Também foi confirmada a não influencia do neurônio HP2a sobre os outros neurônios estudados.

Para fechar a questão da avaliação da influência entre os neurônios, e com a intenção de fazer uma nova comparação entre as amostras de pré-exposição e exposição, tentou-se explorar a possível influência do neurônio HP15a sobre os neurônios HP12a e HP12b de maneira conjunta, para fazer isto a codificação foi dada pelas seguintes regras,

\begin{tabular}{|l|c|}
\hline \multicolumn{1}{|c|}{ Condição } & Estado \\
\hline Não dispara nenhum dos três neurônios & 0 \\
\hline Dispara HP12a ou HP12b & 1 \\
\hline Dispara somente HP15a & 2 \\
\hline
\end{tabular}

E as respectivas árvores estimadas para as etapas de pré-exposição e exposição são,

Durante a pré-exposição

Figura 4.12: Árvores de contexto estimadas para a avaliação da influência do neurônio HP15a sobre HP12a e HP12b conjuntamente: Comparacão entre as amostras de pré-exposição e exposição

Observa-se que durante o período de pré-exposição tem uma clara influência do neurônio HP15a sobre os neurônios HP12a e HP12b de maneira conjunta. Já tinha sido ressaltada a influência sobre cada um deles de maneira separada durante essa mesma etapa do experimento. No entanto, no período de exposição, somente foi detectada a influência de HP15a sobre HP12a, e nesta última árvore também não se encontrou evidência de que os dois neurônios (HP12a e HP12b) de maneira conjunta estejam sendo influenciados por HP15a. 
De outro lado, é sabido que o tamanho da amostra do período de pré-exposição é de 580.000 pontos amostrais, enquanto a amostra da etapa de exposição é de 128.000 pontos. Surgindo assim a duvida natural, de se o tamanho de amostra está modificando os resultados, de maneira que não foram identificadas essas associações durante o período de exposição por causa de uma falta de observações ou então obedece a reais diferenças no comportamento dos neurônios entre as duas etapas do experimento.

Adicionalmente, durante o período de pré-exposição o rato pasa por diferentes estados comportamentais (vigília, vigilia WT, sono REM, sono SWS). Então a questão é se essa situação pode ser a responsável das diferencias nos resultados?

\subsection{Comparações entre sono e vigília}

Para essa etapa da análise foram considerados os hipnogramas de 1 e 10 segundos que foram apresentados no capitulo 2, o primeiro passo para a análise, foi a construção de um banco de dados com as sequências de disparos em janelas de $10 \mathrm{~ms}$, do jeito que foi explicado ao inicio deste capítulo, adicionando agora o estado comportamental do rato ge4, de acordo com a informação contida nos hipnogramas de 1s e 10s. Assignando os seguintes códigos para cada estado comportamental.

\begin{tabular}{|c|c|c|c|c|}
\hline Estado & Vigília & Sono SWS & Sono REM & Vigília WT \\
\hline Código & 1 & 2 & 3 & 4 \\
\hline
\end{tabular}

Tabela 4.10: Codificação do estado comportamental

Foi registrada a informação do rato ge4 durante 17369 segundos, por tanto o hipnograma de 10s conta com 1737 observações. A seguinte tabela mostra as frequências absolutas e relativas para cada estado comportamental, em cada hipnograma

\begin{tabular}{|c|c|c|c|c|}
\hline \multirow{2}{*}{$\begin{array}{c}\text { Estado } \\
\text { Comportamental }\end{array}$} & \multicolumn{2}{|c|}{ Hipnograma 1s. } & \multicolumn{2}{c|}{ Hipnograma 10s. } \\
\cline { 2 - 5 } & Freq. abs. & Freq. rel. & Freq. abs. & Freq. rel. \\
\hline 1 & 4976 & 0,2865 & 890 & 0,5124 \\
2 & 4867 & 0,2802 & 532 & 0,3063 \\
3 & 0 & 0 & 44 & 0,0253 \\
4 & 0 & 0 & 271 & 0,1560 \\
5 & 1382 & 0,0796 & 0 & 0 \\
6 & 58 & 0,0033 & 0 & 0 \\
7 & 2 & 0,0001 & 0 & 0 \\
9 & 6084 & 0,3503 & 0 & 0 \\
\hline Total & 17369 & 1 & 1737 & 1 \\
\hline
\end{tabular}

Tabela 4.11: Frequências absolutas e relativas da informação contida nos hipnogramas 
Considerando que em ambos casos deve estar registrado o estado comportamental predominante, deveria ser possível obter uma versão do hipnograma de 10 segundos a partir da identificação do estado mais frequente de 10 em 10 segundos no hipnograma de 1 segundos. Foi feita uma comparação entre a versão do hipnograma de 10 segundos construído a partir do hipnograma de 1 segundo e o hipnograma de 10 segundos elaborado pela equipe que fez a coleta dos dados. A seguinte tabela apresenta essa comparação,

\begin{tabular}{|c|c|c|c|c|c|}
\hline Hipnograma & \multicolumn{3}{|c|}{ Hipnograma 10 seg. } & \multirow{2}{*}{ Total } \\
\cline { 2 - 5 } de 1 seg. & 1 & 2 & 3 & 4 & \\
\hline 1 & 498 & 0 & 0 & 0 & 498 \\
2 & 1 & 495 & 1 & 0 & 497 \\
5 & 0 & 0 & 0 & 150 & 150 \\
6 & 0 & 0 & 7 & 0 & 7 \\
9 & 391 & 37 & 36 & 121 & 585 \\
\hline
\end{tabular}

Tabela 4.12: Comparação entre informação dos hipnogramas de 1 seg. e 10 seg.

No hipnograma de 1 segundo se encontraram códigos de significado desconhecido, e com a tabela anterior se confirma que não é possível usar a informação do hipnograma de 1 segundo para reproduzir o hipnograma de 10 segundos. Concluindo assim que porem, seja ideal usar o hipnograma de 1 segundo, neste caso é melhor fazer as análises com os dados do hipnograma de 10 segundos, que contem informação mais confiável.

Foram agrupados os dois estados de vigília (vigília e Estado WT) e os estados de Sono (SWS e REM), de forma tal que foram considerados dois estados comportamentais e se identificaram as porções da amostra onde o rato ge4 estava em estado de vigília exclusivamente. Escolhendo inicialmente as maiores frações de tempo em que o rato se encontrou nesses estados, durante o período de pré-exposição. Os intervalos de tempo analisados foram,

\begin{tabular}{|c|c|c|}
\hline Amostra & vigília & Sono \\
\hline 1 & $4450-5120$ & $3530-3900$ \\
\hline 2 & $1890-2220$ & $3930-4150$ \\
\hline
\end{tabular}

Tabela 4.13: Porções da amostra para a vigília e o sono

Foi conservada a estratégia de construção de janelas de $10 \mathrm{~ms}$, com o qual os tamanhos das amostras aqui analisadas foram,

\begin{tabular}{|c|c|c|}
\hline Amostra & Vigília & Sono \\
\hline 1 & 67000 & 37000 \\
\hline 2 & 33000 & 22000 \\
\hline
\end{tabular}

Tabela 4.14: Tamanhos de amostra para a análise separada de vigília e o sono 
Seguem as árvores obtidas para as quatro amostras nos neurônios do hipocampo,

\begin{tabular}{|c|c|c|c|c|}
\hline Neurônio & Vigília1 & Vigília2 & Sono1 & Sono2 \\
\hline HP2a & & & & \\
\hline HP12a & & & & \\
\hline $\mathrm{HP} 12 \mathrm{~b}$ & & & & \\
\hline HP15a & & & & \\
\hline
\end{tabular}

Figura 4.13: Árvores de contexto estimadas para amostras de vigília e sono de forma separada As árvores observadas para as amostras onde o rato se encontra em estado de vigília são semelhantes às amostras de quando ele se encontra em estado de sono. Se observa uma tendência de que amostras menores apresentam árvores de menor altura.

O passo seguinte foi a modelagem da amostra inteira de pré-exposição, considerando na configuração dos estados, o comportamento do neurônio (Disparo / Não disparo) e o estado comportamental do animal (Vigília / Sono), de forma semelhante a como foi feita a análise da etapa de exposição onde foram incorporados os objetos na construção dos estados. Neste caso os estados foram definidos assim,

\begin{tabular}{|c|c|c|}
\hline Estado comportamental & Disparo & Estado \\
\hline Vigília & Não & 0 \\
Vigília & Sim & 1 \\
Sono & Não & 2 \\
Sono & Sim & 3 \\
\hline
\end{tabular}

Tabela 4.15: Codificação para a análise conjunta do estado comportamental e o disparo de um neurônio 
Na seguinte tabela são apresentadas as frequências relativas associadas às sequências construídas de acordo com o alfabeto mostrado acima, também é incluída a proporção de disparos durante o período de pré-exposição que corresponde à soma das frequências dos estados 1 e 3 . Nas ultimas colunas são comparadas as proporções de disparo dos neurônios de acordo com o estado comportamental (vigília/sono).

\begin{tabular}{|c|c|c|c|c|c|c|c|}
\hline \multirow{3}{*}{ Neurônio } & \multicolumn{2}{|c|}{ Vigília } & \multicolumn{2}{|c|}{ Sono } & \multirow{3}{*}{$\begin{array}{l}\text { Proporção de } \\
\text { disparos em } \\
\text { pré-exposição }\end{array}$} & \multirow{3}{*}{$\begin{array}{c}\text { Proporção de } \\
\text { disparos } \\
\text { em vigília }\end{array}$} & \multirow{3}{*}{$\begin{array}{c}\text { Proporção de } \\
\text { disparos } \\
\text { em sono }\end{array}$} \\
\hline & Não & Sim & Não & Sim & & & \\
\hline & 0 & 1 & 2 & 3 & & & \\
\hline $\mathrm{HP} 2 \mathrm{a}$ & 0,6656 & 0,0085 & 0,3188 & 0,0070 & & & 0,02 \\
\hline $\mathrm{HP} 12 \mathrm{a}$ & 0,6060 & 0,0681 & 0,2961 & 0,0298 & & & \\
\hline HP12b & 0,6089 & 0,0652 & 0,2987 & 0,0271 & 0,0924 & 0,0968 & 0,0833 \\
\hline HP15a & 0,6666 & 0,0076 & 0,3202 & 0,0057 & 0,0132 & 0,0112 & 0,0174 \\
\hline
\end{tabular}

Tabela 4.16: Frequências relátivas das sequências relativas à interação entre estado comportamental e disparo dos neurônios

De forma semelhante ao visto no período de exposição, se encontrou que os neurônios HP2a e HP15a são os que menor taxa de disparo têm, também observamos que o rato ge4 permaneceu o $67,41 \%$ do tempo em estado de vigília. Seguem as árvores obtidas para cada um dos quatro neurônios,

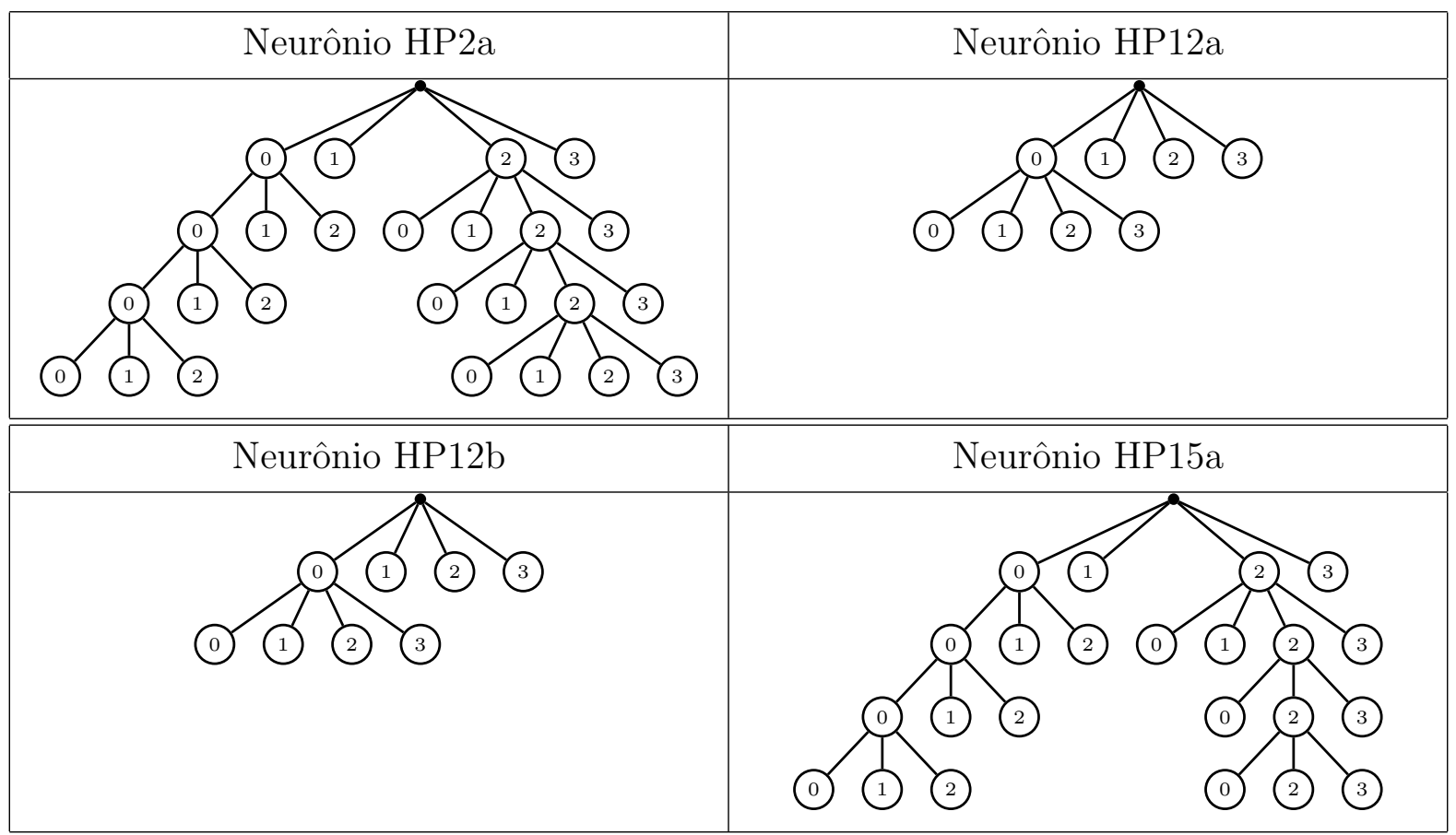

Figura 4.14: Árvores de contexto estimadas para estado comportamental e disparo dos neurônios conjuntamente 
Continua-se observando a mesma estrutura das árvores para os neurônios HP2a e HP15a, indicando que toda vez que eles disparem, o passado vai ser esquecido, independentemente do estado comportamental do rato. Os neurônios HP12a e HP12b, apresentam um comportamento diferente, tal vez eles estejam sendo influenciados pelos outros neurônios. Isto motivou a avaliação da influência de cada neurônio sobre os outros três, considerando ao mesmo tempo o estado comportamental do rato durante o período de pré-exposição.

Na seguinte tabela a codificação dos estados da sequência criada no caso em que é testada a influência do Neurônio A sobre o Neurônio B,

\begin{tabular}{|c|c|c|c|}
\hline Disparo do & Disparo do & \multicolumn{2}{|c|}{ Estado comportamental } \\
\cline { 3 - 4 } Neurônio A & Neurônio B & Vigília & Sono \\
\hline 0 & 0 & V0 & S0 \\
0 & 1 & V2 & S2 \\
1 & 0 & V1 & S1 \\
1 & 1 & V1 & S1 \\
\hline
\end{tabular}

Tabela 4.17: Codificação para avaliação da influência do neurônio A sobre o neurônio B, considerando o estado comportamental

Inicialmente foi testada a influência do neurônio HP2a sobre os outros três neurônios do hipocampo, considerando a amostra de exposição e diferenciando pelos dois estados comportamentais (vigília/Sono), as árvores estimadas são apresentadas na figura 4.15.

No caso dos neurônios HP12a e HP12b, observa-se o comportamento do processo de renovação na parte relacionada com a vigília, indicando que para esquecer o passado basta com o disparo de algum dos neurônios, sem indicar algum deles especificamente, já quando o rato fica em estado de sono, basta com olhar um passo para atrás para predizer o futuro. Assim a conclusão é que não foi encontrada evidência de que o neurônio HP2a esteja influenciando os neurônios HP12a e HP12b.

Com relação ao neurônio HP15a, a árvore escolhida mostra o comportamento de um processo de renovação para ambos estados comportamentais: vigília e sono. No entanto, não há indícios de estar sendo influenciado pelo neurônio HP2a, sendo que basta com o disparo de qualquer dos dois neurônios em questão para esquecer o passado. 

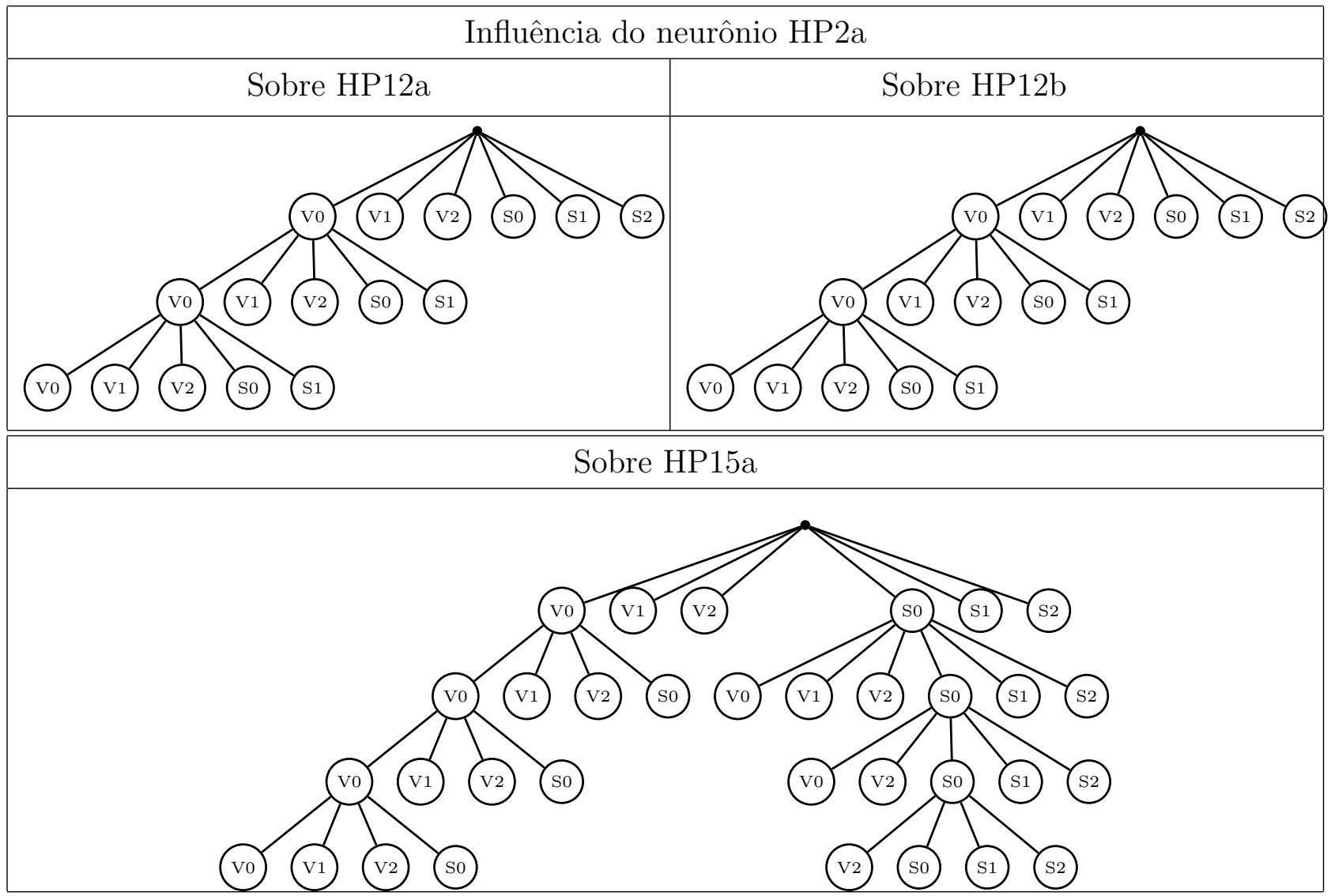

Figura 4.15: Árvores de contexto para a avaliação da influência do neurônio HP2a, considerando o estado comportamental

Seguindo a mesma logica, foi avaliada a influência do neurônio HP12a sobre os outros três neurônios do hipocampo, obtendo as árvores da figura 4.16. As árvores estimadas indicam que não tem influência do neurônio HP12a sobre algum dos outros, no caso dos neurônios HP2a e HP15a se observa o já familiar comportamento do processo de renovação sem dar maior relevância a algum dos neurônios.

No caso da avaliação da influencia do neurônio HP12b, foram encontradas as árvores que são apresentadas na figura 4.17. Onde se percebe uma clara evidência de que o neurônio HP12b não influencia os neurônios HP2a e HP15a, isto justificado no fato de que o estado 2 não é contexto, além de que os estados 1 e 4 são contextos, indicando que nestes casos o passado não vai ser esquecido quando o neurônio HP12b dispara. Na avaliação da influência sobre HP12a, a árvores selecionado corresponde à uma cadeia de Markov de ordem 1, concluindo assim que não tem evidência de que HP12a esteja sendo influenciado por HP12b.

Por último, foi avaliada a influência do neurônio HP15a, obtendo as árvores que aparecem na figura 4.18. Neste caso não é identificada uma influência do neurônio HP15a sobre HP2a, isto 

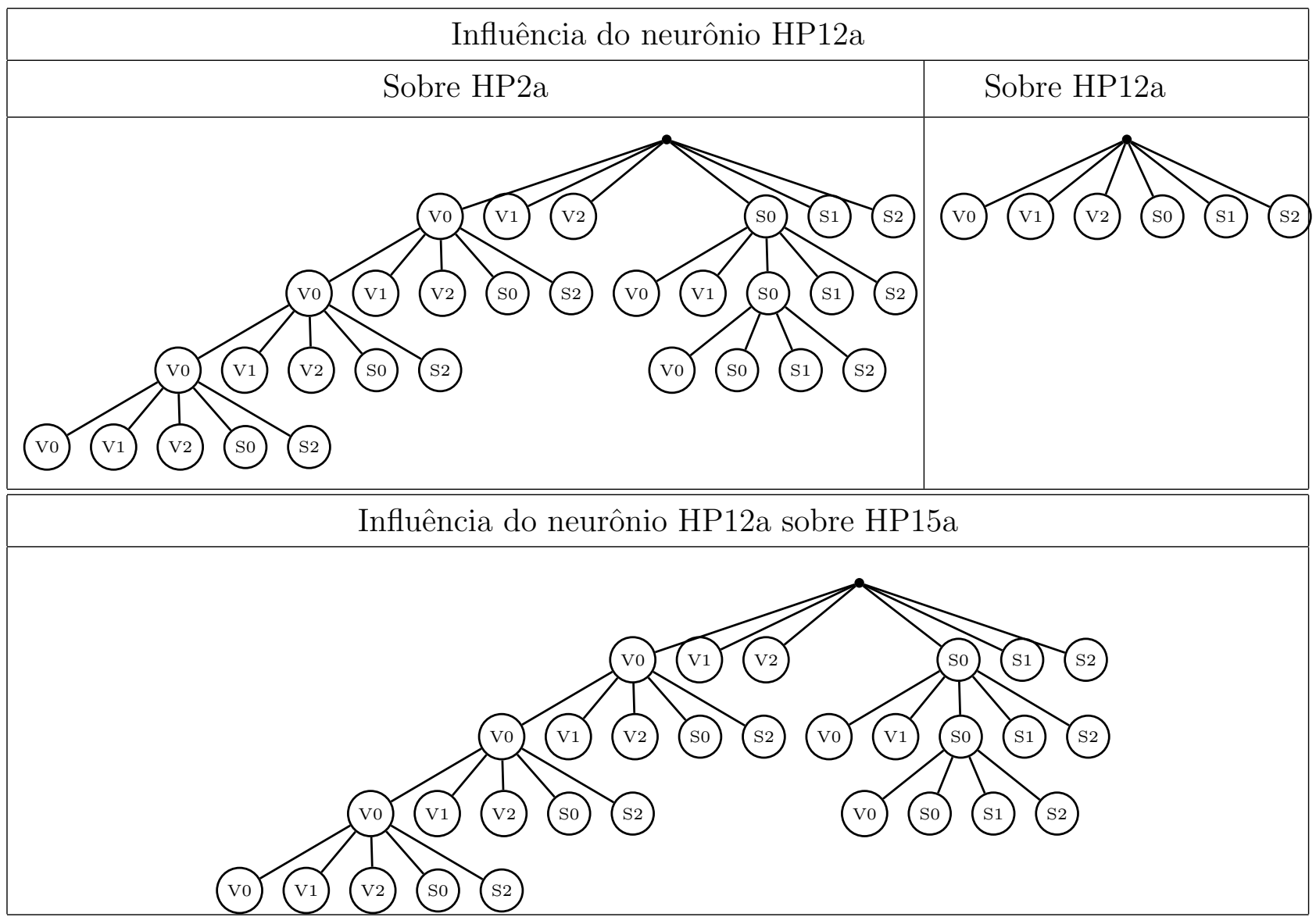

Figura 4.16: Árvores de contexto para a avaliação da influência do neurônio HP12a, considerando o estado comportamental

aparentemente contradiz o encontrado na análise feita no final da seção 4.4, onde foi escolhida uma árvore que mostrou a influência de HP15a sobre HP2a. Sendo que para os dois casos o tamanho da amostra é o mesmo, só que agora o tamanho do alfabeto é maior, o qual pode estar indicando que para esse alfabeto, precisamos de uma amostra maior para conseguir corroborar a associação entre esses dois neurônios.

As árvores estimadas no caso da avaliação da influência de HP15a sobre HP12a e HP12b, indicam em ambos casos que durante o estado de vigília HP15a está influenciando eles, devido a que nas duas árvores escolhidas o estado 1 não é contexto, enquanto observamos que basta com aparecer o estado 2, para que o passado seja esquecido, lembrando que o estado 2 corresponde ao disparo do neurônio HP15a enquanto o animal se encontra em estado de vigília. Com relãção ao estado de sono, não foi encontrada evidência de que o neurônio HP15a exerça influencia sobre os outros neurônios, mas isto pode obedecer ao fato de que o rato permaneceu em estado de sono somente o $32,58 \%$ do tempo. 


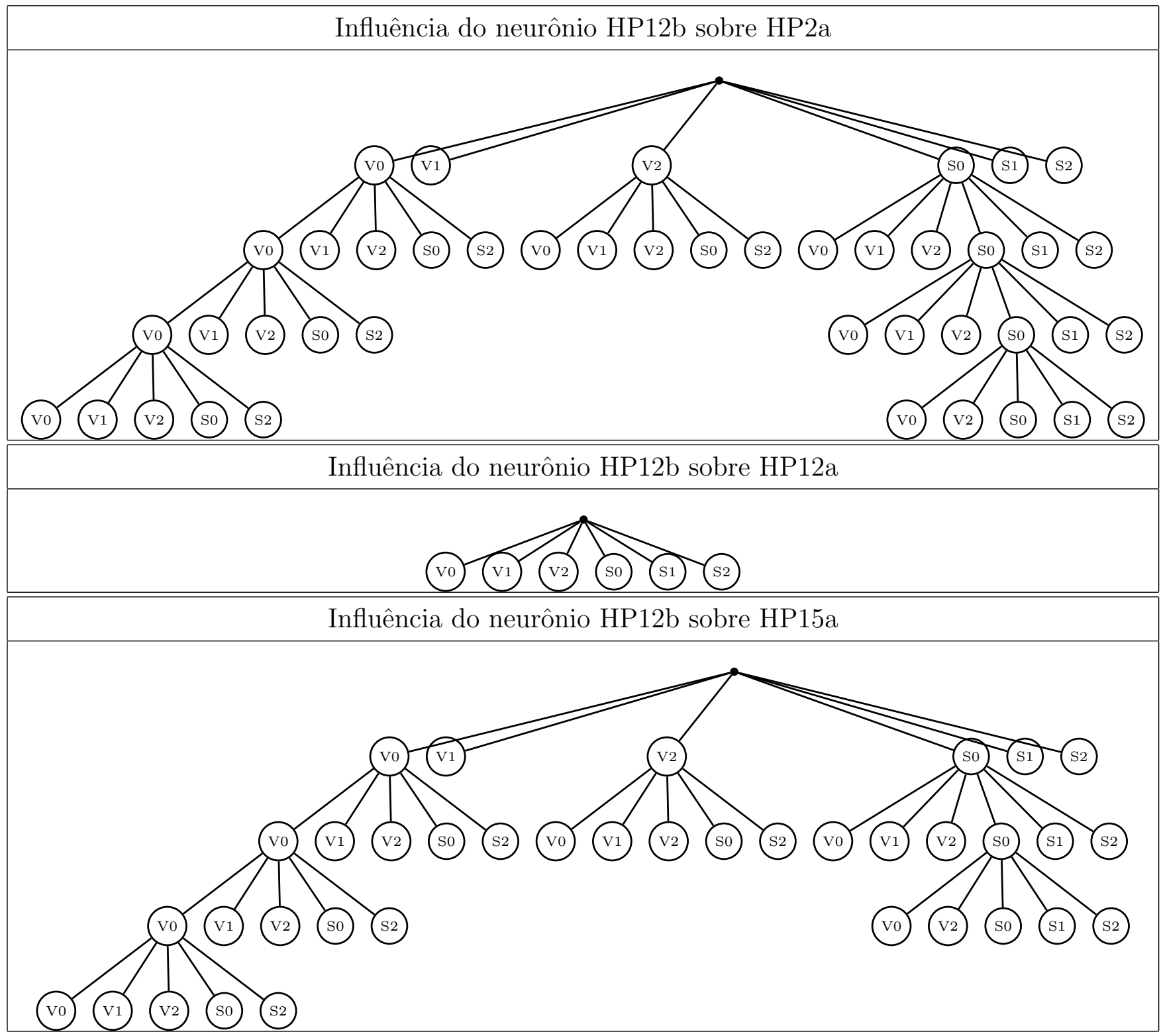

Figura 4.17: Árvores de contexto para a avaliação da influência do neurônio HP12b, considerando o estado comportamental 

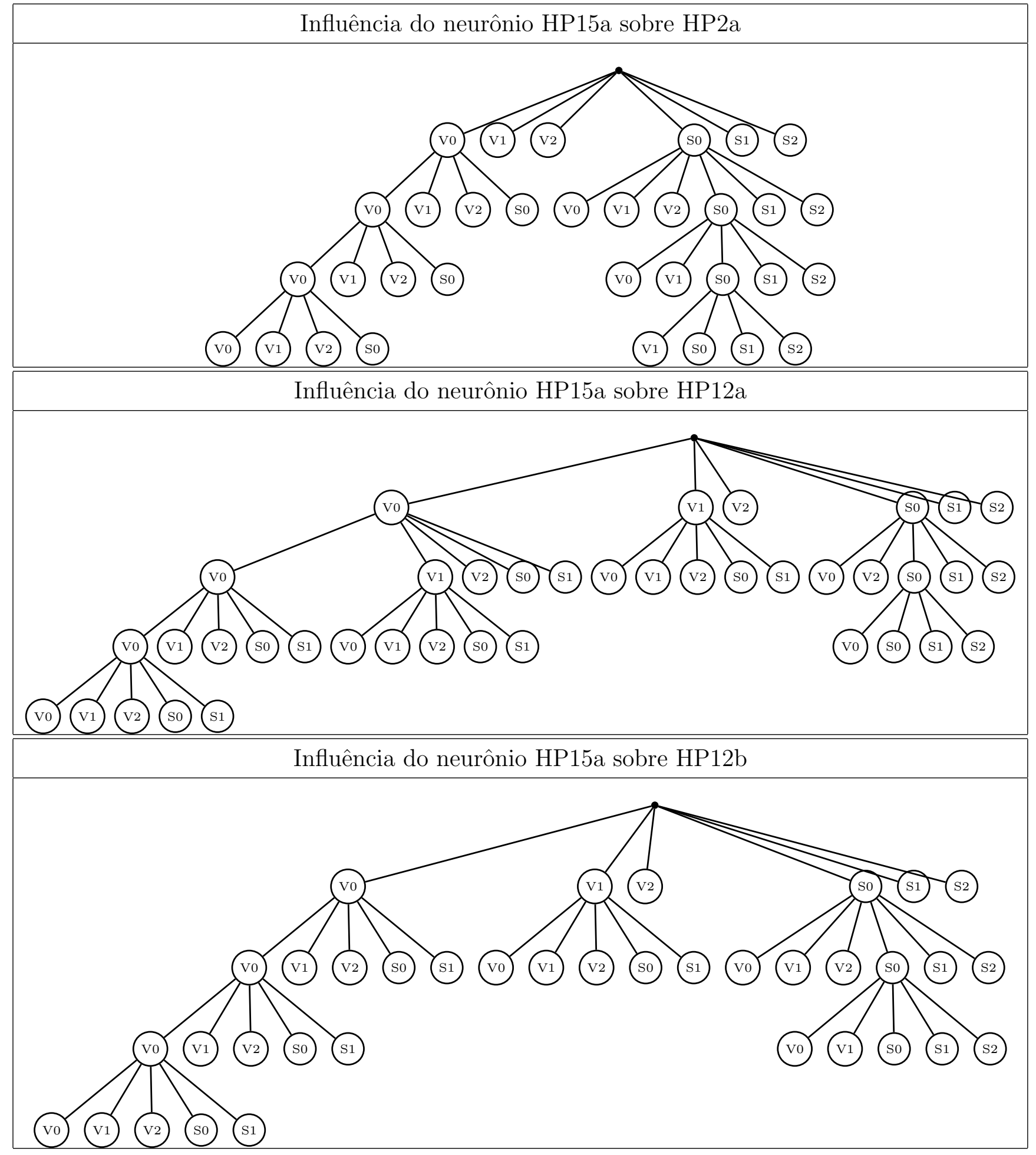

Figura 4.18: Árvores de contexto para a avaliação da influência do neurônio HP15a, considerando o estado comportamental

\subsection{Análise conjunta dos quatro neurônios}

Em um esforço adicional, para tentar identificar se algum dos quatro neurônios tem um efeito sobre os outros neurônios, foi feita a seguinte codificação, 


\begin{tabular}{|l|c|}
\hline \multicolumn{1}{|c|}{ Condição } & Estado \\
\hline Dispara somente HP2a & 1 \\
\hline Dispara somente HP12a & 2 \\
\hline Dispara somente HP12b & 3 \\
\hline Dispara somente HP15a & 4 \\
\hline Qualquer outro caso & 0 \\
\hline
\end{tabular}

A seguinte foi a árvore resultante,

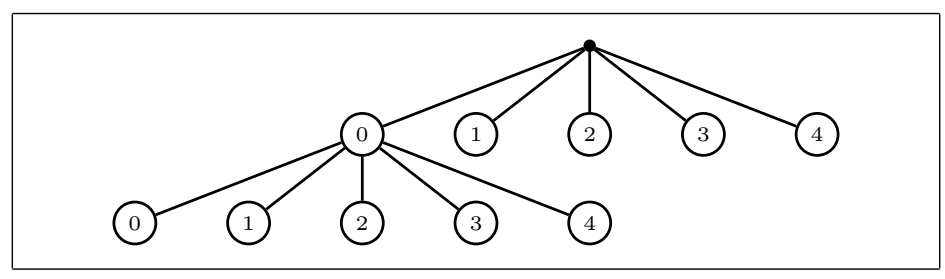

Essa última árvore estaria sugerindo que basta com que seja disparado um único neurônio, independentemente de qual for, para ser esquecido o passado e predizer o seguinte passo da sequência.

Nos exercícios apresentados nas anteriores seções, foram usadas quatro sequências de disparos (uma para cada neurônio) em janelas de $10 \mathrm{~ms}$., agora continuando com a ideia de analisar os quatro neurônios de maneira conjunta, foi construída uma única sequência que indica os tempos em que algum dos quatro neurônios foi disparado, identificando a cada instante o neurônio que disparou e aplicando a seguinte codificação:

\begin{tabular}{|c|c|}
\hline Neurônio & Código \\
\hline HP2a & 1 \\
HP12a & 2 \\
HP12b & 3 \\
HP15a & 4 \\
\hline
\end{tabular}

Tabela 4.18: Códigos assignados para cada neurônio

Assim foi obtida uma sequência do seguinte tipo: '234331...', indicando que primeiro disparou o neurônio HP12a, seguido de HP12b, HP15a e assim sucessivamente. Durante o período de exposição o animal permaneceu em estado de vigília, na seguinte tabela se apresentam as frequências absolutas e relativas dos disparos durante essa fase do experimento, 


\begin{tabular}{|c|c|c|}
\hline Neurônio & Freq. absoluta & Freq. relativa \\
\hline HP2a & 2152 & 0,058 \\
HP12a & 15752 & 0,425 \\
HP12b & 13903 & 0,375 \\
HP15a & 5289 & 0,143 \\
\hline
\end{tabular}

Tabela 4.19: Frequências absolutas e relativas dos disparos de cada neurônio, durante o período de exposição

Já durante o período de pré-exposição o rato esteve tanto em estado de vigília como de sono, permanecendo neste último o $68,34 \%$ do tempo. A seguinte tabela contem as frequências de disparo dos quatro neurônios, segundo o estado comportamental.

\begin{tabular}{|c|c|c|c|c|c|}
\hline \multirow{2}{*}{$\begin{array}{c}\text { Estado } \\
\text { Comportamental }\end{array}$} & \multicolumn{4}{|c|}{ Neurônio } & \multirow{2}{*}{ Total } \\
\cline { 2 - 6 } & 1 & 2 & 3 & 4 & \\
\hline \multirow{2}{*}{ Vigília } & 5053 & 41405 & 39473 & 4566 & 90497 \\
& $(0,056)$ & $(0,457)$ & $(0,436)$ & $(0,050)$ & $(1)$ \\
\hline \multirow{2}{*}{ Sono } & 4119 & 18011 & 16325 & 3461 & 41916 \\
& $(0,098)$ & $(0,430)$ & $(0,389)$ & $(0,083)$ & $(1)$ \\
\hline \multirow{2}{*}{ Total } & 9172 & 59416 & 55798 & 8027 & 132413 \\
& $(0,069)$ & $(0,449)$ & $(0,421)$ & $(0,061)$ & $(1)$ \\
\hline
\end{tabular}

Tabela 4.20: Frequência de disparos de cada neurônio, durante a etapa de pré-exposición

Foram construídas três sequências sobre as quais foi estimada sua árvore de contextos:

- Sequência 1: Essa sequência tem um total de 37096 observações, correspondentes ao total de disparos dos quatro neurônios do hipocampo analisados durante a etapa de exposição.

- Sequência 2: Contem 132413 observações, identificando os disparos dos quatro neurônios durante a etapa de pré-exposição.

- Sequência 3: A terceira sequência está ligada à etapa de pré-exposição, onde além de identificar o neurônio que disparou, se diferenciam os estados de acordo com o estado comportamental do animal (Vigília/Sono). A seguinte tabela define o espaço estado desta sequência:

\begin{tabular}{|c|c|c||c|c|c|}
\hline Neurônio & Vigília / Sono & Estado & Neurônio & Vigília / Sono & Estado \\
\hline HP2a & Vigília & 1 & HP2a & Sono & 1 \\
HP12a & Vigília & 2 & HP12a & Sono & 2 \\
HP12b & Vigília & 3 & HP12b & Sono & 3 \\
HP15a & Vigília & 4 & HP15a & Sono & 4 \\
\hline
\end{tabular}


As seguintes são as árvores obtidas para cada umas das sequências,

- Sequência 1:

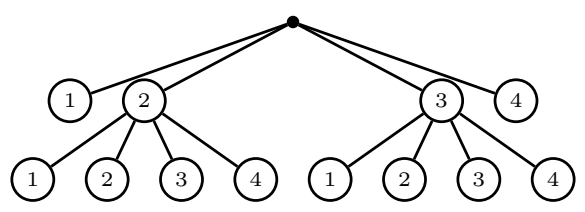

Figura 4.19: Árvore de contextos estimada para a sequência 1

É uma árvore de altura dois, que indica que os neurônios HP2a e HP15a são contextos, isto é, para predizer o futuro todas vez que esses neurônios disparam, o passado da sequência é esquecido. Pelo contrário quando o último neurônio em disparar é HP12a ou HP12b, é necessário observar um passo mais para atrás.

- Sequência 2:

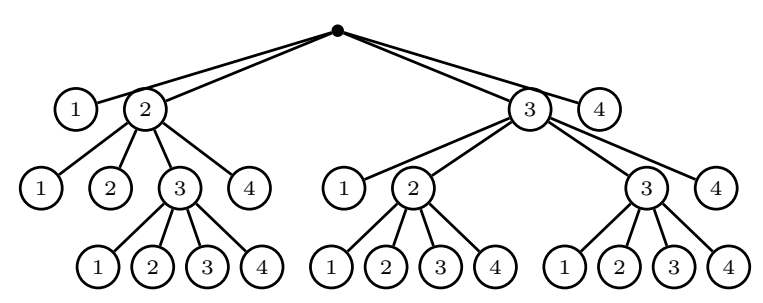

Figura 4.20: Árvore de contextos estimada para a sequência 2

Sendo que a sequência 2 tem um tamanho de amostra maior que o associado à sequência 1 sobre o mesmo alfabeto, foi obtida uma versão ampliada da árvore escolhida na primeira sequência. Os neurônio HP2a e HP15a continuaram sendo contextos.

- Secuencia 3:

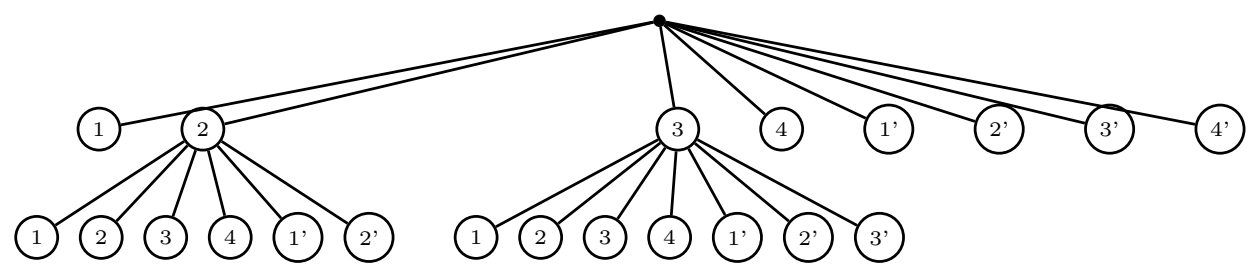

Figura 4.21: Árvore de contextos estimada para a sequência 3

A árvore estimada tem uma estrutura semelhante à apresentada na sequência 1 na parte associada com o estado de vigília, está mostrando que quando o rato se encontra em estado 
de sono é necessário observar dois passos para atrás, nos casos em que o último neurônio em disparar seja HP12a ou HP12b. Em qualquer outro caso, basta com observar o último estado para predizer o futuro.

Não parece ser estranho que o neurônio HP15a seja contexto, porque isto confirma as análises apresentadas ao longo do capítulo, o que sim parece ir contra os outros resultados é o fato do neurônio HP2a ser contexto. Foi observado que com um maior tamanho de amostra a árvore estimada apresenta uma maior profundidade, então surgiu a questão de se um incremento no tamanho da amostra poderia fazer que a estrutura da árvore fosse modificada de tal forma que o neurônio HP2a deixasse de ser um contexto. Essa questão é abordada na seguinte seção.

\subsection{Discussão sobre o tamanho da amostra}

Nessa seção são apresentados dois exercícios, o primeiro corresponde a uma simulação com a intenção de determinar o tamanho de amostra para estimar uma árvore contexto dada. No segundo foram usados os dados do experimento já analisada e simulando uma extensão da amostra foi mostrado que em alguns casos a estrutura da árvore estimada pode ser diferente, indicando que o tamanho de amostra em alguns casos é insuficiente.

\subsubsection{Exercício 1}

Neste primeiro exercício que abre a discussão sobre o tamanho da amostra, foi definida de forma arbitrária uma árvore de contextos junto com suas probabilidades de transição, supondo que essa árvore é a geradora de um conjunto de dados. A ideia é determinar a proporção de correta estimação para vários tamanhos de amostra, para esse exercício foi usada a versão do algoritmo contexto proposta por Bühlman e Wyner (1999). A árvore geradora $\tau$ foi,

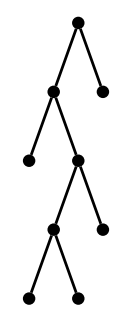

Figura 4.22: Árvore geradora $\tau$ para o primeiro exercício de simulação 
E as probabilidades de transição assignadas a cada um dos seus contextos foram,

$$
\begin{aligned}
q_{1} & =p\left(X_{n}=0 \mid X_{n-1}=1\right)=0.75 \\
q_{00} & =p\left(X_{n}=0 \mid X_{n-1}=0, X_{n-2}=0\right)=0.4 \\
q_{110} & =p\left(X_{n}=0 \mid X_{n-1}=0, X_{n-2}=1, X_{n-3}=1\right)=0.8 \\
q_{0010} & =p\left(X_{n}=0 \mid X_{n-1}=0, X_{n-2}=1, X_{n-3}=0, X_{n-4}=0\right)=0.3 \\
q_{1010} & =p\left(X_{n}=0 \mid X_{n-1}=0, X_{n-2}=1, X_{n-3}=0, X_{n-4}=1\right)=0.1
\end{aligned}
$$

Usando a anterior árvore de contextos anterior foram simuladas amostras de tamanhos 1000 , 2000, 3000, 4000 e 5000. Em cada amostra foi aplicado o algoritmo contexto com a intenção de estimar a árvore de contextos e foi comparada com a árvore $\tau$. Para cada contexto em $\tau$ foi calculada a proporção de amostras onde o respetivo contexto estava contido na árvore de contextos estimada. A seguinte tabela mostra essas proporções,

\begin{tabular}{|c|c|c|c|c|c|}
\hline \multirow{2}{*}{$\begin{array}{c}\text { Tamanho } \\
\text { de amostra }\end{array}$} & \multicolumn{6}{|c|}{ Contextos de $\tau$} \\
\cline { 2 - 6 } & 1 & 00 & 011 & 0100 & 0101 \\
\hline 1000 & 1 & 0,4905 & 0,4905 & 0 & 0 \\
\hline 2000 & 1 & 1 & 1 & 0,0425 & 0,0425 \\
\hline 3000 & 1 & 1 & 1 & 0,418 & 0,418 \\
\hline 4000 & 1 & 1 & 1 & 0,8625 & 0,8625 \\
\hline 5000 & 1 & 1 & 1 & 0,9875 & 0,9875 \\
\hline
\end{tabular}

Tabela 4.21: Proporções de correta estimação dos contextos de $\tau$, segundo o tamanho de amostra

Também foi verificada a altura da árvore estimada, seguem as proporções calculadas para cada tamanho de amostra considerado,

\begin{tabular}{|c|c|c|c|}
\hline \multirow{2}{*}{$\begin{array}{c}\text { Tamanho } \\
\text { de amostra }\end{array}$} & \multicolumn{3}{|c|}{ Contextos de $\tau$} \\
\cline { 2 - 4 } & 1 & 3 & 4 \\
\hline 1000 & 0,5095 & 0,4905 & 0 \\
\hline 2000 & 0 & 0,9575 & 0,0425 \\
\hline 3000 & 0 & 0,582 & 0,418 \\
\hline 4000 & 0 & 0,1375 & 0,8625 \\
\hline 5000 & 0 & 0,0125 & 0,9875 \\
\hline
\end{tabular}

Tabela 4.22: Proporções de correta estimação da altura de $\tau$, segundo o tamanho de amostra 
Concluindo desta forma que coletando 4000 observações, a árvore seria corretamente estimada aproximadamente no $86,25 \%$ dos casos. É importante ressaltar que aqui o ponto de partida foi a árvore que gera os dados, mas é natural que na pratica se desconheça essa árvore, em lugar dela é possível supor alguma árvore especifica, gerada a partir de experiências passadas, por exemplo no caso da modelagem de disparos de neurônios eventualmente pode se supor o comportamento de um processo de renovação, ou testes pilotos podem ser executados com a finalidade de ter uma ideia aproximada do tipo de árvore que pretende ser estimada.

\subsubsection{Exercício 2}

Nas seções anteriores foi mostrado que quando foi usada a amostra do período de pré-exposição as árvores estimadas são de maior profundidade em comparação com as árvores obtidas durante o período de exposição, isto obedece provavelmente ao incremento no tamanho da amostra. Assim surgiu a questão de se o tamanho de amostra usado no experimento é suficiente para estimar as árvores geradoras ou se um incremento no tamanho de amostra poderia modificar a árvore estimada conduzindo a conclusões diferentes.

Para dar resposta a essa pergunta foi usada a sequência 1 apresentada na seção 4.6, aplicando o seguinte tratamento aos dados:

1. Foram estimadas as probabilidades de transição da árvore completa de altura $\log _{|A|} n=$ $\log _{4} 37096 \approx 7$.

2. Usando como ponto de partida a amostra coletada, junto com as probabilidades de transição estimadas no anterior item, foram simuladas duas extensões da amostra: a primeira para que o tamanho da amostra fosse de duas vezes o tamanho original e no segundo caso o tamanho foi de cinco vezes a amostra coletada.

3. Foram estimadas as árvores de contexto para as amostras extendidas e foi verificado em cada caso que neurônios satisfaziam as condições para ser estados de renovação.

4. Os anteriores ítems foram repetidos 25 vezes, obtendo assim 25 amostras com duas vezes o tamanho inicial e outras 25 de cinco vezes o tamanho da amostra, com suas respectivas árvores de contextos estimadas. Isto com a intenção de determinar uma proporção de casos onde a estrutura da árvore muda com relação à estimada na seção 4.6.

Nas 25 novas amostras de tamanho 74192 (duas vezes o tamanho original) foi obtida a mesma 
árvore apresentada na figura 4.19. No caso das amostras de tamanho 185480 teve três tipos de árvores, a seguinte figura apresenta essas árvores, junto com a frequência delas,

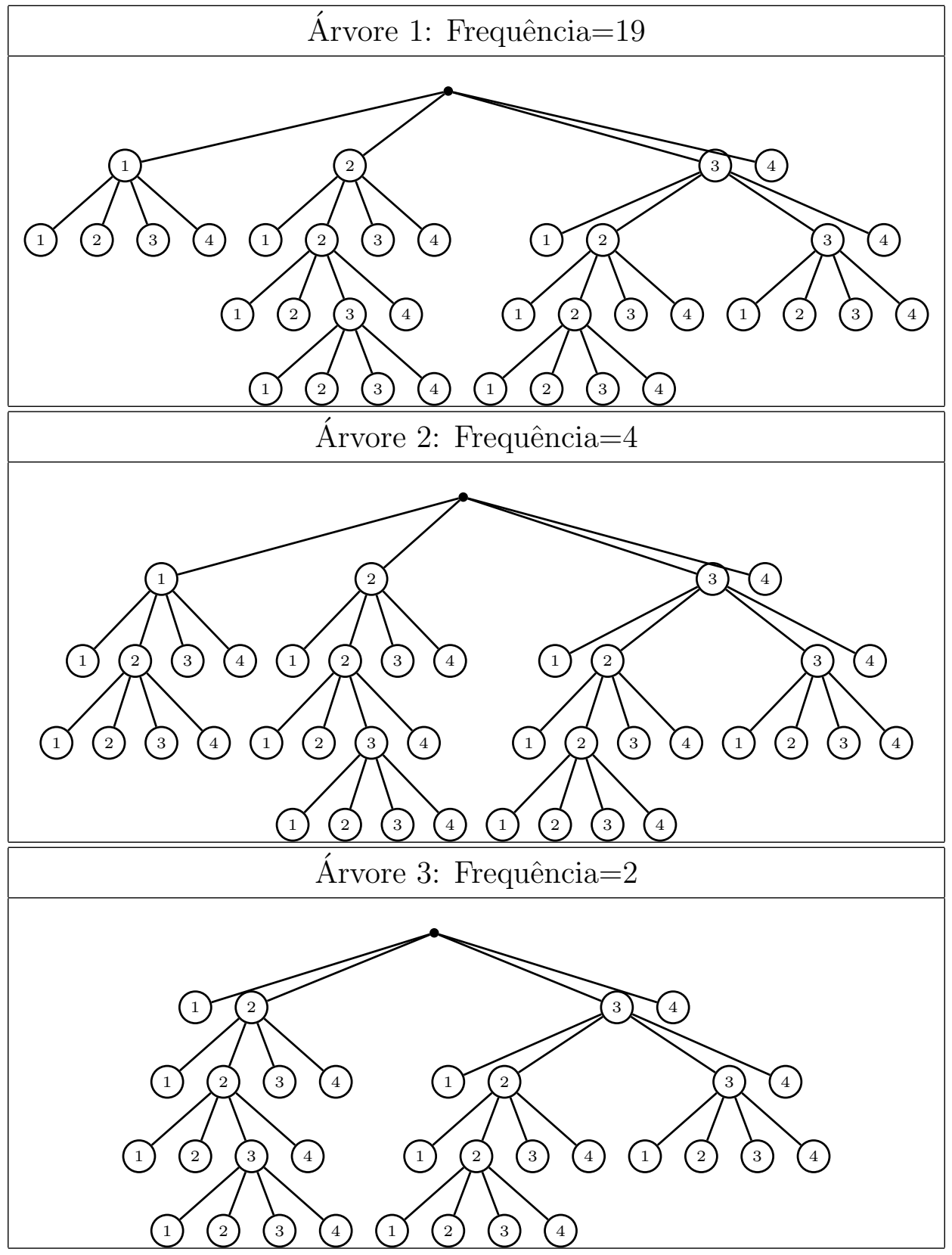

Figura 4.23: Árvores estimadas no segundo exercício de simulação

Em 23 das 25 amostras se verificou que o neurônio HP2a (codificado como 1), não é contexto. Enquanto o neurônio HP15a, continua sendo contexto, corroborando a ideia de que é um neurônio que não está sendo influenciando pelo comportamento de nenhum dos outros, como já foi apresentado nas análises ao longo deste capítulo. 


\section{Capítulo 5}

\section{Conclusões}

Nos quatro neurônios analisados se evidenciou o comportamento de um processo de renovação quando eles são modelados individualmente, indicando sempre que para predizer basta com observar o passado até o último disparo do neurônio. Nos neurônios HP2a e HP15a, que são os que disparam com menor frequência, as árvores obtidas são de maior profundidade, de modo que neste caso o disparo deles é um estado de renovação.

Não foi encontrada evidência de uma mudança na estrutura das árvores quando o rato está em contato com a comida, e mais uma vez o comportamento de um processo de renovação é claro nos neurônio HP2a e HP15a.

Não foi possível determinar associações entre o comportamento dos neurônios a partir da modelagem conjunta. Não se observou coerência entre os modelos teóricos criados para a análise conjunta e as árvores estimadas, provavelmente isto foi causado por ter um tamanho de amostra insuficiente que permitisse identificar árvores mais precisas.

Na medida que o alfabeto cresce as árvores estimadas são de menor profundidade, chegando ao ponto de estimar cadeias de Markov de ordem 1, portanto, para analisar o comportamento dos neurônios em conjunto devem se procurar alternativas diferentes as apresentadas na seção 4.2 .

Na seção 4.4 foram sugeridas condições suficientes que apontam a uma influência do neurônio HP15a, sobre os outros três neurônios considerados na análise. Além disso, no final dessa seção se mostraram árvores que indicam que o neurônio HP15a influencia os neurônios HP12a e HP12b conjuntamente.

A estrutura das árvores estimadas é semelhante durante estado de vigília e sono, o comportamento de um processo de renovação se mantem para os quatro neurônios. 
Em geral a amostra de pré-exposição fornece árvores mais precisas devido à maior quantidade de observações, fazendo que em alguns casos as conclusões sejam diferentes e ressaltando a importância de ter um adequado tamanho de amostra para fazer este tipo de análise.

Na seção 4.5 se mostrou evidência de que o neurônio HP15a tem uma influencia sobre HP12a e HP12b durante a vigília, no entanto isto mesmo não aconteceu durante o estado de sono, provavelmente devido a que o tamanho de amostra do estado de sono é consideravelmente menor que o de vigília.

Exercícios de simulação podem ser feitos para determinar tamanhos de amostra ideais para a implementação deste tipo de análise. Em geral, os tamanhos de amostra deste experimento aparentemente não são pequenos, mesmo assim se comprovou que em muitos casos são insuficientes para identificar as verdadeiras árvores geradoras dos processos, e em ocasiões podem conduzir a conclusões erradas. 


\section{Referências Bibliográficas}

Bühlman e Wyner (1999) Peter Bühlman e Abraham Wyner. Variable length markov chains. The Annals of Statistics, 27:480-513. Citado na pág. [1, 2, 8, 9, 47, 67]

Buesing et al. (2011) Lars Buesing, Johannes Bill, Bernhard Nessler e Wolfgang Mass. Neural dynamics as sampling: A model for stochastic computation in recurrent networks of spiking neurons. PLOS Computational Biology, 7:1-22. Citado na pág. [2]

Csiszár e Talata (2006) Imre Csiszár e Zsolt Talata. Context tree estimation for not necessarily finite memory processes, via bic and mdl. IEEE Transactions on Information Theory, 52:10071016. Citado na pág. $[1,13,15]$

Ferrari e Wyner (2003) Fiorenzo Ferrari e Abraham Wyner. Estimation of general stationary processes by variable length markov chains. Scandinavian Journal of Statistics, 30:459-480. Citado na pág. [8]

Galves et al. (2012) Antonio Galves, Charlotte Galves, Jesus Garcia, Nancy Garcia e Florencia Leonardi. Context tree selection and linguistic rhythm retrieval from written texts. The Annals of Applied Statistics, 6:186-209. Citado na pág. [1, 2, 13, 14, 15, 16, 23]

Gervasoni et al. (2004) Damien Gervasoni, Shih-Chieh Lin, Sidarta Ribeiro, Ernesto Soares, Janaina Pantoja e Miguel Nicolelis. Global forebrain dynamics predict rat behavioral states and their transitions. The Journal of Neuroscience, 24:11137-11147. Citado na pág. [6]

Leonardi (2007) Florencia Leonardi. Cadeias estocásticas parcimoniosas com aplicações à classificação e filogenia das sequências de proteínas. Tese de Doutorado, Instituto de Matemática e Estatística, Universidade de São Paulo, Brasil. Citado na pág. [2]

Ribeiro et al. (2007) Sidarta Ribeiro, Xinwu Shi, Matthew Engelhard, Yi Zhou, Hao Zhang, Damien Gervasoni, Shi-Chieh Lin, Kazuhiro Wada, Nelson Lemos e Miguel Nicolelis. Novel experience induces persistent sleep-dependent plasticity in the cortex but not in the hipocampus. Frontiers in Neuroscience, 1:43-55. Citado na pág. [4, 5] 
Rissanen (1983) Jorma Rissanen. A universal data compression system. IEEE Transactions on Information Theory, 29:656-664. Citado na pág. [1, 8, 11]

Rolls e Deco (2010) Edmund Rolls e Gustavo Deco. The Noisy Brain: Stochastic Dynamics as a principle of brain function. Oxford University Press. Citado na pág. [2]

Shepherd (1994) Gordon Shepherd. Neurobiology. Oxford University Press, third ed. Citado na pág. [2]

Vasconcelos (2010) Nivaldo Vasconcelos. Análise da codificação de objetos complexos no córtex sensorial primário e hipocampo. Tese de Doutorado, Centro de Engenharia Elétrica e Informática, Universidade Federal de Campina Grande, Brasil. Citado na pág. [2, 5]

Willems et al. (1995) Frans M.J. Willems, Yuri M. Shtarkov e Tjalling J. Tjalkens. The context-tree weigthing method: Basic properties. IEEE Transactions on Information Theory, 41:653-664. Citado na pág. [15] 


\section{Apêndice A}

\section{Codificação de sequências de disparos}

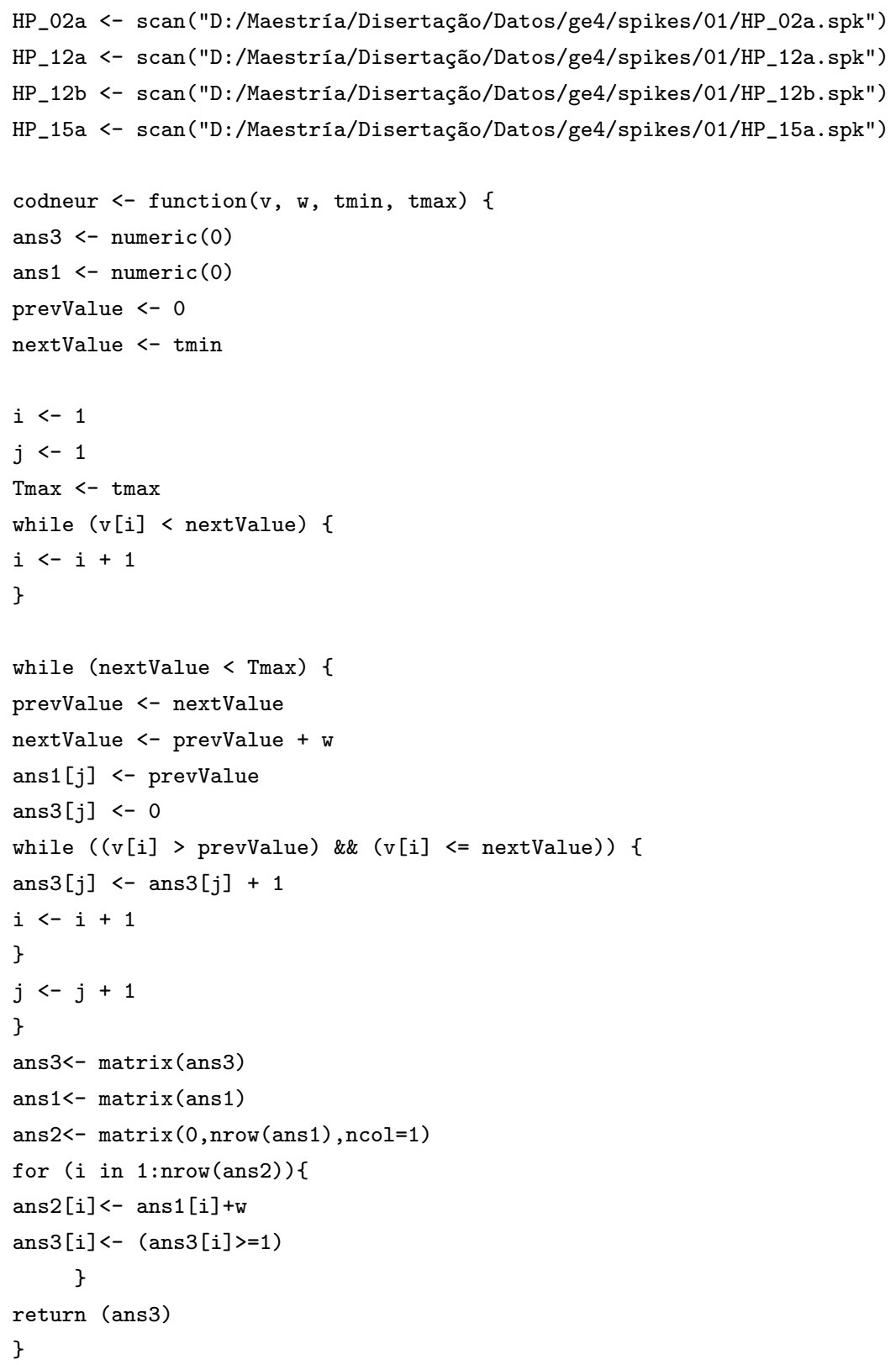




\section{Apêndice B}

\section{Codificação de disparos com contato com os objetos(Comida/Não comida)}

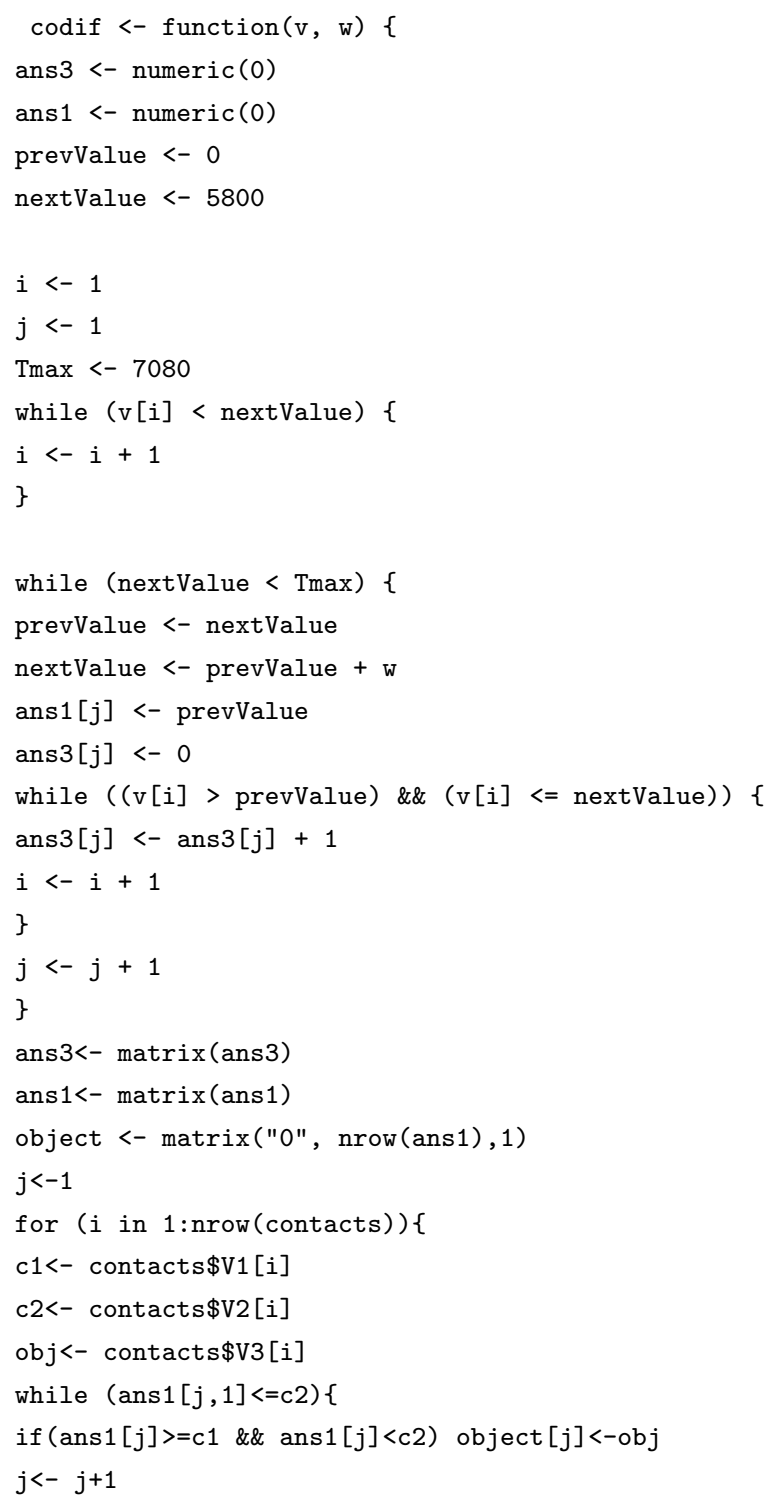


\}

\}

ans $2<-\operatorname{matrix}(0, \operatorname{nrow}(\operatorname{ans} 1), \mathrm{ncol}=1)$

seq <- $\operatorname{matrix}(0, \operatorname{nrow}(\operatorname{ans} 1), 1)$

for (i in $1: \operatorname{nrow}(\operatorname{ans} 2))\{$

ans2[i]<- ans1 [i]+w

ans3 $[i]<-(\operatorname{ans} 3[i]>=1)$

if (ans3[i]==1 \&\& object[i]!="3") seq[i]=1

if $(\operatorname{ans} 3[i]==0$ \&\& object $[i]==" 3 ")$ seq[i]=2

if (ans3[i]==1 \&\& object $[i]==" 3 ")$ seq[i]=3

\}

ans <- cbind (ans1, ans2, ans3, object, seq)

seqA1<<- t(ans [1:nrow(ans),3])

seqA2 $<-t$ (ans $[1: \operatorname{nrow}($ ans $), 5])$

return (ans)

\} 


\section{Apêndice C}

\section{Codificação de disparos com estado comportamental (Vigília/Sono)}

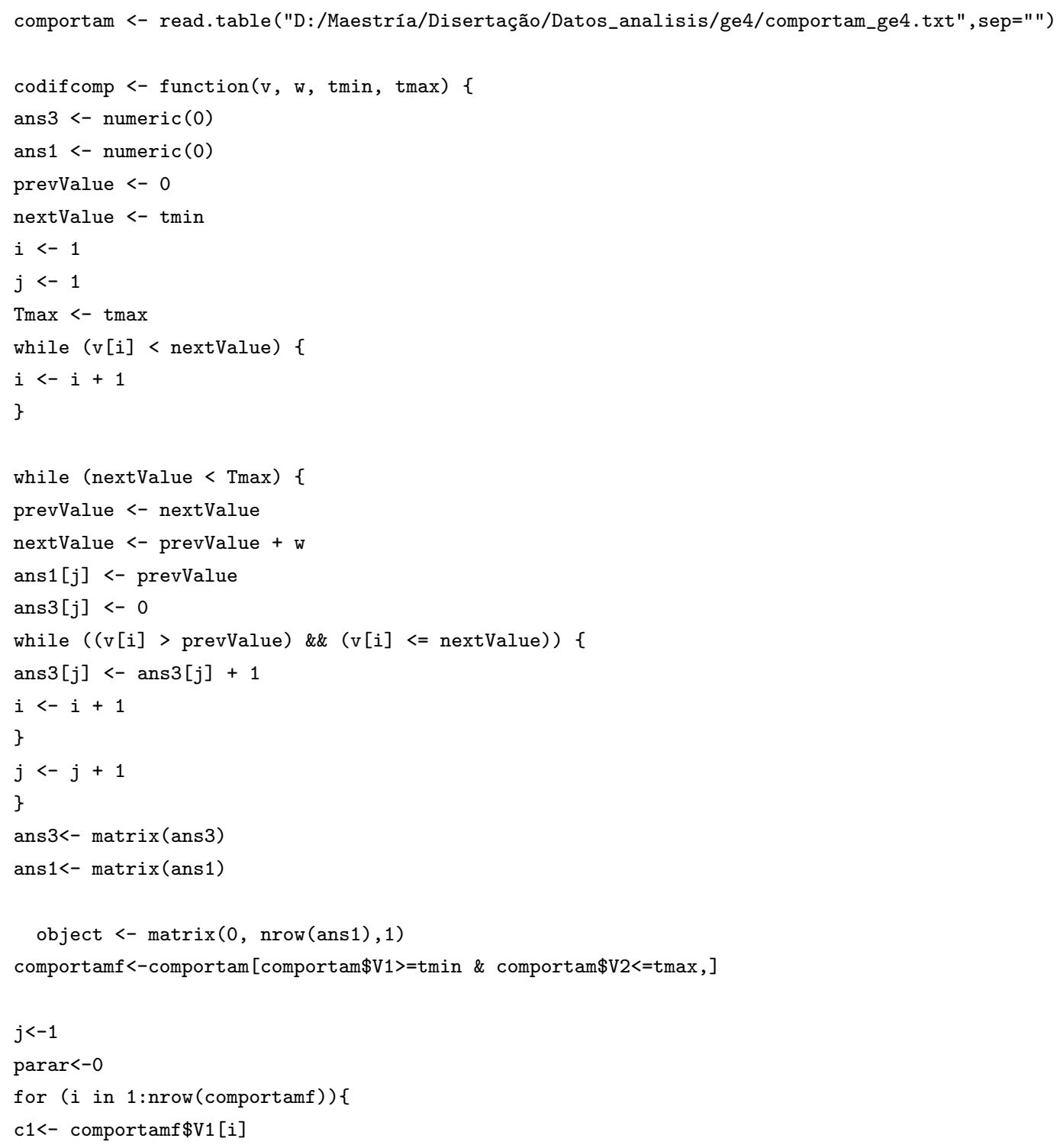




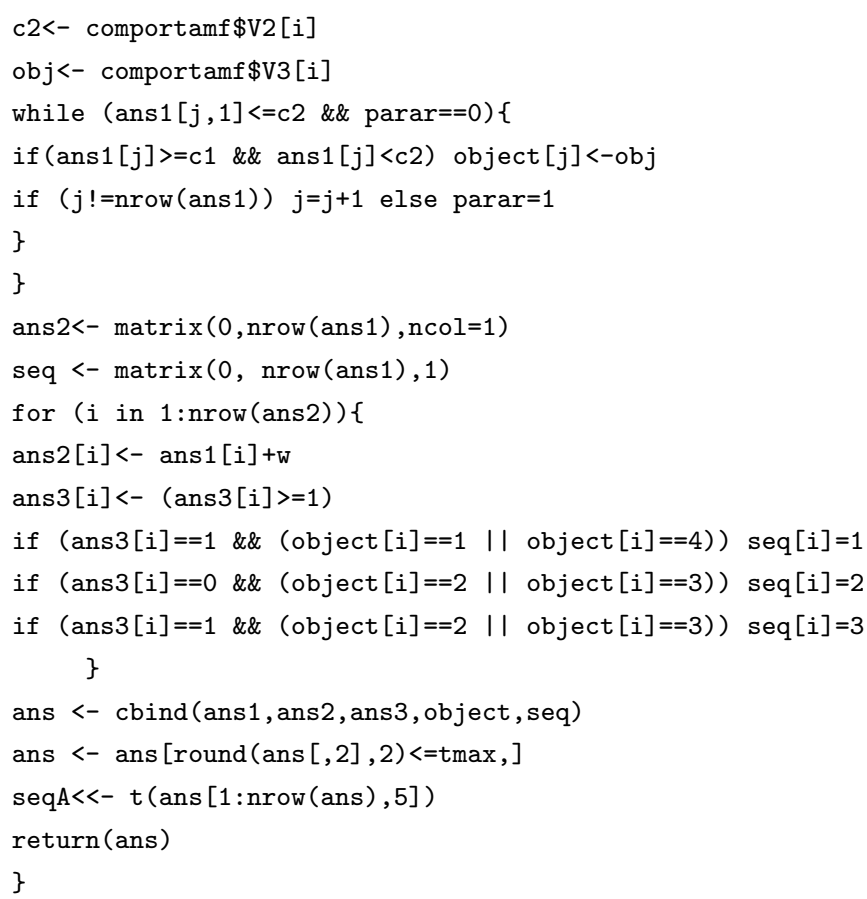




\section{Apêndice D}

\section{Função para o cálculo de probabilidades de transição}

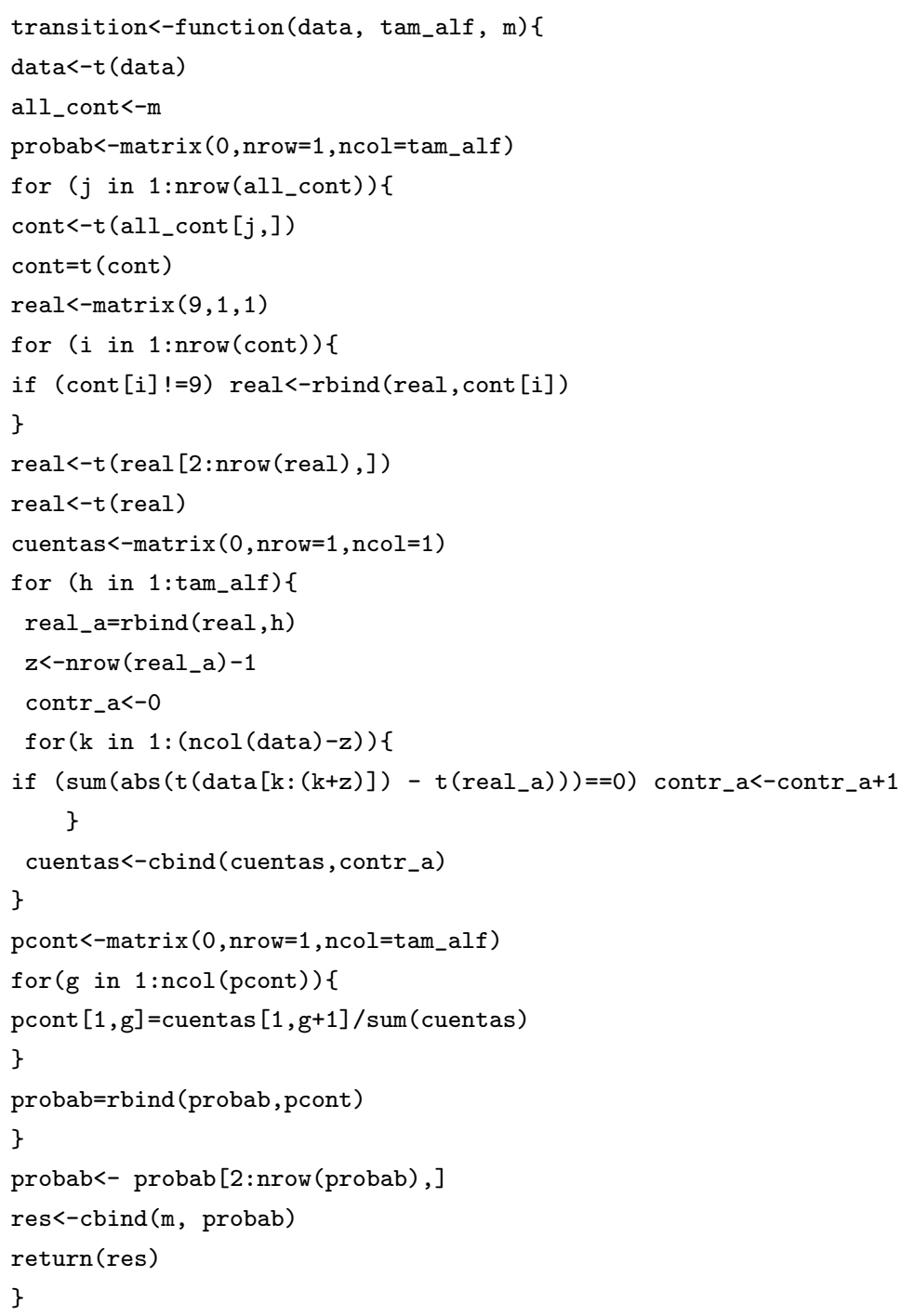




\section{Apêndice $E$}

\section{Disposição de dados para a analise da seção 4.6}

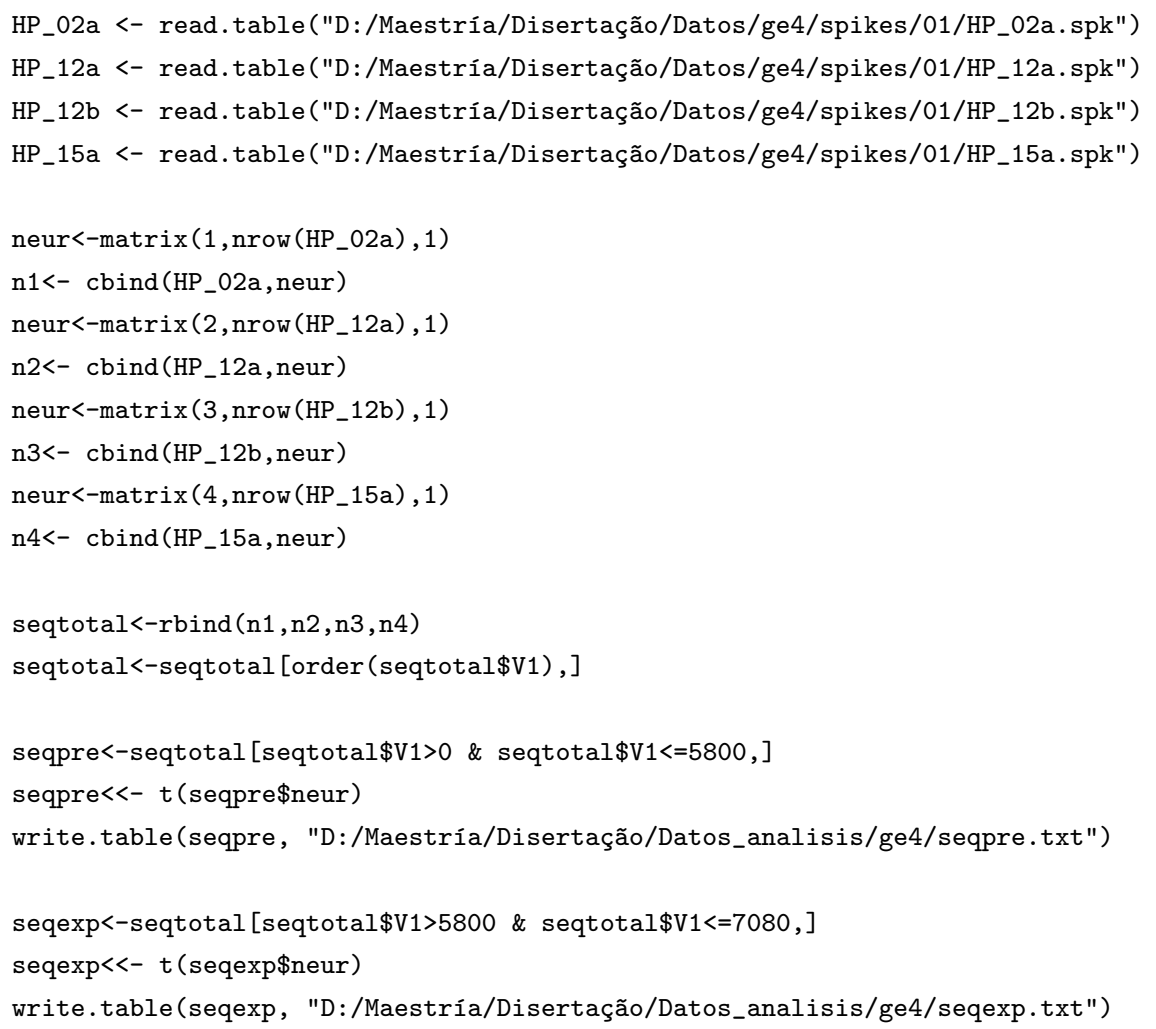


\}

\}

fin<-cbind (seqtotal, behaviour)

fin $\$$ sono $<-0$

fin\$seq. comp $<-$ fin $\$$ neur

for ( $i$ in 1 :nrow $($ fin $))\{$

if $($ fin $\$$ behaviour $[i]==2$ || fin\$behaviour $[i]==3$ ) fin\$sono $[i]<-1$

\}

for ( $i$ in 1 :nrow $(f i n))$ \{

if ( $f$ in $\$$ sono $[i]==1)$ fin\$seq. comp $[i]<-f i n \$$ neur $[i]+4$

\#\#Filtro del periodo de pre-exposición y disposición de la secuencia para análisis seq. comp. pre $<-f$ in [fin $\$ V 1<=5800$,

seq. comp. pre<-t (seq. comp.pre\$seq. comp)

write.table(seq.comp.pre, "D:/Maestría/Disertação/Datos_analisis/ge4/seq_comp_pre.txt") 


\section{Apêndice $F$}

\section{Disposição de dados para avaliação de influência por estado comportamental}

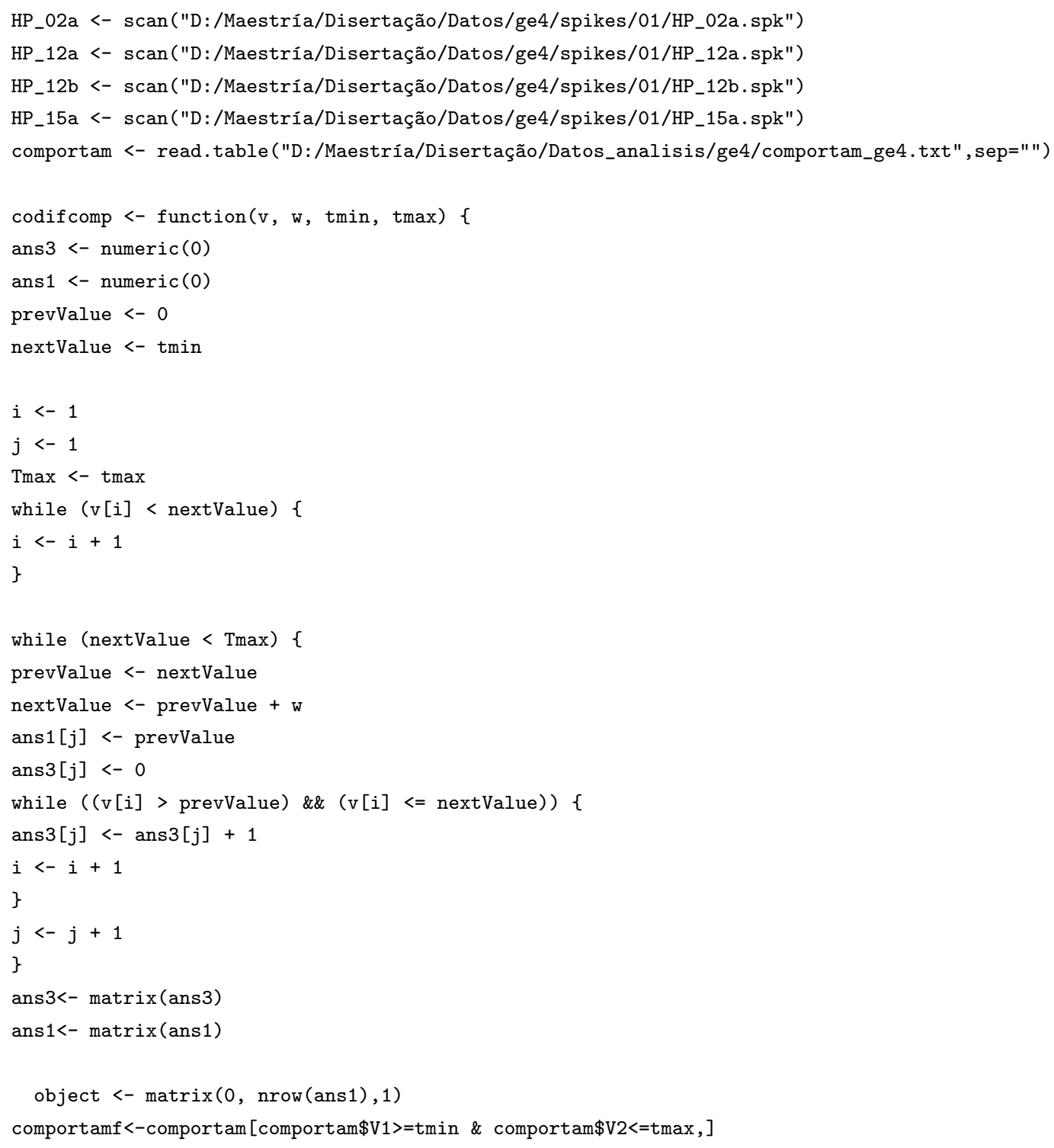




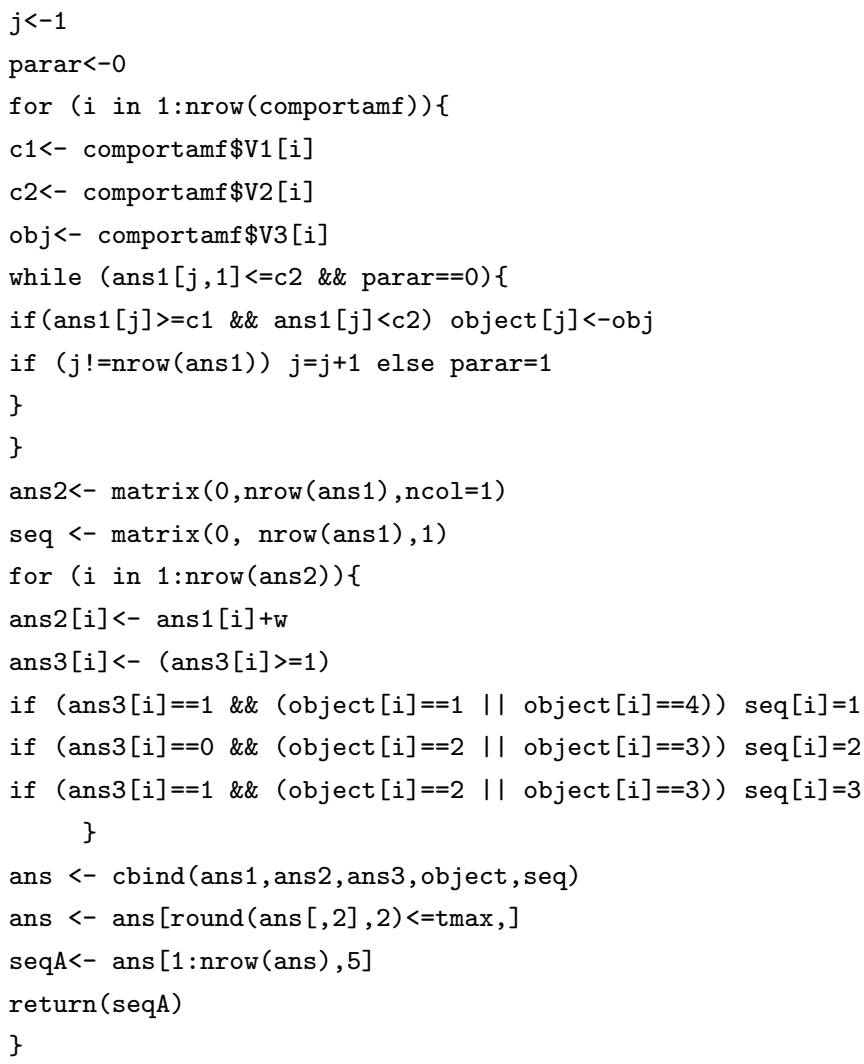




\section{Apêndice G}

\section{Funções para simulação de sequências, usando a árvore maximal}

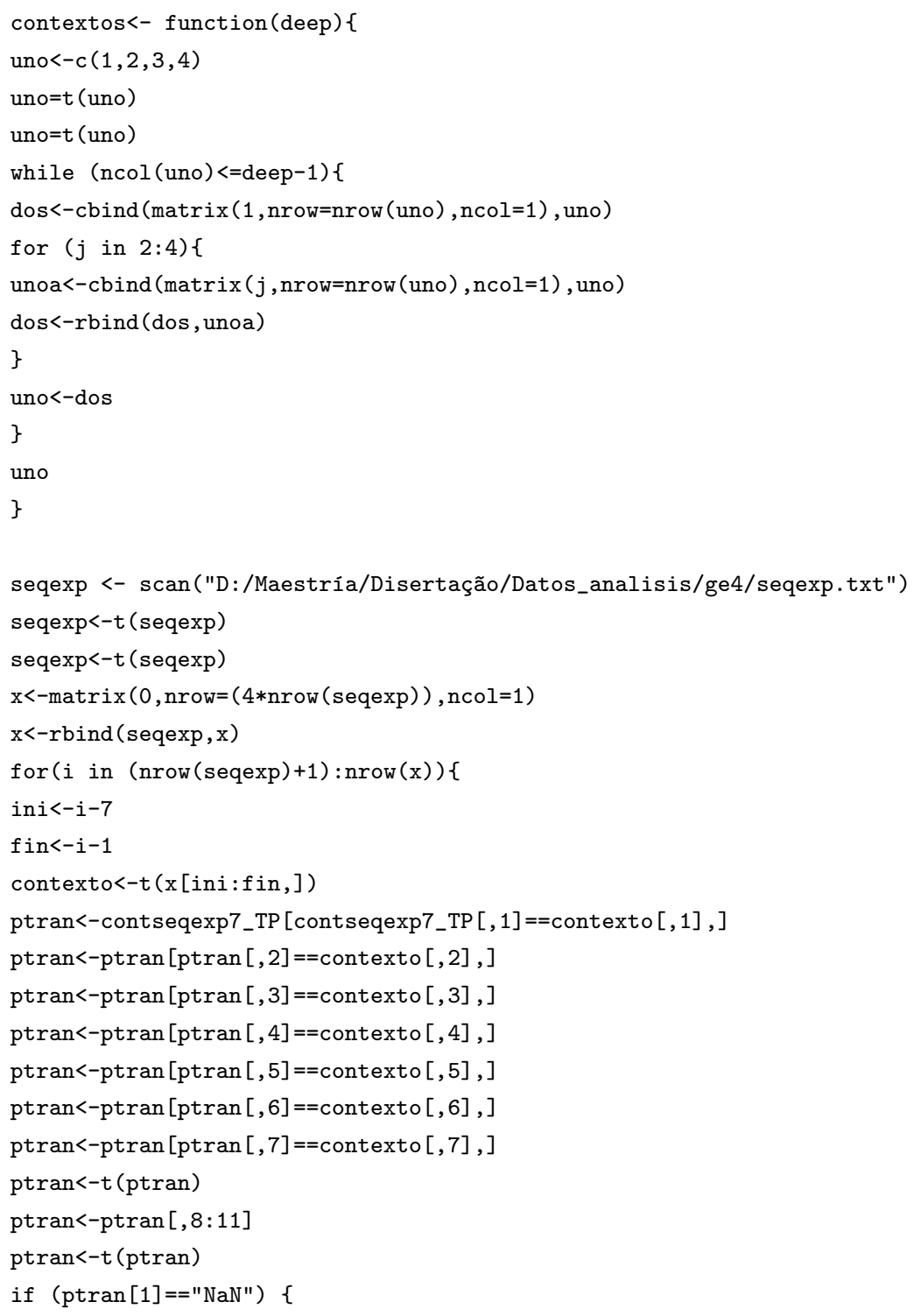




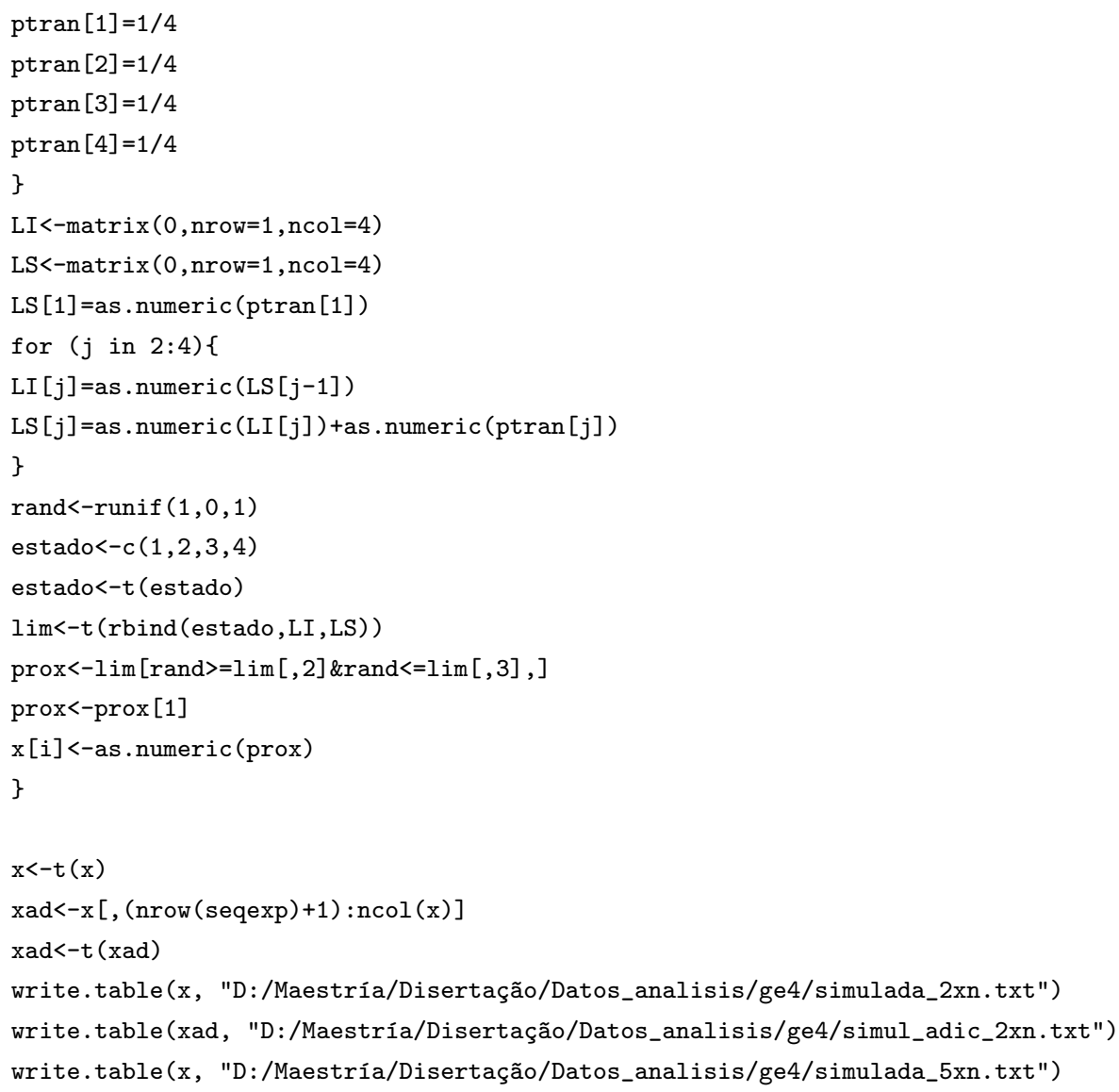




\section{Apêndice $\mathrm{H}$}

\section{Programa para o primeiro exercício de simulação da seção 4.7}

Este programa foi feito em SAS, gera amostras usando a árvore contexto apresentada no primeiro exercício de simulação da seção 4.7, posteriormente estima a árvore contexto usando o algoritmo contexto na versão de Bühlman e Wyner (1999) e determina os contextos correta e incorretamente estimados para amostras de diferente tamanho.

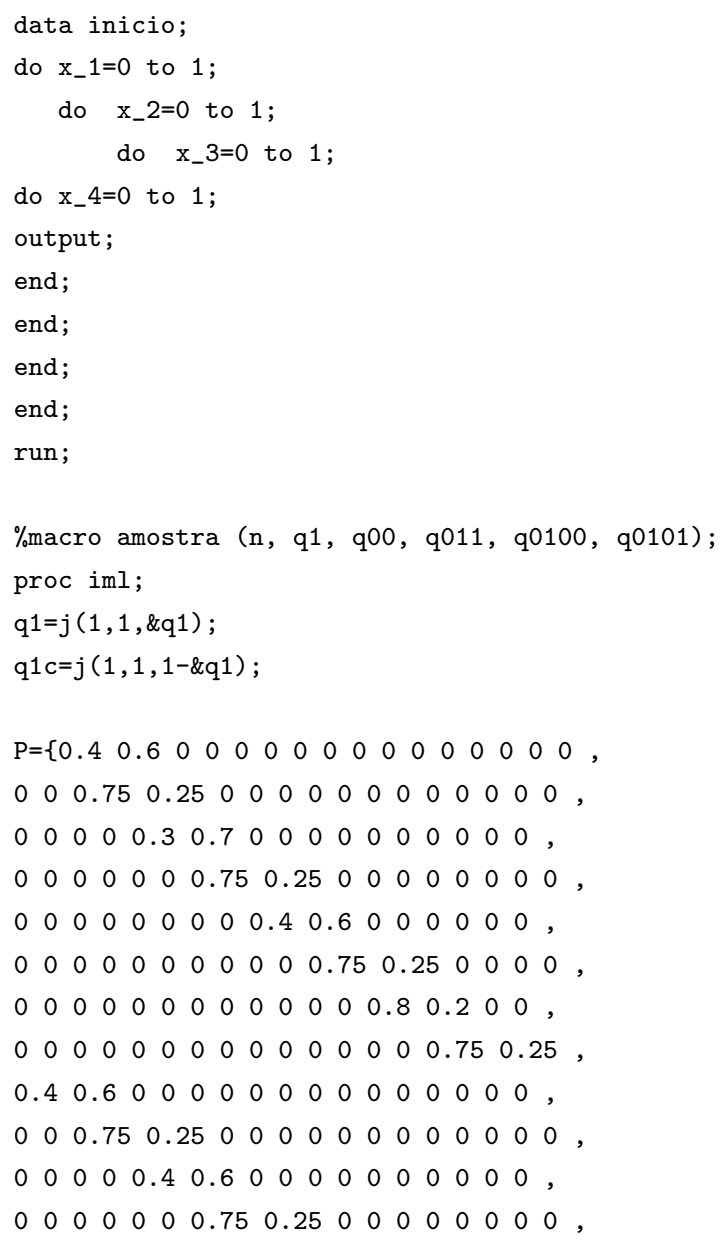


000000000000.40 .600000000 ,

000000000000000.750 .2500000 ,

0000000000000.80 .200 ,

$\begin{array}{llllllllllllllll}0 & 0 & 0 & 0 & 0 & 0 & 0 & 0 & 0 & 0 & 0 & 0 & 0 & 0 & 0.75 & 0.25\} ;\end{array}$

$A=t(P-I(16))$;

$A[16]=,j(1,16,1)$;

$B=\{0,0,0,0,0,0,0,0,0,0,0,0,0,0,0,1\}$;

$\mathrm{Mu}=\operatorname{solve}(\mathrm{a}, \mathrm{b})$;

$\operatorname{MLi}=j(\operatorname{nrow}(M u), 1,0)$;

$\operatorname{MLs}=j(\operatorname{nrow}(M u), 1,0)$;

$\operatorname{MLs}[1]=\mathrm{Mu}[1]$;

do $k=2$ to $\operatorname{nrow}(\mathrm{Mu})$;

MLi $[\mathrm{k}]=\operatorname{MLs}[\mathrm{k}-1]$;

$\operatorname{MLs}[\mathrm{k}]=\mathrm{Mli}[\mathrm{k}]+\mathrm{Mu}[\mathrm{k}]$;

end;

/*print mu;*/

use inicio;

read all $\operatorname{var}\left\{\mathrm{x}_{-} 1, \mathrm{x}_{-} 2, \mathrm{x}_{-} 3, \mathrm{x}_{-} 4\right\}$ into ini;

rand $=j(1,1$, ranuni $(0))$;

$x=j(\& n, 1,0)$;

do $k=1$ to $\operatorname{nrow}(\mathrm{Mu})$;

if $\operatorname{MLi}[\mathrm{k}]<\operatorname{rand}[1]$ \&\& $\operatorname{rand}[1]<\operatorname{MLs}[\mathrm{k}]$ then do;

$\mathrm{x}[1: 4]=\mathrm{t}($ ini $[\mathrm{k}]$,$) .$

end;

end;

do $\mathrm{k}=5$ to $\operatorname{nrow}(\mathrm{x})$;

if $x[k-1]=1$ then do;

if $\operatorname{ranuni}(0)<\& q 1$ then $x[k]=0$;

else $\mathrm{x}[\mathrm{k}]=1$;

end;

if $\mathrm{x}[\mathrm{k}-1]=0$ \&\& $\mathrm{x}[\mathrm{k}-2]=0$ then do;

if $\operatorname{ranuni}(0)<\& q 00$ then $x[k]=0$;

else $x[k]=1$;

end;

if $\mathrm{x}[\mathrm{k}-1]=0$ \&\& $\mathrm{x}[\mathrm{k}-2]=1$ \&\& $\mathrm{x}[\mathrm{k}-3]=1$ then do;

if $\operatorname{ranuni}(0)<\& q 011$ then $x[k]=0$;

else $x[k]=1$;

end;

if $\mathrm{x}[\mathrm{k}-1]=0$ \&\& $\mathrm{x}[\mathrm{k}-2]=1$ \&\& $\mathrm{x}[\mathrm{k}-3]=0$ \&\& $\mathrm{x}[\mathrm{k}-4]=0$ then do;

if $\operatorname{ranuni}(0)<\& q 0100$ then $x[k]=0$;

else $x[k]=1$;

end;

if $\mathrm{x}[\mathrm{k}-1]=0$ \&\& $\mathrm{x}[\mathrm{k}-2]=1$ \&\& $\mathrm{x}[\mathrm{k}-3]=0$ \&\& $\mathrm{x}[\mathrm{k}-4]=1$ then do;

if $\operatorname{ranuni}(0)<\& q 0101$ then $x[k]=0$;

else $x[k]=1$;

end;

end;

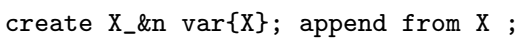

quit;

$\%$ mend;

$\%$ macro algcont(n);

proc iml; 
new $=j(2,1,0)$;

new $[2]=1$;

use X_\&n;

read all var $\{\mathrm{x}\}$ into $\mathrm{X}$;

cant_n=j(2,1,0);

$\mathrm{n}=\operatorname{nrow}(\mathrm{X})$;

do $l=1$ to $\operatorname{nrow}(\mathrm{x})$;

do $k=1$ to $\operatorname{nrow}($ new);

if $\mathrm{t}(\mathrm{x}[\mathrm{l}])=$ new $[\mathrm{k}$,$] then cant_n [\mathrm{k}]=$ cant_n $[\mathrm{k}]+1$;

end;

end;

/*Árvore inicial*/

do until( $\operatorname{col}=f \operatorname{loor}(\log 2(n)) \mid \operatorname{maxim}<=\operatorname{sqrt}(n))$;

old=new ;

cant_o=cant_n;

new $=j(1, n \operatorname{col}(o l d)+1,9)$;

cant_n=9;

do $\mathrm{k}=0$ to 1 ;

new=new $/ /($ old $\mid$ l j (nrow (old $), 1, k))$;

cant_n=cant_n//cant_o;

end;

do $k=1$ to nrow(new);

if cant_n $[\mathrm{k}]>0$ then do;

cant_n $[\mathrm{k}]=0$;

do $1=1$ to $(\operatorname{nrow}(x)-(n \operatorname{ncol}(n e w)-1))$;

if $\mathrm{t}(\mathrm{x}[\mathrm{l}: 1+(\mathrm{ncol}(\mathrm{new})-1)])=$ new $[\mathrm{k}$,$] then cant_n [\mathrm{k}]=$ cant_n $[\mathrm{k}]+1$;

end ;

end;

end;

new=new $[2: \operatorname{nrow}($ new $)$,$] ;$

cant_n=cant_n[2:nrow $($ cant_n $)$,$] ;$

$\operatorname{col}=\mathrm{ncol}$ (new);

$\operatorname{maxim}=\max ($ cant_n $)$;

end;

T0 $=01 d ;$

$\mathrm{T} 1=j(1, \mathrm{ncol}(\mathrm{T} 0), 9)$;

$\operatorname{decis} 0=j(\operatorname{nrow}(\mathrm{TO}), 1,0)$;

$\operatorname{decis} 1=9$;

/***Poda da árvore****/

itera $=0$;

do until (sum(decis1)-9=nrow (decis0));

do $z=1$ to nrow(T0);

if $\operatorname{decis} 0[z]=0$ then do;

contp $=\mathrm{T} 0[\mathrm{z}$,$] ;$

$\mathrm{a}=9$;

do $j=1$ to $n \operatorname{col}$ (contp);

if contp $[j]<9$ then $a=a|| \operatorname{contp}[j]$;

end;

$\operatorname{contp}=a[, 2: \operatorname{ncol}(a)]$; 
ncont $\mathrm{p}=0$;

do $l=1$ to $(\operatorname{nrow}(x)-(n \operatorname{col}(\operatorname{contp})-1))$;

if $t(x[1: 1+(n \operatorname{col}(\operatorname{contp})-1)])=$ contp then $n$ contp=ncontp +1 ;

end;

if ncontp $>0$ \&\& ncol(contp) $>1$ then do;

contp $0=$ contp || 0 ;

contp1=contp | | 1 ;

newcont $0=\operatorname{contp}[, 2: \operatorname{ncol}(\operatorname{contp})]|| 0$;

newcont $1=\operatorname{contp}[, 2: \operatorname{ncol}(\operatorname{contp})]|| 1$;

ncontp $0=0 ; n \operatorname{contp} 1=0 ;$ nnewcont $0=0 ;$ nnewcont $1=0$;

do $l=1$ to $(\operatorname{nrow}(x)-(n \operatorname{col}(\operatorname{contp} 0)-1))$;

if $t(x[1: 1+(n \operatorname{col}(\operatorname{contp} 0)-1)])=\operatorname{contp} 0$ then $n \operatorname{contp} 0=n \operatorname{contp} 0+1$;

end;

do $l=1$ to $(\operatorname{nrow}(x)-(\operatorname{ncol}(\operatorname{contp} 1)-1))$;

if $t(x[1: 1+(n \operatorname{col}(\operatorname{contp} 1)-1)])=\operatorname{contp} 1$ then $n \operatorname{contp} 1=n \operatorname{contp} 1+1$;

end;

do $l=1$ to $(\operatorname{nrow}(x)-(\operatorname{ncol}($ newcont 0$)-1))$;

if $t(x[1: 1+(n \operatorname{col}(n e w \operatorname{cont} 0)-1)])=$ newcont 0 then nnewcont $0=$ nnewcont $0+1$;

end;

do $l=1$ to $(\operatorname{nrow}(x)-(\operatorname{ncol}($ newcont 1$)-1))$;

if $t(x[1: 1+(n \operatorname{col}(n e w \operatorname{cont} 1)-1)])=$ newcont 1 then nnewcont $1=$ nnewcont $1+1$;

end;

if ncontp0+ncontp1>0 then P0_contp=ncontp0/(ncontp0+ncontp1); else P0_contp=1/2;

if $n$ contp0+ncontp1>0 then $\mathrm{P} 1$ _contp=ncontp1/(ncontp0+ncontp1); else P1_contp=1/2;

if nnewcont0+nnewcont1>0 then P0_newcont=nnewcont0/(nnewcont0+nnewcont1); else P0_newcont=1/2;

if nnewcont0+nnewcont1>0 then P1_newcont=nnewcont1/(nnewcont0+nnewcont1); else P1_newcont=1/2;

if $\mathrm{PO}$ _contp $>0$ \&\& PO_newcont $>0$ \&\& $\mathrm{P} 1 \_$contp $>0$ \&\& P1_newcont $>0$

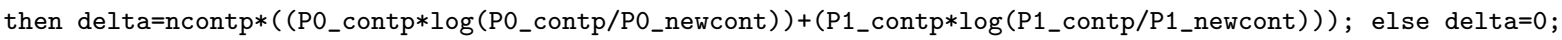

end; else do; delta=0; end;

conth=contp;

if conth[1]=1 then conth[1]=0; else conth[1]=1;

posh $=0$;

conth9=j(1, ncol (TO) ,9);

do $j=1$ to $\operatorname{ncol}$ (conth);

conth9 $[$ ncol $(\operatorname{conth} 9)-(j-1)]=\operatorname{conth}[\operatorname{ncol}(\operatorname{conth})-(j-1)]$;

end;

do $\mathrm{k}=1$ to $\operatorname{nrow}(\mathrm{T} 0)$;

if $\mathrm{TO}[\mathrm{k}]=$, conth 9 then posh $=\mathrm{k}$;

end;

nconth=0;

do $l=1$ to $(\operatorname{nrow}(x)-(\operatorname{ncol}(\operatorname{conth})-1))$;

if $t(x[1: 1+(n \operatorname{col}($ conth $)-1)])=$ conth then nconth=nconth +1 ;

end;

if nconth $>0$ \&\& ncol (conth) $>1$ then do;

conth $0=\operatorname{conth}|| 0$;

conth $1=\operatorname{conth}|| 1$;

newconth $0=\operatorname{conth}[, 2: \operatorname{ncol}(\operatorname{conth})]|| 0$;

newconth1 $=\operatorname{conth}[, 2: \operatorname{ncol}(\operatorname{conth})]|| 1$;

nconth $0=0 ; n \operatorname{conth} 1=0 ;$ nnewconth $0=0 ;$ nnewconth $1=0$;

do $l=1$ to $(\operatorname{nrow}(x)-(n \operatorname{col}(\operatorname{conth} 0)-1))$; 
if $t(x[1: 1+(n \operatorname{col}(\operatorname{conth} 0)-1)])=\operatorname{conth} 0$ then $n \operatorname{conth} 0=n \operatorname{conth} 0+1$;

end;

do $l=1$ to $(\operatorname{nrow}(x)-(\operatorname{ncol}(\operatorname{conth} 1)-1))$;

if $t(x[1: 1+(n \operatorname{col}(\operatorname{conth} 1)-1)])=\operatorname{conth} 1$ then $n \operatorname{conth} 1=n \operatorname{conth} 1+1$;

end;

do $l=1$ to $($ nrow $(x)-(n \operatorname{col}($ newconth 0$)-1))$;

if $t(x[1: 1+(n \operatorname{col}($ newconth 0$)-1)])=$ newconth 0 then nnewconth $0=$ nnewconth $0+1$;

end;

do $l=1$ to $(\operatorname{nrow}(x)-(n \operatorname{col}($ newconth 1$)-1))$;

if $t(x[1: 1+(n \operatorname{col}($ newconth1)-1) $])=$ newconth1 then nnewconth1=nnewconth1+1;

end;

if nconth0+nconth1>0 then $\mathrm{PO}$ _conth=nconth0/(nconth0+nconth1); else PO_conth=1/2;

if nconth0+nconth1>0 then $\mathrm{P} 1$ _conth=nconth1/(nconth0+nconth1); else P1_conth=1/2;

if nnewconth0+nnewconth1>0 then P0_newconth=nnewconth0/(nnewconth0+nnewconth1); else P0_newconth=1/2;

if nnewconth0+nnewconth1>0 then P1_newconth=nnewconth1/(nnewconth0+nnewconth1); else P1_newconth=1/2;

if P0_conth $>0$ \&\& P0_newconth $>0$ \&\& P1_conth $>0$ \&\& P1_newconth $>0$ then

deltah=nconth $*\left(\left(\mathrm{PO} \_\right.\right.$conth $* \log \left(\mathrm{PO} \_\right.$conth/PO_newconth $\left.)\right)+(\mathrm{P} 1$ _conth $* \log (\mathrm{P} 1$ _conth/P1_newconth $\left.))\right)$; else deltah=0;

end; else do; deltah=0; end;

if $n \operatorname{col}(\operatorname{contp})=1$ then do;

$\operatorname{decis} 0[z]=1$;

newcont=contp;

$a=j(1, n \operatorname{col}(T 1), 9)$;

$\mathrm{a}[\mathrm{ncol}(\mathrm{T} 1)]=$ newcont [1] ;

$\mathrm{T} 1=\mathrm{T} 1 / / \mathrm{a}$;

decis1=decis $1 / / 1$;

if $p o s h>0$ then do;

$\operatorname{decis} 0[\mathrm{posh}]=1$;

newcont=conth;

$a=j(1, n \operatorname{col}(T 1), 9)$;

$\mathrm{a}[\mathrm{n} \operatorname{col}(\mathrm{T} 1)]=$ newcont $[1]$;

$\mathrm{T} 1=\mathrm{T} 1 / / \mathrm{a}$;

decis1=decis $1 / / 1$;

end;

end;

else do;

if $p o s h=0$ then do;

$\operatorname{decis} 0[z]=1$;

newcont=contp;

$a=j(1, n \operatorname{col}(T 1), 9)$;

do $i=1$ to ncol (newcont);

$a[n \operatorname{col}(a)-(i-1)]=$ newcont $[n \operatorname{col}$ (newcont) $-(i-1)]$;

end;

$\mathrm{T} 1=\mathrm{T} 1 / / \mathrm{a}$;

decis1=decis1//1;

end;

else do;

if $\operatorname{delta}<3.841 * \log (\operatorname{nrow}(\mathrm{x}))$ \&\& deltah<3.841*log(nrow $(\mathrm{x}))$ then do;

$\operatorname{decis} 0[z]=2$; decis $0[\mathrm{posh}]=2$;

newcont=contp $[, 2: \operatorname{ncol}(\operatorname{contp})]$;

$a=j(1, n \operatorname{col}(T 1), 9)$;

do $i=1$ to ncol (newcont);

$a[n \operatorname{col}(a)-(i-1)]=$ newcont $[n \operatorname{col}$ (newcont) $-(i-1)]$;

end;

$\mathrm{T} 1=\mathrm{T} 1 / / \mathrm{a}$; 
$\operatorname{decis} 1=\operatorname{decis} 1 / / 0$;

end;

else do;

$\operatorname{decis} 0[z]=1 ; \operatorname{decis} 0[\mathrm{posh}]=1$;

newcont=contp;

$a=j(1, n \operatorname{col}(T 1), 9)$;

do $i=1$ to ncol(newcont);

$\mathrm{a}[\mathrm{ncol}(\mathrm{a})-(\mathrm{i}-1)]=$ newcont $[\mathrm{ncol}$ (newcont) $-(i-1)]$;

end;

$\mathrm{T} 1=\mathrm{T} 1 / / \mathrm{a}$;

$\operatorname{decis} 1=\operatorname{decis} 1 / / 1$;

newcont=conth;

$a=j(1, n \operatorname{col}(T 1), 9)$;

do $i=1$ to $n \operatorname{col}$ (newcont);

$a[n \operatorname{col}(a)-(i-1)]=$ newcont $[n \operatorname{col}$ (newcont) $-(i-1)]$;

end;

$\mathrm{T} 1=\mathrm{T} 1 / / \mathrm{a}$;

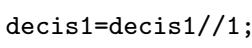

end;

end;

end;

end;

end;

$\mathrm{T} 1=\mathrm{T} 1[2: \operatorname{nrow}(\mathrm{T} 1)$,$] ;$

decis1=decis1 [2:nrow(decis1),];

itera=itera+1;

$\operatorname{decis} 0=\operatorname{decis} 1$;

$\mathrm{T} 0=\mathrm{T} 1$;

$A 1=j(1, \operatorname{ncol}(T 0), 9)$;

do $k=1$ to nrow(decis1);

if $\operatorname{decis} 1[\mathrm{k}]=1$ then $\mathrm{A} 1=\mathrm{A} 1 / / \mathrm{T} 1[\mathrm{k}$,$] ;$

end;

T1=A1; decis1=j(nrow $(T 1), 1,1) ; \operatorname{decis} 1[1]=9$;

end;

/*Comparação da árvore estimada com a árvore que gerou os dados*/

arvore $=\left\{\begin{array}{llllllllllllllllllll}0 & 0 & 1 & 0,1 & 0 & 1 & 0,9 & 1 & 1 & 0,9 & 9 & 0 & 0,9 & 9 & 9 & 1\end{array}\right\}$;

arvore $9=j(5, \operatorname{ncol}(\mathrm{TO}), 9)$;

do $i=1$ to nrow(arvore9);

do $j=n \operatorname{col}$ (arvore9)-3 to $n \operatorname{col}$ (arvore9);

arvore $9[i, j]=\operatorname{arvore}[i, j-(n \operatorname{col}(\mathrm{TO})-4)]$;

end;

end;

compcont=j(nrow (arvore9) $, 3,0)$;

tamco $=j($ nrow $(T 0), 1,0)$;

do $i=1$ to $\operatorname{nrow}(\mathrm{TO})$;

do $j=0$ to $n \operatorname{ncol}(\mathrm{TO})-1$;

if $\mathrm{TO}[i, \mathrm{ncol}(\mathrm{TO})-j]<9$ then tamco[i]=tamco[i]+1;

end;

end;

altura $=\max ($ tamco $)$;

do $i=1$ to nrow(arvore9); 
$a=\operatorname{arvore} 9[i$,$] ;$

do $j=1$ to $\operatorname{nrow}(\mathrm{TO})$;

if $\mathrm{a}=\mathrm{T} 0[j$,$] then compcont [i, 1]=1 ; / *$ Contexto estimado correctamente*/

end;

if compcont $[i, 1]=0$ then do;

$b=9$;

do $\mathrm{k}=1$ to $\mathrm{ncol}(\mathrm{a})$;

if $\mathrm{a}[\mathrm{k}]<9$ then $\mathrm{b}=\mathrm{b} \mid \mathrm{a}[\mathrm{k}]$;

end;

$\mathrm{N} 1=\mathrm{b} ; \mathrm{N} 1[1]=1 ;$

$\mathrm{NO}=\mathrm{b} ; \mathrm{NO}[1]=0$;

do $l=1$ to nrow(TO);

if $\mathrm{TO}[1, \mathrm{ncol}(\mathrm{T} 0)-\mathrm{ncol}(\mathrm{N} 1)+1: \mathrm{ncol}(\mathrm{T} 0)]=\mathrm{N} 1 \mid \mathrm{TO}[1, \mathrm{ncol}(\mathrm{T} 0)-\mathrm{ncol}(\mathrm{NO})+1: \mathrm{ncol}(\mathrm{TO})]=\mathrm{N} 0$ then compcont $[\mathrm{i}, 2]=1$;

end;

end;

if compcont $[i, 1]=0$ \& compcont $[i, 2]=0$ then compcont $[i, 3]=1 ; / *$ Contexto sub-estimado*/

end;

result $=$ compcont $[+$,$] ;$

result=result | | altura;

create result var\{igual sobrest subest altura\};

append FROM result;

quit;

proc append base=poster.result_\&n data=result; quit;

$\%$ mend;

$\%$ macro simulatodo (tam, num);

$\%$ do $j=1 \%$ to \&num;

$\%$ amostra (\&tam, $0.75,0.4,0.8,0.4,0.1$ ) ;

$\%$ algcont (\&tam);

$\%$ end;

$\%$ mend;

options nosource nonotes;

$\%$ simulatodo $(4000,50)$ 